\title{
Anorexia nervosa : towards an early identification
}

Citation for published version (APA):

Weeda-Mannak, W. L. (1984). Anorexia nervosa : towards an early identification. [Doctoral Thesis, Maastricht University]. Rijksuniversiteit Limburg. https://doi.org/10.26481/dis.19840914ww

Document status and date:

Published: 01/01/1984

DOI:

10.26481/dis.19840914ww

Document Version:

Publisher's PDF, also known as Version of record

\section{Please check the document version of this publication:}

- A submitted manuscript is the version of the article upon submission and before peer-review. There can be important differences between the submitted version and the official published version of record.

People interested in the research are advised to contact the author for the final version of the publication, or visit the DOI to the publisher's website.

- The final author version and the galley proof are versions of the publication after peer review.

- The final published version features the final layout of the paper including the volume, issue and page numbers.

Link to publication

\footnotetext{
General rights rights.

- You may freely distribute the URL identifying the publication in the public portal. please follow below link for the End User Agreement:

www.umlib.nl/taverne-license

Take down policy

If you believe that this document breaches copyright please contact us at:

repository@maastrichtuniversity.nl

providing details and we will investigate your claim.
}

Copyright and moral rights for the publications made accessible in the public portal are retained by the authors and/or other copyright owners and it is a condition of accessing publications that users recognise and abide by the legal requirements associated with these

- Users may download and print one copy of any publication from the public portal for the purpose of private study or research.

- You may not further distribute the material or use it for any profit-making activity or commercial gain

If the publication is distributed under the terms of Article $25 \mathrm{fa}$ of the Dutch Copyright Act, indicated by the "Taverne" license above, 


\section{ANOREXIA NERVOSA \\ towards an early identification}


Cover design: Gallery 'Arts for Life' Nijmegen, The Netherlands. Photo : Bert Andree

Printed in : Hilversum (The Netherlands), 1984 by Benedictus Press. 


\section{ANOREXIA NERVOSA \\ towards an early identification}

\section{Proefschrift}

ter verkrijging van de graad van Doctor in de Geneeskunde

aan de Rijksuniversiteit Limburg te Maastricht op gezag van de Rector Magnificus Prof. Dr. H.C. Hemker volgens besluit van het College van Dekanen in het openbaar te verdedigen in de Aula wan de Universiteit op vrijdag 14 september 1984 des namiddags te $16.00 \mathrm{uur}$

door

WINIFRED LOUISE WEEDA-MANNAK

geboren te Salatiga (Ind.) 
Promotores: Prof. Dr. J.J.C.B. Bremer, Rijksuniversiteit Limburg Prof. Dr. M.J. Drop, Rijksuniversiteit Limburg

Referenten: Prof. Dr. J. de Haan, Rijksuniversiteit Limburg Prof. Dr. C. P. Kimball, University of Chicago 
'Les moments très beaux sont toujours mélancholiques, on voudrait les fixer, on ne peut pas'.

Maurois, Climats

Dedicated to

the memory of my father my mother

Peter

Justin 
Lay-out

Proof-reading
: Isel van Noppen

: M. Sanders, Ph. D. 


\author{
A woman who wants to succeed \\ has to think as a man \\ to work like a horse \\ to be like a woman \\ and to took like a tittle gim \\ Anonymus
}

DANK WOORD

Het schrijven van een proefschrift betekent meer dan de schriftelijke rapportage van een onderzoek. Ik hecht eraan op deze plaats alle personen te bedanken, die elk op hun eigen wijze aan deze ontwikkeling hebben bijgedragen.

In de allereerste plaats wil ik mijn ouders danken, wijlen mijn vader en mijn moeder. Hun beslissing in een ver verleden om veel wat hen lief was te verlaten met het oog op optimale ontwikkelingsmogelijkheden voor hun kinderen, moet veel meer hebben gekast dan ze ons lieten blijken. De standvastigheid, het optimisme en de levenskracht waarmee $z i j$ hun loyaliteit met deze beslissing uitdrukten, is voor mij steeds een voorbeeld geweest.

Mijn 'grote" broers, Ron en Dick, ben ik erkentelijk voor hun inzet om mij reeds op jonge leeftijd en spelenderwijs in een 'mannen'wereld te socialiseren.

Mijn echtgenoot Peter dank ik voor zijn vertrouwen, zijn aanmoediging, zijn kritiek en zijn belangstelling voor mijn werk. Peter, zonder jou zou veel van wat nu bereikt en bereikbaar is, onmogelijk zijn. In de afgelopen periode heb je, ook op moellijke momenten, achter mij, maar vooral naast mij gestaan.

Mijn opleiders aan het Pedagogilsch Instituut van de Rijksuniversiteit Utrecht en Prof. dr. W. Everaerd van het Instituut voor Klinische Psychologie en Psychotherapie van de Rijksuniversiteit Utrecht hebben mij vooral geleerd dat er 'niets praktischer is dan een goede theorie'. 
Bij de start van het onderzoek in 1976 heb ik veel geleerd in de contacten met Dr. C. Lafeber, Afdeling Psychiatrie van het Academisch Ziekenhuis Utrecht, Prof. dr. H.M. Krans, Afdeling Endocrinologie en Stofwisselingsziekten van het Academisch Ziekenhuis Leiden en Prof. dr. G. Russel1, Institute of Psychiatry, The Bethlem Royal Hospital and Maudsley Hospital in London. Ook Prof. dr. P.J.C. van Breda Vriesman, capaciteltsgroep Immunologie, ben ik erkentelijk voor zijn aanmoediging en steum bij de start van het anorexia nervosa onderzoek.

De leden van het onderzoeksteam, met wie ik de afgelopen jaren meer dan prettig heb gewerkt, wil ik met name noemen:

Prof. dr. J.J.C.B. Bremer, capaciteitsgroep Medische Psychologie, miljn promator, ben ik zeer erkentelijk voor het vertrouwen en de mogelijkheden die hij heeft geboden om dit onderzoek op te zetten en uit te voeren.

Prof. dr. M.J. Drop, capaciteitsgroep Medische Sociologie, eveneens mijn promotor, dank ik voor de consciëncieuze en onnavolgbare wijze warmee $z i j z i c h$ steeds vanaf het prille begin van deze studie heeft ingezet.

Bij de verwerking van alle onderzoeksgegevens is de kennis maar vooral de steun van Ir. L. Strijbosch, capaciteitsgroep Medische Informatica en statistiek, onmisbaar geweest. Ik ben hem dan ook bijzonder erkentelijk dat een beroep op hem nooit tevergeefs was.

Dr. F. Smits, capaciteitsgroep obstetrie en Gynaecologie dank ik voor de wijze warop hij zich voor het onderzoek heeft ingezet en die onze samenwerking van begin af aan zeer plezierilg makte.

De onderzoeksassistentie van mevr. M. Witte, mevr. R. Gierlings en mevr. M. Strijkers had ik in dit onderzoek niet kunnen missen. Hun inzet, nauwgezetheid en hun vermogen te improviseren, maakten dat het werk efficlient verllep; hun gevoel voor humor, dat ik op de onderzoeksactiviteiten met plezier terug kan kijken.

De referenten Prof. dr. J. de Haan, capaciteitsgroep obstetrie en Gynalecologie en Prof. dr. C.P. Kimba11, University of Chicago, ben ik zeer erkentelijk voor de snelheid waarmee zij dit manuscript hebben gelezen. Dat deze snelheid niet ten koste gïng van zorgvuldigheid, heeft in belangrijke mate bijgedragen tot de uiteindelijke vorm van dit proefschrift. 
Dit onderzoek vereiste een nauwkeurige voorbereiding en organisatie. Hierbij is dankbaar gebruik gemaakt van de adviezen van het Ministerie van Volksgezondheid, Dr. F. Wafelbakker; de DGD te Utrecht, Dr. F. van Wieringen en Drs. P. van der Meer; de DGD te Heerlen, Drs. W.J. Balvert en Drs. W. Lempers; de afdeling obstetrie en Gynaecologie van het Maria Ziekenhuis te Tilburg, Dr. H. Kock en Dr. H. Merkus.

Bij de uitvoering van het onderzoek is in nauwe samenwerking gewerkt met

- een achttal instellingen en scholen in Utrecht, Maastricht, Heerlen en sittard, die ik on de anonimiteit van de proefpersonen te warborgen, helaas niet met name kan noemen; een tweetal, eveneens om bovengenoemde reden niet met name te noemen balletacademies in Nederland. Echter de inzet van alle directies en docenten om dit onderzoek mogelijk te maken wil ik niet onvermeld laten. Ik ben hen daarvoor zeer erkentelijk.

- de Afdeling Interne Geneeskunde van het Groot Ziekengasthuis te Den Bosch, in het bijzonder ben ik dank verschuldigd aan $\mathrm{Dr}$. J. Raats;

- de Afdeling Obstetrie en Gynaecologie van het Maria Ziekenhuis en Elisabeth Ziekenhuis te Tilburg;

- de Afdeling Obstetrie en Gynaecologie van het Ziekenhuis Annadal te Maastricht (Hoofd: Prof. dr. J. de Haan)

- de Afdeling Obstetrie en Gynaecologie van het Academisch Ziekenhuis Utrecht, (Hoofd: Prof. dr. A. Haspels) met name Dr. H. Coelingh Bennink;

- de Stichting Anorexia Nervosa;

- zelfhulpgroepen voor Anorexia Nervosa, in het bijzonder de zelfhulpgroepen te Roermond en Groningen.

De vele proefpersonen die bereid waren hun medewerking te verlenen dank ik voor hun vertrouwen en voor de moeite die zij zich getroost hebben.

De inzet van Isel van Noppen, secretaresse bif de capaciteitsgroep Medische Psychologie mag ik zeker niet onvermeld 1aten; zij verzorgde vanaf het begin de tekst en lay-out van dit proefschrift en was, ondanks de veelvuldige correcties niet uit haar (stralende) humeur te brengen. 
Willem Diepeveen van de Gallery Arts for Life en Bert Andree dank ik voor de omslag van dit proefschrift.

Drs. Pim Wippoo, drs. Josette ten Have, drs. Maud Clysen, drs. MarieLouise Jongsma, drs. Ineke Kraus en drs. Marian van de Pool wisten mij, in een lange avond in Amsterdam tot de vrouw-specifieke stellingen van dit proefschrift te inspireren.

Tot slot wil ik de laatste zinmen richten aan mijn allergrootste vriend, Justin, die echter nog te klein en te jong is om deze te kunnen lezen en begrijpen. Ik sluit niet geheel uit dat dit proefschrift nog sneller klaar zou zijn geweest als jij niet steeds met jeugdige nieuwsgierigheid had gevraagd, welke letters ik nu weer schreef, of mijn manuscript gebruikte als verkeersdrempel voor je auto's...

Ik sluit wèl uit, dat mijn herinnering aan deze uren dierbaarder zou zijn geweest.

Maas tricht, 14 september 1984 
CONTENTS

page

Preface

Chapter 2. The concept of anorexia nervosa

2.2. History of the concept

2.3. Characterizing symptoms of anorexia nervosa

2.4. Prevalence

2.5. Prognosis

2.6. Summary

Chapter 3. Methodological issues of research on anorexia nervosa

3.1. Introduction

3.2. Conceptual controversies

3.2.2. The status of a distinct disease entity

3.3. Methodological difficulties of psychosomatic research and the clinical approach

3.4. Major methodological shortcomings of research on anorexta nervosa 
Chapter 4. The early identification of anorexia nervosa

4.1. Introduction

4.2. The development of anorexia nervosa 47

4.3. Predisposing factors 49

4.3.1. Blological factors 49

4.3.2. Psychological factors 50

4.3.3. Environmental factors 51

4.4. Am epidemiological approach of anorexia nervosa 53

4.5. Towards an early identification of anorexia nervosa and related disorders 54

4.5.1. Research questions 57

4.6. Summary 58

Chapter 5. Outline of the study 61

5.1. Introduction 63

5.2. Theoretical notions and propositions 63

5.3. The choice of a research design 65

5.4. Selection of research groups 67

5.4.1. Criteria for selection of the anorexia nervosa (AN) group 68

5.4.1.1. Procedures 70

5.4.2. Criteria for selection of the secondary amenorrhea (AM) group 71

5.4.2.1. Procedures 75

5.4.3. Criteria for selection of the asymptomatic female (AF) group $\quad 75$

5.4.3.1. Procedures $\quad 76$

$\begin{array}{ll}\text { 5.5. Measures } & 77\end{array}$

5.5.1. Measurement of the anorectic characteristics 77

5.5.1.1. Interview and examination 77

5.5.1.2. Anorexia Nervosa Inventory for Self-Rating (ANIS) $\quad 78$ 
5.5.2. Measurement of psychological characteristics

5.5.2.1. The Achievenent Motivation Test

5.5.2.2. The Achievement Motivation Test for Children

5.5.3. Measurement of LH, FSH and 17-betaoestradiol

5.6. Statistical analysis

5.6.1. The Box-and-Whisker plot

5.6.2. Discriminant function analysis

5.6.3. Multiple regression analysis

5.7. Summary

Part II. EMPIRICAL ASPECTS

Chapter 6. Comparison of the AN, AM and AF group on anorectic and psychological characteristics

6.1. Intraduction

6.2. Theoretical considerations and hypotheses

6.3.1. Description of the AN, AM and AF groups

6.3.2. Endocrinological characteristics of the AN and AM groups

6.4. Comparison of the AN, AM and AF groups

6.4.1. Anorectic characteristics

6.4.2. Psychological characteristics

6.5. Discriminant function analysis 
Chapter 7. Some further evidence for the discriminative value of the Fear of Failure. Comparison with ballet dancers

7.1. Introduction

7.2. Methods

7.2.1. Subjects

7.2.2. Procedures

7.2.3. Measures

7.3. Results

7.3.1. Description of the BA group of 16 years and older

7.4. Comparison of the $A N$ and $B A$ group of 16 years and older

7.4.1. Psychological characteristics

7.4.2. Anorectic characteristics

7.5. Theoretical considerations and hypotheses

7.6. Results

7.6.1. Description of the BA and AF group younger than 16 years

7.7. Comparison of the BA and AF group younger than 16 years.

7.7.1. Anorectic characteristics

7.7.2. Psychological characteristics

7.8. Discussion

Chapter 8. The role of anorectic and psychological characteristics in the development of anorexia nervosa

8.2. Theoretical considerations research questions

8.4. Comparison of the drop-outs and participants 129 8.4.1. AF group 
8.5.1. Multiple regression analys is with $\mathrm{AF}$ subjects with weight loss

8.5.2. Multiple regression analysis with AF subjects with an increased preoccupation with weight and dieting

8.5.3. Multiple regression analysis with $A M$ subjects with weight loss

8.5.4. Multiple regression analysis with $\mathrm{AM}$ subjects with increased an preaccupation with weight and dieting

8.5.5. Multiple regression analysis with $B A$ subjects with weight loss

8.5.6. Multiple regression analys is with $B A$ subjects with an increased preoccupation with weight and dieting

8.6. Interpretation of the findings

8.7. Illustrative cases

8.7.1. Selection of individuals with significant weight joss

8.7.2. I1lustrative cases of subjects developing anorexila nervosa

8.7.3. Illustrative cases of subjects with extreme weight loss

8.8. Discussion

8.9. Summary

Part III. IMPLICATIONS

9.2. Methodological 1imitations

9.3. Theoretical inferences

9.3.1. The development of the of negative fear of fallure 
9.3.2. The role of parent-child interaction in the development of the negative fear of fallure

9.3.3. The role of society in the development of the negative fear of fallure

9.4. Implications

9.4.1. For research

9.4.2. For practice

9.4.3. For intervention

9.5. Summary

Summary

Samenvatting

References

Curriculum Vitae 
Chapter 1. INTRODUCTION

"An anorexic girl is not simply a girl or young woman, who does not eat and can be considered cured when she resumes eating. She is someone who does not know how to live except by non-eating". Sheila MacLeod, The art of starvation (1981). 
Chapter 1. INTRODUCTION

Those who are familiar with the treatment of anorexia nervosa patients will also be acquainted with the difficult task of altering the seemingly self-perpetuating course of this serious disorder.

Long-term evaluation of the treatment of anorexia nervosa has obtained similar prognostic results: $40 \%$ of the patients fully recovered, $30 \%$ improved, but kept their anorectic symptoms and 30\% were chronically afflicted or died. A comparison of the results of treated anorexia nervosa patients with the prognostic findings of untreated cases suggests that the benefits of medical treatment in anorexia nervosa are only marginal; of the untreated cases, one third recovered, one third remained anorectic and one third became worse.

Since it has been frequently found that a short duration of the disease is associated with a more favourable prognosis of anorexia nervosa, efforts must be made to diagnose the disorder early in its course. Since it still remains unclear how anorexia nervosa can be identified early, the present study was undertaken. The role of anorectic and psychological characteristics as factors that predispose a person to the onset of anorexia nervosa will be studied.

Early identification of anorexia nervosa has been hampered by two major impediments, one of which is of theoretical and the other of methodological origin.

Much has been written about the disorder. The contradictions and confusion in the literature that have accumulated in the last century are considerable. To understand the major theoretical controversies, information on the evolution of thinking about anorexia nervosa as a psychobiosocial disorder will be necessary. A brief history of the concept of anorexia nervosa will therefore be provided in Chapter 2. One of the methodological problems of anorexia nervosa can be directly related to the fact that anorexia nervosa is a multidetermined disorder, which implies that psychological and biological as well as social 
factors contribute to the pathogenesis and maintenance of it. The fact that anorexia nervosa has traditionally been studied after its onset has also hampered an early identification of the disorder.

The major shortcomings of retrospective studies of disease in general and those of anorexla nervosa in particular will be outlined in chapter 3 .

To identify anorexia nervosa early, persons must also be studied before the onset of disease, while those with mild symptoms of anorexila nervosa have to be followed to determine if the full picture of the disease develops. The rationale of this study is the need for information on the onset and early symptoms of anorexia nervosa. Hence the first step toward an early identification is an empirical one. The choice of the design for the study, the selection of variables, subjects and methods will be described in Chapter 4 and Chapter 5. The results of a comparative study will be presented in Chapter 6 and 7 . Data from a longitudinal study to determine the predictive value of anorectic and psychological characteristics will be provided in chapter 8 . The interpretation of the findings and its implications will be finally discussed in Chapter 9.

In this study anorexia nervosa has been viewed as a psychobiosocial disease. This view is predicated on the assumption that the onset and maintenance of anorexia nervosa is the result of multiple interacting factors of biological, psychological and social origins.

Consequently, the research program has been a collaborative study of

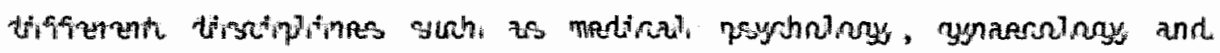
obstetrics, medical sociology and adolescent medicine.

Despite the view of anorexia nervosa as a multidetermined disorder, much emphasis has been placed upon the psychological and behavioral factors. Not surprisingly the choice of psychological variables has been inspired by Bruch's works (1973, 1978) and her clinical descriptions of anorectic patients and by the work of the Dutch author Lafeber $(1963,1971)$.

originally it was also intended to examine biological markers by extensive hormonal testing of blood samples of all subjects.

The original plan, however, had to be abandoned for several reasons. 
One of these was the costs of such a large-scale endocrinological investigation. Another reason was that the majority of the asymptomatic subjects who did not object to participating in the study, objected to an obligatory venapuncture. For ethical reasons it was decided to recommend examining blood samples only in doubtful cases to exclude the possibility of organic disease.

The research took place at the Faculty of Medicine of the Rijksuniversiteit Limburg and was carried out in the Netherlands from 1981 through 1984. This dissertation was written to report on the results of this three year study and wi11, it is hoped, contribute to an early identification and intervention of amorexia nervosa and related dietary disorder. 
PART 1. THEORETICAL ASPECTS

Chapter 2. THE CONCEPT OF ANOREXIA NERVOSA

"In an address on medicine, delivered at oxford in the autumn of 1868, I referred to a peculiar form of disease occurring mostly in young women, and characterised by extreme emaciation, and of ten referred to latent tubercle, and mesenteric disease. I remarked that at present our diagnosis of this affection is negative, so far as determining any positive casue from which it springs."

William W. Gu11. (1873) 
Chapter 2. THE CONCEPT OF ANOREXIA NERVOSA

\subsection{Introduction}

Anorexia nervosa literally means "loss of appetite of nervous origin'. The term is actually a misnomer since loss of appetite usually does not occur until very late in the starvation process.

A1 though anorexia nervosa patients may behave as if they are not hungry, this behaviour does not seem to originate in a real absence of appetite. Anorectic patients fear that giving in to their feelings of hunger and appetite may lead to loss of control over eating and hence result in weight gain. Consequently, anorexia nervosa has been called a weight phobia (Crisp, 1970). The fear of becoming obese, hawever, does not diminish as weight loss progresses. The need to control body weight at a low level leads to a relentless pursujt of thinness. The German name 'Pubertätsmagersucht' to refer to the condition of selfinflicted starvation focusses on the pursuit of thinness as one of the most crucial aspects of the disorder.

\subsection{Histary of the concept}

The earliest medicall account of anorexia nervosa was published in 1694 by Richard Morton, an English physician. He described the major characteristics of anorexia nervosa such as amenormea, constipation, extreme emaciation "like a skeleton only clad with skin", overactivity and indifference to the conditton, but used the term, "nervous atrophy" to typify the case. Two hundred years later the syndrome was identified again and described by Lasègue (1873) and Gu1l (1874), respectively as "anorexie hystérlque' and 'anorexila nervosa'. The last name, although incorrect, became widely accepted.

In the absence of an organic explanation, Morton assumed that the 'nervous consumption' originated in "sadness and anxilous cares". Gull 
and Lasergue also acknowledged the signifficance of psychological factors in the genesis of anorexia nervosa, proposing that the illness was due to a morbid mental state or a 'perversion mental'.

Until Simmonds" publications in 1914 and 1916 anorexia nervosa was considered to be a mental disease. But his description of a fatal case of cachexila due to pituitary destruction focussed almost exclusively on the emaciation and resulted in the replacement of the term "anorexia nervosa' by 'hypophysial emacilation' and to the search for endocrine factors in the pathogenesis. The conviction that destruction of the pituitary results in cachexia gradually disappeared, due to the work of Berkman (1948) and Sheehan and Summers (1949).

Re-emphasis on the contribution of psychological factors in the pathogenesis of anorexia nervosa followed due to the work of Bliss and Branch (1960) and especially Bruch (1962, 1973). A historical overview reflecting the evolution of prevalent thinking about anorexia nervosa was presented by Lucas $(1981,1982)$. Five major eras were defined: the descriptive era (1868-1914), the pituitary era (1914-1946), the era of rediscovery of the 111 ness (1930-1961), the psycho-analytic era (19401967) and the modern era (1961- 1. There is a great interest in anorexia nervosa from different medical and behavioral disciplines, and several multidisciplinary conferences on anorexia nervosa and related disorders have been held: Bethesda (U.S.A.) in 1976, Toronto (Canada) in 1981 and Noordwijkerhout (The Netherlands) in 1982 and a forthcoming one in Swansey (Great Britain) in 1984. The modern era reflects the thinking about anorexia nervosa as a 'final common pathway' resulting from an interplay of biological, psychological and social factors (Russel1, 1977; Lucas, 1981, 1982; Garner et al., 1981). Hence anorexia nervosa has been conceptualized as a psychobiosocial disorder (Lipowski, 1984).

\subsection{Characterizing symptoms of anorexia nervosa}

\section{Somatic features}

The most striking feature of anorexia nervosa is usually emaciation, 
which, however, may not be immediately visible since the anorectic patient frequently wears clothes which effectively mask her thinness. Usually the patient presents herself to a doctor many months or years after initial weight loss. Starvation-related symptoms which can be observed at examination are: dry skin and hair; carotenemia; cold, blue extremities; bradycardia; hypothermia; hypotension; and sometimes lanugo hair. Other starvation-related features are constipation and insomnia.

In most cases the initial weight loss is due to an elective dietary restriction especially avoidance of carbohydrate containing food. Frequently the patient may also resort to other devices such as selfinduced vomiting, the use of laxatives and excessive physical exercise. Reduced potassium levels can be observed in those patients who use llaxatives and vomiting excessively to control their body weight. About half of the patients with anorexia nervosa have periods of overeating, usualiy compensated by vomiting or purging (Casper et a1., 1980; Garfinkel et a1., 1980).

The absence of a regular menstrual cycle is also one of the hallimarks of anorexia nervosa and may have occurred shortly after initial weight 10ss in about $70 \%$ of anorexia nervosa patients (Fries, 1977). In a significant proportion $(16 \%)$ the onset of amenorrhea has even been found to precede any weight loss (ibid).

Most of the hormonal changes in anorexia nervosa such as a fall in testosterone levels and elevated levels of growth hormone are restored to normal after weight is regained (Garfinke1 et a1., 1975; Krans, 1978; Schwabe et al., 1981). The amenorrhea may not only precede significant weight 10s5, but may also persist after weight is restored.

\section{Psychological features}

The psychological characteristics of anorexia nervosa have often been neglected. The psychic consequences of starvation such as preoccupation with food, loss of emotion and sexual interest, lack of concentration and alertness, lability of mood have frequently been milstaken as typical psychological features of the disorder. Many of the characteristics regularly ascribed to the anorexia nervosa syndrome such as 
absessionality, indecisiveness, firratibllity, the tendency to socially withdraw and infantlle regression have been found to be related, at least partly, to the starvation (Keys et 1., 1950; Casper and Davis, 1977; Bruch, 1978).

A crucial psychological aspect of anorexia nervosa is a denial of 111 ness. It has been a matter of discussion whether thinness, hunger or fatigue are inaccurately perceived, repressed or neglected (Bruch, 1973, p.252). Denial, suppression or repression, however, all refer to conscious or unconscious processes utilized by the individual in attempting to elfiminate from the consciousness either feelings or thoughts that usually give rise to an unpleasant affect (Kimball, 1981, p.29). 'Probably in no other morbid condition is the outsider more effectively and frequently denied access to an appreciation of the relationship between behaviour and manner on the one hand and inner experifence on the other than in the case with the anorectic" (Crisp, 1980, p.15). A second cardinal psychological feature is the perception of ineffectiveness, the way in which patients experience themselves as acting only in response to demands from other people and not as doing things because they want to (Bruch, 1973). It is believed that to feel a sense of mastery and control, the achievement of an ever decreasing body weight becomes necessary.

Disturbance of body-image has also been repeatedly found in anorexia nervosa patients and has therefore been considered a psychological characteristic specific to the disorder. Since the tendency to overestimate one's own body size is shared with pregnant, obese and also normal, non-anorectic young women (Button et all., 1977; Halmi et al., 1977; Fries, 1981) the specificity of this characteristic for anorexila nervosa can be questioned (Hsu, 1982).

Perfectionism, the tendency to overachieve can also be frequently observed in anorexia nervosa patients. It has been postulated that anorectic patients tend to come from upper and middle class families (Bruch, 1978; Norris, 1979; Crisp, 1980; Ong et a1., 1982). However, it is not certain whether this personal characteristic is related to referral factors or may be specific to anorexia nervosa. 
2.4 Prevalence

Epidemiological studies of anorexia nervosa are bedevilled in two main ways. First, several investigations have concerned patients presented to medical services. However, as a consequence of one of the crucial features, denial of 111 ness, only a proportion of anorexia patients may seek medical treatment. Second, findings on the prevalence in the general population may suffer from the lack of consistent diagnostic criteria.

Crisp et a7. (1976) surveyed nine populations of schoolgiris during 1972-1974 and estimated that the prevalence of anorexia nervosa was 1:100 in the 16-18 age group. Morgan and Sylvester (cited in Hill, 1976) studying the entire admission of 728 18-year old female students at the University of Bristol have estimated a prevalence rate of $2 \%$. If less stringent criteria are employed the prevalence rates are higher. Nylander (1971) studying a representative sample of 1241 schoolgirls, aged 14-19 years in Scandinavia found that the minimum rate of anorexia nervosa was $0.65 \%$, but that it could vary from 1.2 to $2.7 \%$ when less stringent criteria were used. Russe11 (1972) studied a sample of 121 nurses and female medical students and 110 schoolgirls aged 16-18. He found that $4 \%$ had experienced a minimum weight loss of seven pound and amenorrhea of at least six months duration simultaneousiy.

Ballot et al. (1981) investigated 1246 schoolgirls in Johannesburg and suggest a prevalence rate of 3 in every 100 when the criterion of $20 \%$ underweight is applied to diagnose anorexia nervosa.

Theander (1970) identified all the cases of anorexta nervosa admitted to psychiatric and general hospitals over 30 years in Sweden and found a striking increase in admissions. Duddle (1973) also found an increase of anorexia nervosa in the university population at Manchester, which could not be due to an increased proportion of females in the student population.

Recently, some concise data on the admission rate of clinically treated patients with anorexia nervosa in hospitals in the Netherlands has been provided (Hoogendoorn, 1983). Strong evidence exists to conclude 
that in Dutch hospitals nowadays the condition is observed more often than in the recent past.

A1 though Theander (1970) found an increase of anorexia nervosa, he also noted that the patients which had been referred in the last part of his study were less severely 111 than those who had been referred during the first part. Accordingly he questioned whether the increase of anorexia nervosa reflects an actual increase, or is due to other factors of which the most important is an increasing awareness of the condition. The increase of anorexia nervosa, however, has not been observed in South-East Asia. A study on the frequency of presentation of anorexia nerwosa was carried out in Malaysia and indicated that anorexia nervosa is a very rare condition and is not increasing (Buhrich, 1981 ).

Recent investigations on the prevalence of mild or subclinical forms of anorexia nervosa (Garner and Garfinke1, 1980; Button and whitehouse, 1981; Mann et a1., 1983) suggest that there is also an increasing prevalence of mild forms in the Western industrialized countries, if these findings are compared to the previous results of Nylander's (1971) study. Individuals with subclinical anorexia nervosa show a major preoccupation with weight and distressing and troubling concern with food intake (Mann, et al., 1983, p.575) as assessed by a high score on the Eating Attitude Test (Garner and Garfinke1, 1979). There is a persistent drive to lose weight and to achieve an unusually low body weight. Their food intake is severely restricted and eating is associated with feelings of tension and guilt. Other devices, such as excessive exercise or laxative abuse may be practised in attempts to lase weight. Although subjects with mild anorexia nervosa show the characteristic anorectic features of anorexia nervosa, their weight remains within relatively normal limits and menstruation persists, al though it may be irregular.

Button and whitehouse (1981) found that mild anorexia nervosa occurred in about $5 \%$ of their sample of female college students, which is a much higher rate when compared to Nylander"s (1971) study. There is considerable evidence that mild or subclinical forms of anorexia nervosa are very prevalent now (Garner and Garfinkel, 1980; Button and 
Whitehouse, 1981; Mann et a1., 1983).

However, thus far evidence is lacking to decide with certainty whether there has been an actual increase of anorexia nervosa or whether an increase of admissions reflects better recognition and changes in referral behaviour of doctors.

2.5 . Prognosis

Despite methodological differences between follow-up studies of anorexia nervosa, similar results on the outcome of the disease have been obtained. Of all anorexia nervosa patients about $40 \%$ fully recovered, $30 \%$ were improved and $30 \%$ were chronically afflicted or died as a result of the disease (Garfinke1 and Garner, 1982; Steinhausen, 1983). Cremerius (1978) studied a small sample of untreated amorexia nervosa patients and found that one third remained anorectic, one third became worse and one third showed improvement. His findings are simflar to those of other studies of untreated cases (Mayer, 1961; Cremerius, 1965).

There is an increasing recognition based upon results from prognostic and follow-up studies that anorexia nervosa patients tend to improve depending upon their personal characteristics and history such as age at onset, sex, social class and duration of disease, rather than upon the different ways they have been treated (Garfinkel et a1., 1977a, b; Goldberg, 1980; Hsu, 1980). The most agreed upon finding is that of a poor prognosis with a long duration of the disorder (Seidensticker and Tzagournis, 1968; Morgan and Russe1 1, 1975; Pierloot et a1., 1975; Crisp et al., 1977; Russe11, 1977; Bruch, 1978; Hsu et a1., 1979; Hsu, 1980; Steinhausen, 1983). 'Duration of il1ness' has been defined in this respect as the time between the onset of symptoms and the patient's admission to medical treatment. It has been stated that poor prognosis may be due to the self-perpetuating nature of anorexia nervosa, the loss of social contacts and the development of an 'anorectic' identity (Garfinkel and Garner, 1982). Marked individual differences are observed in the severity of psychological changes, due to 
hunger, depending on the pre-iliness personality, the damaging effects of increased isolation and the severity of the starvation (Bruch, 1978). Since early intervention may alter the self-perpetuating course of anorexia nervosa and prevent the development of secondary effects early identification of the disorder is considered of significant importance (Bruch, 1978; Hodgman, 1979; Rohde, 1980).

\subsection{Summary}

The concept of anorexta nervosa has a long history that has been traced back to 17 th century's medical accounts (Morton, 1689). The appraach to the disorder has evolved from monocausal thinking to the present conceptualization of anorexia nervosa as a multi-determined disorder. Anorexta nervosa may be viewed as a final common pathway resulting from an interplay of several biological, psychological and social factors and resulting in a clinical picture characterized by a variety of somatic and psychological features. Most somatic findings are related to the starvation process and have been found to disappear after wellght gain. Although the persistence and recurrence of the menstrual cycle is related to body weight, body weight cannot be considered the only determining factor of menstruation.

The most outstanding psychological characteristics are the relentless pursuit of thinness, the feeling of ineffectiveness and the denial of 111 ness.

clinical studies of anorexia nervosa have frequently reported that anorexia nervosa is increasing. Epidemialogical studies of mild forms of the disorder have confirmed this increase for mild cases as well. However, it is not yet known to what extent the rise may be actual or may be due to a helghtened medical awareness.

Generally speaking, the prognosis of anorexia nervosa is not favourable. If $1 t$ is shown that early identification and intervention may improve treatment results, efforts should be made towards an early diagnosis of anorexila nervosa. 
Chapter 3. METHODOLOGICAL ISSUES OF RESEARCH ON ANOREXIA NERVOSA

"Whenever a dispute has raged for any length of time, there was at the bottom of it, never a problem about mere words, but always a genuine problem of things".

I. Kant, 1786, cited in K.R. Popper: The logic of scientific discovery. (1959). 
Chapter 3. METHODOLOGICAL ISSUES OF RESEARCH ON ANOREXIA NERVOSA

\subsection{Introduction}

Studies of anorexia nervosa have frequently been characterized by methodological inadequacies. Some of the methodological difficulties are those of psychosomatic research in general such as the interrelationships of biological, psychological and social factors. 0thers are inherent in studying the disease from the point of view of clinical medicine. The fact that the methodologically difficult issues are not always adequately dealt with has important consequences and decreases the internal and external validity of empiral findings.

Some methodological probiems, however, reflect basic theoretical controversies in the history of anorexia nervosa.

The purpose of the chapter is first to review some of the major conceptual disagreements about anorexia nervosa as well as some of the methodological difficulties of psychosomatic research and the clinical approach in general. Secondly, some of the major methodological shortcomings of research on anorexia nervosa will be summarized and discussed in this chapter.

\subsection{Conceptual controversies}

\subsubsection{Definition and diagnosis}

Experienced clinicians in the field of anorexia nervosa have stated that diagnosing anorexia nervosa is easier than defining the disorder (Selvini Palazolli, 1974; Bruch, 1978; Tolstrup, 1982). Anorexia nervosa has been considered such a complex clinical picture that it cannot be defined satisfactority by simply listing a number of symptoms.

In the early fifties it became generally accepted that anorexia ner- 
vosa could be defined by three features: fallure to eat, loss of weight and amenorrheal (Nemiah, 1950; Beck and Bröchner-Mortensen, 1954; Kay and Leigh 1954 ).

Later by introducing a most liberal definition of anorexia nervosa as 'a loss of weight of 25 lbs or more that can be attributed to psychological causes" (B1iss and Branch, 1960), the disorder was reduced to one symptom, "weight 1055 ". Since welght 1 loss may occur in every case of psychogentic malnutrition such as schizophrenia, hysteria, depression, etc., this definition of anorexia nervosa has been severely criticlzed (Bruch, 1973; Selvini Palazol1i, 1974). Anorexia nervosa was not viewed as a symptom or a complex of symptoms but considered to be a distinct disease entity (Crisp, 1970; Russel1, 1970; Bruch, $1973)$.

Diagnosing anorexia nervosa was seen as a 'highly clinical operation' in as much as it implies that psychological and behavioural features must be evaluated instead of focussing only on the emaciation.

It is not surprising that most doctors, unfamiliar with evaluating the attitudes and behaviour of their patients in making diagnoses, have strongly emphasized the criterion 'extrene weight loss due to psychological cause'. Hence unspecific cases of psychogenic malnutrition have been mistaken as typical cases of anorexia nervosa.

A recent study of the diagnostic criteria of anorexia nervosa was carried out in 1978 in the Netherlands among 55 medical specialists of internal medicine, pediatrics, gynaecology, psychiatry and general practice (Weeda-Mannak, 1979). The results of this study suggested that the criterion of extreme welight loss in the absence of organic disease is commonly (100\%) accepted as reflecting the most crucial feature of anorexia nervosa.

3.2.2. The status of a distinct disease entity

Presently it is generally acknowledged in the literature that anorexia nervosa is more than loss of weight due to psychological causes. The crucial difference between anorexia nervosa and psychogenic emaciation 
is that the weight loss in anorexia nervosa stems from a pursuit of thinness or a fear of becoming fat, while this is not the case in psychogenic malnutrition.

The acceptance of anorexila nervosa as a distinct disease entity, however, does not imply that the theoretical interpretation of the pursuit of thinness cannot vary considerably. Bruch (1973) emphasized the struggle for a sense of identity and effectiveness as the core psychodymamic issue of anorexia nervosa. 0thers have postulated that anorexia nervosa manifests the fear of sexual development and maturation (Crisp, 1977) or the fear of rejection (Selvini Palazo111, 1974; Boskind-Lodah1, 1976 ; Casper, 1981).

Despite the lack of consensus on the etiology and pathogenesis of the disorder, agreement on the criteria for the disorder gradually developed. Feighner et al. (1972) have drawn up a set of rules to define the anorectic attitude and behaviour. Their diagnostic criteria for anorexia nervosa became widely accepted especially for research purposes. Recently the Feighner criteria have been replaced by the DSMIII criteria for anorexia nervosa (Diagnostic and Statistical Manual of Mental Disorders, 1980). In spite of the emphasis on anorectic symptomatoTogy, the DSM-III criteria for anorexia nervosa are unsatisfactory. One of the reasons is that, without citing reasons the criterion amenorrhea has been excluded. Strict application of these criteria to runners, ballet dancers, athletes and others has resulted in detecting cases of anorexia nervosa. Hence, exclusive emphas is on the anorectic and not the psychological symptoms may lead to diagnosing false positives. The DSM-III criteria for anorexila nervosa can be criticized on these grounds (Weeda-Mannak et a)., 1983). To some degree "fear of fatness, pursuit of thinness, dieting with consequent welight 10ss occur very commonly in non-anorectic adolescents and young females of Western industrialized cultures. It has been postulated that anorexia nerwosa may represent an extreme point on a continuum of this common preoccupation with weight and dieting (Nylander, 1971; Russel1, 1972; Fries, 1977) and that prolonged and intensive dieting leads to the development of anorexia nervosa due to starvation. Other authors, however, have claimed that the psychological 
characteristics and dynamic issues underlying the dieting and weight loss in anorexila nervosa are different from those in ordinary dieting ICrisp and Stonehill, 1973; Bruch, 1973, 1978; Selvinil Palazoll1, 19741.

"Defining the underlying basic disturbances in psychiatric terms, with focus on the core dynamic issues revealed that the noneating and associated welght loss were late features, secondary to underlying personality dilsturbances' (Bruch, 1973, p.251).

Recent studies appear to be compatible with the notion that the psychological characteristics underlying the anorectic behaviour and weight loss of anorexia nervosa patients are different when compared to other subjects with anorectic symptoms (Garner et a1., 1983; WeedaMannak et a1., 1983).

Garner et a1. (1983) compared the psychological traits of patients with anorexia nervosa with those of weight-preoccupied women from samples of college and ballet students. Their results indicated that the scores of anorectic patients were indeed different from those of other weight-preoccupied subjects on the subscales "ineffectiveness, interpersonal, distrust and interoceptive awareness" of the Eating Disorder Inventory (EQI). 'Normal dieters' could also be distinguished from anorexia nervosa patients and extremely weight preoccupied subjects. Normal dieters only had elevated scores an the subscales "drive for thinness, body dissatisfaction and perfectionism'.

Concurrently Weeda-Mannak et al. (1983) compared the psychological characteristics of anorexia nervosa patients with those of patients with secondary amenorichea and healthy controls. Preliminary results indicated that secondary amenorrhea patients had significantly elevated scores on the Anorexia Nervosa Inventory for Selfrating (ANIS) and on the subscale 'Drive to Achieve' of the Achievenent Motivation Test if compared to healthy subjects. When secondary amenorrhea patients were compared to the anorexia nervosa patients, their scores were lower. The most outstanding difference in which the anorexia nervosa patients could be distinguished from secondary amenorrhea patients and from healthy subjects was the avoidance of failure underiying the 'Drive to Achieve'. These findings will be further discussed in Chap- 
ter 6 .

It may be concluded from these studies that significant psychological differences seem to exist between anorexia nervosa patients and subjects who to some degree share anorectic and menstrual characteristics. A1though it is evident that anorexia nervosa may occur with varying degrees of severity, the results of both studies indicate that anorexia nervosa patients can be psychologically differentiated from other subjects sharing the same preoccupation with weight.

Yet it cannot be concluded from these data based on patient-control studies that the characterizing psychological differences predispose a person to the disorder.

3.3.

Methodological difficulties of psychosomatic research and the clinical approach

Anorexia nervosa is a disease with multiple biological, psychological and social interacting causes. Hence the various factors as well as their interactions must be taken into account in investigating the disorder. For this reason studies of anorexia nervosa must be multidisciplinary and efforts must be made in the future to study the differential effect of the multiple factors involved in the onset and course of anorexia nervosa. The search for one single or monocausal pathogenesis has not proven to be very fruitful and must be replaced by a search for multicausal pathogenetic factors. The fact that different disciplines using different languages to describe similar phenomena have to cooperate for this purpose can be seen as one of the impeding factors for an integrated study (Weiner, 1977; Kimbal1, 1979 ).

Most studies of anorexia nervosa came from clinical medicine. Clinical medicine focusses largely on the medical care of sick people, who have presented themselves for help. Not every one who has anorexia nervosa will seek medical treatment, so the samples studies may lack representativeness.

Denial of illness is one of the cardinal features of anorexia nervosa 
leading to patfent delay in seeking medical treatment (Weeda-Mannak, 1983). The time between the onset of disease and the patient's admission to medical treatment has varied from seven months (Casper and Davis, 1977; Strober, 1980) to several years (Morgan and Russe11, 1975). Information collected a considerable time after the onset of disease may suffer from inaccuracy and imprecision.

Second, information from patients who have been diagnosed as having anorexia nervosa may be biased since cases may have a different recall of past events than controls (Neale and Liebert, 1980).

It is therefore not surprising that results of studies identifying externally precipitating events in anorexia nervosa, have varied widely (Theander, 1970; Morgan and Russe11, 1975; Casper and Davis, 1977; Crisp et a1., 1980). Results on precipitating events of other psychosomatic diseases, moreover, have revealed that common initiating events occur in different diseases (Weiner, 1977).

A third serious methodological difficulty of studying severe anorexia nervosa patients is the fact that these patients need to be hospitalized. Hospitalization itself may produce effects and create a methodological problem in selecting an appropriate control group for an external validation.

3.4. Major methodological shortcomings of research on anorexia nervosa

In the light of these methodological difficulties, most research on anorexia nervosa shows considerable contradictory results and can be serilously crittized on methodological grounds.

\section{- The lack of representativeness}

Most studies of anorexia nervosa have been based upon patients attending medical services. Only a proportion of amorexia nervosa patlents, however, may seek medical treatment. The samples which have been investigated may represent only extreme and severe cases of anorexia nervosa and therefore cannot be considered representative. 


\section{- The lack of empirical validation of causal inferences}

Significant correlations between anorexia nervosa and other variables such as the presence of certain psychological traits have been found. And although causation implies correlation, correlational data alone do not allow statements about causation. Aggrevating factors are: 1 . the fact that so-called causal inferences have seldomly been tested and 2. the fact that in many cases, where empirical evidence of causal inferences has been provided, the data have been collected by an experimenter who also inferred the causal relationship. The validity of such findings could be questioned as it has been shown that experimenter's expectations generally make the data collected favourable to the investigator's hypotheses (Rosenthal and Fode, 1963a; 1963b). An example of this phenomenon can be found in psycho-analytic studies of anorexia nerwosa, according to which anorexia nervosa could be considered an expressiom of the fear of sexuality, specifically of 'oral impregnation'. The fear of oral impregnation became a diagnostic criterion to warrant the diagnosis of anorexia nervosa.

- The lack of definition and operationalization of theoretical constructs

One example, the lack of agreement on defining and diagnosing anorexia nervosa has been discussed previously (3.2.1.). Moreover experimental variables considered of crucial importance have seldom been operationally defined and objectively assessed in anorexia nervosa. Perfectionism or overachievement is a frequent clinically observed characteristic. This feature, however, was seldom operationally defined and objectively measured in anorexia nervosa patients.

The serious conceptual controversies and methodological shortcomings of research on anorexia nervosa are summarlized in Table 3.1. Undoubtedly these factors decrease the valldity as well as the rellability of empirical results and make comparison between studies hardly possible. It is evident that the summarized methodological shortcomings are by no means unique to research on anorexia nervosa. 
Table 3.1. Recapltullation of methodologlcally complleatling factors of anorexle nerwosia resemrch

Abstraction Lewel Compllicating factors Methodological consequences

\begin{tabular}{|c|c|c|}
\hline $\begin{array}{l}\text { Conceptual contrower- } \\
\text { sles }\end{array}$ & $\begin{array}{l}\text { 1. Status of disedse } \\
\text { 2. Definltion of disease }\end{array}$ & $\begin{array}{l}\text { 1. Lack of consistent and } \\
\text { precise definition }\end{array}$ \\
\hline $\begin{array}{l}\text { Psychosomatlo dis- } \\
\text { or der }\end{array}$ & $\begin{array}{l}\text { 1. Mult ple factors } \\
\text { 2. Heteroganelty of } \\
\text { dlsease }\end{array}$ & $\begin{array}{l}\text { 1. 'Language' problems } \\
\text { 2. Indefinite onsets of } \\
\text { dlsease }\end{array}$ \\
\hline \multirow[t]{3}{*}{ Selection of subjects } & 1. Hosp Itall lzed potients & $\begin{array}{l}\text { 1. Effect at hospltallza- } \\
\text { tion }\end{array}$ \\
\hline & $\begin{array}{l}\text { 2. Extrene cases of } \\
\text { disease }\end{array}$ & $\begin{array}{l}\text { 2. Lack of representatt ive- } \\
\text { ness }\end{array}$ \\
\hline & $\begin{array}{l}\text { 3. Long duration of } \\
\text { disease }\end{array}$ & $\begin{array}{l}\text { 3. Information may suffer } \\
\text { firon Imaccurate racall } \\
\text { 4. Subject"s blas }\end{array}$ \\
\hline \multirow[t]{4}{*}{ clinlcal approach } & $\begin{array}{l}\text { 1. Observation } \\
\text { 2. Deserliption }\end{array}$ & $\begin{array}{l}\text { 1. Lack of preclselopera- } \\
\text { tionally defined var la- } \\
\text { bles }\end{array}$ \\
\hline & & $\begin{array}{l}\text { 2. Lack of stamdard proce- } \\
\text { dures }\end{array}$ \\
\hline & & 3. Exper Imenter's blas \\
\hline & & $\begin{array}{l}\text { 4. Gap between obserwatlion } \\
\text { and Interpretatlon } \\
\text { 5. Observatlons may not be } \\
\text { conflirmed or falsiflied }\end{array}$ \\
\hline
\end{tabular}

3.5. Summary

The conceptual disagreement about the definition of anorexia nervosa has gradually disappeared in recent years. Diagnostic criteria for the disorder have not been very consistent, although for the time being the DSM-III at least has become widely accepted. The notion of anorexia nervosa as a distinct disease entity or as an extreme point on a continuum is not incompatible. Authors who emphasize the gradual development of anorexia nervosa have particularly focussed on the anorectic symptomatology and on starvation-related factors that sustain and aggravate the disorder. Those who view anorexia nervosa as a 
distinct disease entity have considered the sustaining effect of starvation factors but have emphasized the role of antecedent psychological factors in the development of anorexia nervosa. A definitive answer has not been unanimously agreed on at the moment. Studies are necessary to determine if psychological differences exist between anorexia nervosa patients and subjects who to some degree share similar symptomatology. Prospective studies of mild forms of the disorder should be carried out to determine whether and in relation to which factors the disease will evolve.

It has been shown that previous studies of anorexia nervosa suffer from serious methodological shortcomings such as the lack of representativeness, the lack of empirical validation of causal inferences and the lack of defining and operationalizing of theoretical constructs. These methodological inadequacies have important consequences for the internal and external validity of research findings on anorexia nervosa.

It has also to be taken into account that anorexia nervosa is a multidetermined disorder inciuding many factors that are invalved in the onset and maintenance of the disease. The fact that multiple factors are interrelated in the development of the disorder requires an integrated approach in studying anorexia nervosa in the future. 
Chapter 4. THE EARLY IDENTIFICATION OF ANOREXIA NERVOSA

"The very idea of 'cause' has become meaningless, other than a convenient designation for the point in the chain of event sequences at which intervention is most practicable"

R.E. Kendel1, The role of diagnosis in psychiatry, $1975,0.64$. 
Chapter 4. THE EARLY IDENTIFICATION OF ANOREXIA NERVOSA

\subsection{Introduction}

The significance of early diagnosis and intervention of anorexia nervosa to enhance prognosis has been commoniy acknowlledged. However, little is known about the onset and course of the disease. Present information from retrospective studies of severe and hospitalized patients do not provide a sufficiently empirical basis for an early identification of the disorder. The purpose of this chapter is to present some of the recent information about the onset and course of anorexia nervosa as well as to propose predisposing factors. This is presented in order to provide the rationale for this study and the basis for methodological choïces.

\subsection{The development of anorexia nervosa}

Anorexia nervosa patients almost uniformly report that they started dieting in response to comments about their figure. However, since dieting is not uncommon, the reported cause is questioned as being 'rarely, if ever causative' (Bruch, 1978, p.70). Casper and Davis (1977) in a study on the course of anorexia nervosa systematically asked their patients if they had known beforehand that they would reach their severely emaciated state. Unanimously, the patients answered 'no'.

Attention has also been given to the onset conditions of anorexia nervosa, for instance, changes in 1ife situations (Beumont, 1977, 1978). Externally precipitating events associated with the onset of anorexia nervosa have been found to vary widely from loss of friends or relatives, percelved or experienced fallure, leaving home and entering puberty, to separation and going to college. However, these precipitating events seem to be age-specific and may occur very commonly in adolescence wi thout leading to anorexia nervosa. 
Changes in life situations may have a psychosocial impact on the Individual. However, it is believed in psychosomatic medicine (Weisman, cited in Weiner, 1977; Engel, 1961) that it is nat the event but the success or fallure in coping with a threatening event that is the critical factor that determines whether disease will or will not ensue. Bruch $(1973,1978)$ has focussed on the underlying personality deficits which make anorexia nervosa patients poorly equipped to cope with problematic situations. These psychological characteristics place indivîduals alt risk for developing the disorder.

other authors proposing the continuum hypothesis did not pay much attention to predisposing factors of anorexila nervosa but have stressed the importance of sustaining and aggravating factors, particularly starvation, in the development of the disease (Nylander, 1971).

once the full picture of anorexia nervosa has been developed, the condition appears to consist of at least two clinical subforms: anorectic individuals who control their weight by exclusively abstaining from food, so-called 'abstainers' or 'dieters', and those who pursue thinness by using self-induced vomiting and purging, so-called 'vomiters and purgers" (Beumont, 1976).

Recent studies have revealed that another category within the clinical condition exists. Anorectic individuals can be distinguished as those who develop bulimia and those who do not suffer from these regular episodes of overeating (Casper et al., 1980; Garfinkel et a1., 1980; Strober, 1981; Strober et al., 1982). The categories, bulimic anorexia nervosa and non-bulimic anorexia nervosa patients, also show psychological and behavioral differences. The bulimic category tends to be more socially outgoing, depressive and appears to have more difficulty controlling their impulses (Garfinkel, 1981). However, it still remains unclear whether these differences were present before the onset of the disease and have significance for the course of the disorder.

As these clinical differences are found to be related to prognosis, (Garfinkel et a1., 1977; Hsu et a1., 1979) it will thus be important to diagnose anorexia nervosa as well as related dieting disorders early and to subclassify the individuals according to the way they control their weight and to their eating behaviour. 


\subsection{Predisposing factors}

\subsubsection{Biological factors}

Familial incidence of anorexia nervosa has often been considered as indirect evidence for the role of genetic factors in the disorder. Anorexia nervosa may occur in both mother and child (Ehrensing and Weitzman, 1970; Cantwell et a1., 1977). However, this occurrence has not commonly been reported for larger samples (Dally, 1969; Theander, 1970). While familial incidence in mother and child may be rare, this is not so for the incidence in siblings.

The reported morbidity risk among sisters ranges from $3.1 \%$ (Halmi, 1977; Dally and Gomez, 1979) to 6.6\% (Theander, 1970; Garfinkel et a1., 1980).

Since siblings usually grow up in the same social environment, an overrepresentation of anorexia nervosa in siblings, even twins, however, does not necessary imply a genetic predisposition. Therefore results from studies on familial incidence of anorexia nervosa do not permit any definitive conclusion about the role of genetic factors in anorexia nervosa.

Empirical support for the assumption of genetic factors in the development of the disorder has also been sought in studies of an association between anorexia and Turner"s syndrome. An association between anorexia nervosa and gonadal dysgenesis has been found in several studies (Dickens, 1970; Halmi and Rigas, 1973; Kron et al., 1977; Darby et al., 1981) and it has been suggested that these associations occurred more often than can be explained by chance alone. However, even if the association has occurred more of ten than would be expected on the basis of chance, it is still doubtful whether this occurrence must be attributed to a common underlying genetic predisposition (Kron et al., 1977; Garfinkel and Garner, 1982).

Evidence that biological factors are involved in the initiation of the disease has been inferred from the fact that anorexia nervosa has its onset in puberty. Accordingly it has been postulated that age-specific hormonal changes may sensitize individuals to develop amenorrhea and 
disturbed eating patterns (Weiner, 1977).

The fact that anorexia nerwosa is accompanied by hormonal changes has led to the search for an underlying blological pathology, particularly a hypothalamic-pituitary dysfunction. However, it has been frequently stated that even the fact that amenorrhea may occur prior to other symptoms and may persist after weight gain does not permit a conclusion about the presence of a primary hypothalamic disorder (Bruch, 1973). Russell (1977) proposed that the amenorrhea may be resulting from a primary disturbance of hypothatamic function but that the ful 1 expression of this disturbance is brought about by psychological stress. It can be concluded that a biological vulnerability that may be located in the hypothalamus may predispose to anorexia nervosa. A biological vulnerability, however, is not a sufficient nor a necessary cause for the development of the disorder.

\subsubsection{Psychological factors}

The importance of psychological factors in anorexia nervosa has generally been acknowledged since the first clinical descriptions given by Morton (1694) who assumed that the 'nervous consumption' stemmed from 'sadness and anxious cares'.

Anorexia nervosa differs from the common dieting of many female adolescents since the pursuit of thinness becomes a goal and virtue in itself. It is therefore postulated that the disease evolves from roots antedating the dieting and that serious developmental deficits, predispose an individual to the development of anorexia nervosa. These developmental deficits, however, have been covered by excellent performances; therefore they are seidomly observed by the patient"s parents who commonly describe the good, sometimes perfect behaviour of their children before the anset of anorexia nervosa. Investigations of the self-image of anorexia nervosa patients have shown that anorectic patients, in comparison to their peers, are highly critical of themselves and assume that others view them with the same severe criticism (Casper, 1981). The good, even perfect behaviour of anorectic patients 
and their anxiety to please, seem to be disguises for their feelings of ineffectiveness and worthlessness. A strange dependence on others for approval, direction and acceptance may lead to an increased sensitivity to the opinions and comments of other people. Once having discovered the sense of effectiveness and confidence that comes with restrained eating, the anorexia nervosa patient cannot stop, fearing that this will lead "to 10 ss of control (Bruch, 1973; Casper et al., 1977; Crisp, 1980).

Two defensive attitudes have been considered as characteristic for the period of adolescence, intellectualization and self-denial (Freud, 1930). In arder to master the new developmental tasks adolescents make use of these defense mechanisms. The early tendency of anorectic patients to other-directedness, to placing the well-being of others before their own is expected to require an excessive use of denial of inner sensations, feelings and thoughts. The maladaptive use of this makes the self-denial of amorexia nervosa patients qualitatively different from that of other adolescents.

Cognitive-styles such as dichotomous (all or none) reasoning, superstitious thinking, personalization and rigid morality have also been suggested as predisposing factors of anorexia nervosa (Garner and Bemis, 1982). It may be expected that individuals with this type of cognitive functioning seem to be inadequately equipped to cope with the age-developmental task of adolesence such as autonomous functioning and abstract reasoning.

\subsubsection{Environmental factors}

The developmental deficits of anorexia nervosa have been related to early experiences in childhood (Bruch, 1977, 1980; Selvini Palazolli, 1974) as well as to current patterns of family interactions (Minuchin et a1. 1978, 1983). Psychodynamic formulations focussing on the early experiences in childhood, have emphasized the lack of parental response to child-initiated clues. Although "the children were well cared for in every physical detail, everything was done according to the 
mother"s decisions and feelings, not according to the child's needs" (Bruch, 1977, p.4). SeTvini Palaz011: (1974) has confirmed this view by postulating that assessment of the basic perceptions of an individual is only possible if these perceptions are legitimized and encouraged in an interpersonal relationship with the parent. She further emphasized an additional aggravating factor, that of role attribution. Role attribution is defined as the process in which the child becomes cast in a fixed role, which is the only role its parents can accept without anxiety. Among such roles Selvini Palazolli mentioned as the most common, that of the good dependent girl who always obeys the parental commands. If early perceptions, feelings and needs of his own are not confirmed the child ends up doubting his owm impulses and sensations. Consequently the child will become more helpless and dependent on others and will not develop a sense of self. In a sense, Boskind-Lodah1 (1976, p.248) has critized Bruch's propositions by stating that 'the feeling of not having an identity is not a misperception, but a reality that need not be caused solely by the stereotyped protective mother, but by other cultural, social and psychosocial pressures as well'.

It certainly is belleved that cultural and social pressures by demanding and expecting contradictory roles of modern women to be romantic, tender and competing, at the same time tend to aggravate the inner psychological conflicts (Selvini Palazolli, 1974; Bruch, cited in Magu 1, 1980).

In addition to these factors women have also been subjected to more specific pressures such as the need of a thin body shape. Garner et a1. (1980) collecting body measures and age for both the contestants and the winners of the Miss America Pageant from 1959 through 1978 have found that since 1970 the winners have weighed significantly less than the average contestant before. Other specific factors are the increased emphasis on dieting (Garner et a1., 1980) and the widespread publicity on the need for healthy food and exercise. The importance of socio-cultural factors in the development of anorexia nervosa have also been illustrated by recent studies of ballet and modelling students, female runners (Garner and Garfinkel, 1980; Yates et al., 1982; 
Garner, Garfinkel and 01msted, 1983).

Recently, many investigators have tried to include the social context of the family in their formulations about psychosomatic illness such as anorexia nervosa (Minuchin, 1978, 1983). It is postulated that certain types of family organization are clasely related to the development and maintenance of psychosomatic syndromes in children and that the child's psychosomatic syndromes in turn play an important role in maintaining the family homeostasis. The family organization of anorectic patients are characterized by enmeshment: conflict avoidance, overprotection and rigidity. These familial factors predispose to a lack of sense of identity, absence of coping skills, sensitivity, dependence and developmental cognitive deficits commonly found in anorexia nervosa.

One may conclude from these data that many and various factors may predispose to anorexia nervosa. But still, there is a lack of data from prospective studies to determine the significance of the factors placing the individual at risk to develop anorexia nervosa. For this purpose an epidemiological approach of anorexia nervosa is needed and recommended.

\subsection{An epidemiological approach of anorexia nervosa}

Epidemiology has been defined as the study of disease occurrence in human populations (Friedman, 1980).

Knowledge of the distribution of diseases can be used to investigate etiological factors. The ultimate concerns of epidemiology are the prevention of disease and the maintenance of health. "The great advantage of this kind of approach to prevention is that it may be applicable in the early stage of our knowledge of diseases' (Morris, cited in Mausner and Bahn, 1974).

Chronic diseases are considered to extend over time through a sequence of stages (Mausner and Bahn, 1974). The first stage of disease is the stage of susceptibility, during which the $\$ 11$ ness has not developed but in which the presence of certain so called "risk factors" favor 
its occurrence. In the second presymptomatic stage the disease has not yet manifestated itself through detectable signs or symptoms but the pathogenetic changes have started to occur, however, at a 'subcilinical level". The third stage is the stage of clinical disease. In this stage sufficient changes have accurred that signs or symptoms of disease can be identified. Without adequate treatment, the fourth and last stage of disease may be the stage of chronicity or death. According to this schematic picture of the course of a disease, two epidemiological approaches to early diagnosis have been proposed. The first depends on prompt attention to the earliest symptoms of disease; the second attempts to detect disease in asymptomatic individuals. Accordingly, in this study two groups sharing to some degree anorectic and menstrual characteristics of anorexia nervosa and a healthy population of schoolgirls were selected to conduct a prospective study. The results of this study are presented in Part II of this dissertation.

4.5. Towards an early identification of anorexia nervosa and related disorders

One of the factors impeding an early identification of anorexia nervosa is the lack of information about the onset and course of the disorder. A review of the traditional controversy about the status of anorexia nervosa as a distinct disease entity or an extreme point on a continuum does not justify the conclusion that the two notions are incompatible with each other. However, the views differ significantly in their emphasis on certain predisposing and sustaining factors. Authors who have favored the view of anorexia nervosa as an extreme point on a continuum of preoccupation with weight and dieting focus on the dieting behaviour as risk factors. They state that the feeling of being fat, internally or extermally induced leads, to dieting. Prolonged and intensive dieting ultimately results in the development of the full picture of anorexia nervosa. Starvation was considered to be the aggravating and sustaining mechanism. Little attention was paid to 
psychological factors in initiating and maintaining the disease. Authors who favor the concept of anorexia nervosa as a distinct disease entity emphasize the psychological deficits underlying the preoccupation with weight and dieting rather than the anorectic behaviour and weight loss. Nevertheless, the role of starvation as one of the factors contributing to the course of anorexia nervosa has not been neglected. Despite this, in the early identification of anorexia nervosa emphasis must be directed to the psychological characteristics instead of the anorectic symptoms. Both views criticize the exclusive reliance upon arbitrary quantitative criteria such as the weight loss as the basis for diagnosis.

In the absence of empirical data for the etiology and pathogenesis of anorexia nervosa and in the light of the need of an early identification of the disease it is worthwhile to examine whether psychological differences exist among anorexia nerwosa patients, those subjects who share some degree of anorectic and menstrual characteristics as well as asymptomatic controls. One of the psychological characteristics of anorexia nervosa which is most commonly endorsed is 'the drive for achievement' (Bruch, 1973, p.272), which has also been mentioned by other authors as 'exaggerated ambition' (Theander, 1970, p.9), 'the striving for perfection' (Casper, 1981) or the "drive to achieve" (Boskind-Lodah1, 1976, p.254; Halmi et al., 1977, p.49).

The presence of this psychological characteristic has been confirmed by parents' uniform reports of special goodness and great achievements of their children before the onset of anorexia nervosa. However, according to the anorectic patients' own reports, they have perceived their youth as full of anxiety and fear of not 'being good enough". The drive to achieve likely appeared to stem from the general fear of fallure. The suggestion that the drive to achieve in anorexia nervosa is a disguise for the fear of fallure, has also been identified by others (Selvini Palazol11, 1974, p.68; MacLeod, 1981, p.83).

It has also been suggested that the drive to achieve, although present before disease onset, becomes a matter of urgency when the anorectic patient is faced with changing demands (Bruch, 1973, p.275). Hence it has been proposed that "true prevention (of anorexia nervosa) requires 
that their pleasing superperfection is recognized early as a sign of Inner misery (Bruch, 1978, p.56). These theoretical propositions and inferences, when empirically validated, may have important consequences for the early identification of anorexia nervosa. They imply that anorexla nervosa patients could also be differentiated in an early stage from other subjects, including those sharing mild characteristics of dieting and weight loss in terms of the drive to achieve and the fear of failure. Control studies will be essential to determine whether ather groups share these same characteristics.

Previous studies by McClelland (1953) and others on the achievement motive have indicated that two basic aspects of the drive to achieve may be distinguished: 1. a motive to achieve, an approach motive, and 2. a motive to avoid failure (Atkinson and Feather, 1966; Argyle and Robinson, 1962,1971 .

The motive to achieve has been conceptualized as the positive fear of fallure, al though strictly speaking there is no fear but an optimal situation of arousal to facilitate performance. The motive to avoid fallure, the negative fear of failure, however, refers to the condition of anxiety which interferes with and moreover, debilitates performance behaviour.

A classic experiment by Stamps and Teevan (cited in Birney et al., 1969) on the negative fear of failure and conformity illustrated that individuals who can be psychologically characterized by a strong negative fear of failure tend to conform more to external expectations than those individuals with less strong negative fear of fallure motives. This tendency to conform has also been observed in anorexia nervosa patients and has resulted in assumptions that anorectic patients consider achievement mainly in terms of what rewards it could provoke from others (Boskind-Lohdal, 1976, p.25). They rely upon others to validate their sense of self-worth, since this basic sense of personal power has not been developed. 
4.5.1. Research questions

To examine the effect of psychological characteristics on the onset and development of anorexia nervasa, several research questions have been formulated:

1. Can anorexia nervosa patients (AN) on other than quantitative anorectic symptoms be differentiated from asymptomatic female controls (AF) particularly with respect to the drive to achieve and the motive to avoid fallure (negative fear of failure)?

2. Do anorexia nervosa patients (AN) differ from other individuals sharing to some degree anorectic and menstrual characteristics such as secondary amenorrhea patients (AM) with respect to the drive to achieve and the negative fear of failure?

If differences between the groups can be found and turn out to be statistically significant, we then can formulate another research question about the relationship of psychological and anorectic differences and the development of anorexia nervosa.

3. Is there a relationship between anorectic features, in terms of dieting and consequent weight lass and menstrual characteristics, and the aggravation of anorectic symptoms?

4. Is there a relationship between psychological characteristics in terms of the drive to achieve and the negative fear of fallure, and the aggravation of anorectic symptoms?

If the association between the presence of anorectic symptoms and the maintenance of anorexia nervosa turns out to be more present than the association between psychological characteristics and the development of the disorder, this would favor the hypothesis of anorexia nervosa as an extreme point on a continuum. If on the other hand the relationship between psychological characteristics and the development of anorexia nerwosa appears to be stronger, these data will support the hypothesis of anorexia nervasa as a distinct disease entity.

According to the continuum hypothesis, early identification must aim at detecting initial stages of dieting. While empirical evidence to support the notion of anorexia nervosa as a distinct disease entity will lead to a focus on the psychological characteristics and not on the dieting and weight loss only. 
4.6 .

Summary

For an early identification of anorexia nerwosa and related dietary disorders the need for epideminological approaches to elucidate the various predisposing factors and the processes underlying the devellopment of andrexia nervosa becomes evident.

Although anorexia nervosa may start as a deliberate attempt to lase some welght, it does not appear a sufficient cause to explain the development of the disorder. This may also account for the significance of so-called precipitating events, since it has been frequently 117ustrated in psychosomatic research that not the event but the success or fallure to cope with a threatening event is the critical factor determining whether disease will or will not ensue. With reference to anorexia nervosa it has been emphasized that developmental deficits put individuals at risk of not coping with external demands and hence at risk to the development of anorexia nervosa. It has been pointed at that focussing on the drive to achieve to fend off the fear of failure may lead to an early identification and prevention of the disease.

The seeming absence of coping styles has been related to early experiences in the parent-child interaction, the current patterns of family interactions as well as socio-cultural expectations with respect to the role of girls and women. Other socio-cultural values that put an emphasis on thinness, food-consciousness and exercise have al so been identified as predisposing factors. In the absence of a known aetiology and pathogenesis attention must be paid to the earliest symptoms of anorexila nervosa such as dieting with cansequent weight loss or amenorrhea. Al though amenorrhea may be the first symptom reflecting a hypothalamic dysfunction, empirical evidence is lacking to support the idea of a primary organic disorder in anorexia nervosa.

For the purpose of identifying anorexia nervosa early in its course it is necessary to estimate whether psychological differences exist between anorexia nervosa patients and subjects with no or to some degree similar anorectic and menstrual symptoms. It is also important to know how possible differences relate to the course of the disorder. A 
stronger association of anorectic behavior and the maintenance or aggravating course of these symptoms will be in favour of the continuumhypothesis and implies increased attention to early symptoms such as weight loss and loss of normal menstrual cycles. A stronger relation between the presence of the psychological characteristics (the drive to achieve and the negative fear of fallure) and the maintenance and course of anorectic symptoms will be compatible with the distinct disease entity. These findings imply that more attention must be paid to the psychological characteristics underlying preoccupation with dieting and weight. 
Chapter 5. OUTLINE OF THE STUDY

"Theorie-ontwikkeling implifcert een onderzoeksproces. Daartegenover kan de bron van bepaalde ideeën of zelfs 'modellen' buiten de onderzoeksgegevens 1 iggen".

Barney Glaser/Anselm Strauss: De ontwikkeling van gefundeerde theorie. (1976) 


\section{1.}

\section{Introduction}

The question to what extent anorectic, menstrual and psychological features contribute to the development af anorexia nervosa will be examined in this study. In this chapter the hypotheses will be presented that have been inferred from theoretical notions about anorexia nervosa as an extreme point on a continuum of preoccupation with weight and dieting or as a distinct disease entity with different psychological features underlying the anorectic symptomatology. In addition the choice of a research design and the selection of research samples as well as the operationalization and measurement of the experimental variables will be described.

\subsection{Theoretical notions and propositions}

Authors who proposed the 'continuum hypothesis' have stated that 'true' anorexia nervosa may be considered as the final stage of dieting for understandable cosmetic reasons. Nylander $(1971, p .25)$ in this respect has emphasized the role of prolonged and intense dieting. Fries $(1974, p .40)$ has acknowledged the role of psychological factors in the development but stated that these factors are multivariate, 'such as emotional or sexual conflicts, faulty learning in early life, constitutional make-up, predisposing endocrine disturbance and/or some as yet unknown factors'. In the absence of a known etiology Fries (1977) has advocated to pay attention to the early symptoms, dieting and weight loss, since the true difference between those who do not satisfy and those who do satisfy strict diagnostic criteria for anorexia nervosa is probably 'more a matter of degree of 111 ness, e.g. as measured by the total weight loss or secondary effects of severe ma1mutrition than a matter of diagnosis' (p.174). Other authors (Crisp, 
1970; Russel1, 1970; Bruch, 1973) favoring anorexila nervosa as a distinct disease entity have stated that it is not multiple psychological factors, but a particular and specific combination of developmental deficits that predispose an individual to anorexil nervosa. Accordingly it has been advocated that not only mild weight 10 ss and dieting, but also psychological characteristics such as their striving for perfection to mask their general fear of failure need to be evaluated to ldentify anorexia nervosa early (Bruch, 1973, 1978).

since prospective studies of anorexia nervosa are lacking, these postulations have not been empirically confirmed or falsified.

Traditionally the diagnosis of anorexia nervosa is made when the dieting behaviour has resulted in a loss of welght of at least $25 \%$ of original body weight or standard body weight. This criterion for weight loss has been rather arbitrarily chosen; less stringent criteria for welight loss such as 10\% (Dally, 1969) and 20\% of original body weight (Rollins and Piazza, 1978) have also been suggested. It seems obvious that for the purpose of an early identification of anorexia nervosa less stringent criteria for the amount of welight loss have to be adopted.

In this study subjects are considered to have "mild anorexia nervosa" if they share the fear of fatness and consequent dieting behaviour of anorexia nervosa. However, their body weight remains within normal limits, that is between $75 \%$ and $120 \%$ of standard body weight and their menstrual cycle may persist, although it may be irregular.

To examine the assumptions about the discriminative and preictive rolle of psychological versus anorectic characteristics in anorexia nervasa basic propositions have been inferred and formulated.

Individuals with mild anorectic symptoms, psychologically can be differentiated from anorexia nervosa in terms of the drive to achieve and the motive to avoid failure.

Individuals with mild anorectic symptoms are at an increased risk for the maintenance or aggravation of these symptoms as opposed to those individuals who do not share these anorectic characteristics. 
Individuals with menstrual disorders are at an increased risk of developing anorexia nervosa as apposed to those individuals who do not share these menstrual characteristics.

Individuals with a strong drive to achieve and a strong motive to avold failure are at an increased risk of developing anorexia nervosa as opposed to those individuals who do not share these psychological characteristics.

These postulations may provide information useful for an early identification of anorexia nervosa and dietary disorders.

\subsection{The choice of a research design}

Most research on anorexia nervosa has come from clinical studies and was retrospective in nature. Prospective studies on anorexia nervosa have not been carried out yet.

In view of the basic propositions and resulting hypotheses the present study was designed to compare anorexia nervosa patients with patients with secondary amenorrhea and asymptomatic controls. Anorectic symptoms as well as the psycholagical characteristics, the drive to achieve and the fear of fallure, were assessed in the three groups. Endocrinological characteristics were only assessed in anorexia nervosa and secondary amenorrhea patients. The comparison of cases with controls required a transversal study design. To determine the predictive value of anorectic symptoms, menstrual and psychological characteristics at the onset and development of anorexia nervosa a longitudinal study design was needed. Accordingly an experimental design was chosen and is presented in Table 5.1. 
Table 5.1. The chiosen design

Sibjects

\begin{tabular}{|c|c|c|c|c|}
\hline $\begin{array}{l}\text { Mearsure- } \\
\text { ments }\end{array}$ & $\begin{array}{l}\text { AN } \\
\text { sub- } \\
\text { jects }\end{array}$ & $\begin{array}{l}\text { Subjects with } \\
\text { mild anorectic } \\
\text { symptoms }\end{array}$ & $\begin{array}{l}\text { Asymp- } \\
\text { tomatic } \\
\text { subjects }\end{array}$ & Study method \\
\hline $\begin{array}{l}\text { Measurement A } \\
\text { (stert of the } \\
\text { study) }\end{array}$ & $O_{1 A}$ & $0_{2 A}$ & $0_{3 A}$ & Retrospective \\
\hline $\begin{array}{l}\text { Measurement } B \\
(6 \text { months } 1 \text { atter })\end{array}$ & & $\mathrm{o}_{2 \mathrm{~B}}$ & & \\
\hline $\begin{array}{l}\text { Measurament } B \\
\text { "12 months later) }\end{array}$ & & & ${ }_{38}$ & \\
\hline Study-method & & Prospectilve & Prospect & ve \\
\hline
\end{tabular}

The purposes of measurement $A$ are 1 . to make a comparison between the AN group, a group of indiwiduals sharing mild anorectic and menstrual characteristics (AM) and an asymptomatic (AF) group with respect to anorectic and pychological characteristics. 2. to make a comparison between the $A N$ group and $A M$ group with respect to the endocrinological characteristics LH and FSH and 3. to make a first assessment of anorectic and psychological characteristics in the mild anorectic and AF for the prospective study.

Measurement $B$ is directed at a within-subjects comparison in the mild anorectic group and in the asymptomatic group respectively.

Measurement $B$ was done at 6 months and 12 months after the first assessment. The time interval between the measurements was based upon the retrospective data in the literature on the course of anorexia nervosa. The shortest duration of the disease, as measured by the manifestation of the first symptom to presentation to medical care services is four months at least (Strober and Goldenberg, 1981). Because 
of the possible increased risk of anorexia nerwasa developing in the secondary group, a 6 month interval was chosen.

The groups, which were chosen to make between-groups and within-groups comparisons are:

1. a group of patients who satisfy the diagnostic criteria for anorexia nervosa (AN) (section 5.4.1.);

2. a group of individuals with secondary amenorrhea but who do not satisfy the criteria for anorexia nervosa (AM) (section 5.4.2.);

3. a group of asymptomatic female indivuals (AF) (section 5.4.3.).

Since menstrual characteristics were included for reasons of comparison, the participation of males was excluded.

\subsection{Selection of research groups}

For reasons of accessibility and the fact that adolescents seldom seek medical care and do not often appear in doctor's practices the AF group was selected from a population of students attending secondary and tertiary schools. The group also includes a small sample of females, who had jobs of 'low vocational level'.

The AM group was selected from a population of secondary amenorrhea patients attending outpatient departments of gynaecology and obstetrics.

The AN group was drawn from a population of patients who were not hospitalized for treatment in order to eliminate the effect of hospitalization vis à vis other groups. The AN group was recruited from different self-help groups of anorexia nervosa patients in the country and from the departments of internal medicine, gynaecology and obstetrics of four different hospitals.

It was also decided to select a group of professional ballet students (BA) for a comparison, since other studies have indicated that ballet dancers share some characteristics of anorexia nervosa: increased emphasis on a thin body, irregular or absence of menstrual cycles and a drive to achieve (Druss and Silverman, 1979; Garner and Garfinkel, 
1981; Frisch et a1., 1979: Garner et a1., 1983). Because of the possible increased risk of anorexia nervosa developing in the ballet dancers group a 6 month interwal between first and second assessment was chosen.

The results of the comparison with ballet dancers will be presented in Chapter 7.

In order to reduce possible bias, the four research groups were recruited from different schools and different institutions. Thus the selected subjects may be considered to be a fair representation of the research populations. The criteria for age of all subjects were that they must be older than 11 and younger than 40 years of age. The criteria that were used to select the four research groups will be presented in the following paragraphs.

\subsubsection{Criteria for selection of the anorexia nervosa (AN) group}

Most diagnostic criteria for anorexia nervosa emphasize the fear of fatness and the consequent anorectic behaviour in terms of weight loss. However, recent studies have revealed that the fear of becoming obese may be expressed in behaviours aimed at preventing weight gain such as self-induced vomiting or purgative abuse without necessarily resulting in extreme emaciation (Russel1, 1979; Fairburn and Cooper, $1982)$.

In a study of thirty bulimia nervosa, patients selected according to two criteria, an irrestible urge to overeat, followed by self-induced vomiting or purging and a morbild fear of becoming fat, Russell (1979) found that 17 patients went through an earlier phase of unequivocal anorexia nervosa. The term bulimia nervosa had been chosen to do justice to the bouts of gross overeating. The occurrence of overeating has also been observed in a significant proportion of anorexia nervosa patients (Dally, 1969; Casper et al., 1980; Garfinkel et al., 1980). Previous studies have also indicated that self-induced vomiting and purging frequently occurs in anorexia nervosa (Beumont, 1976; Crisp et a1., 1980; Bhanji and Mattingly, 1981). The only difference between 
anorexia nervosa and bulimia nervosa patients was found with respect to body weight and menstrual functioning at the time of the investigation.

Since the majority of the bulimia nervosa patients in Russelt's study had experienced a previous history of anorexia nervosa fulfilling the necessary criterial for severe weight loss and prolanged amenorrhea, bulimia nervosa has been viewed as 'an aftermath or chronic phase of anorexia nervosa' $(p .444)$.

The sample of anorexia nervosa patients was selected for the study using the diagnostic criteria for anorexia nervosa as presented in Table 5.2 .

Table 5.2. Oriterla for Anorexla Nerwasa (modifled verslon of the DSM- IIII criterla for the disorder)

A. Intense fear of brecoming obese, whlch does not dimlinlsh ws welght loss progress

B. Welght loss of at least 258 of or lginal body wellght, or welght loss from or lglinal body welght plus projected welght gall expected fron standard body wellght for age and helght may be comblined to make the 255.*

C. Primary amenorrhea at milnimum age of 16. years or secondary amenorrhea of at least 3 cycle's duratlon.

D. No known physlcal Ill ness that would accaunt for the wolght loss or the anenor he. .**

* For subjects under $\$ 8$ years of age, growth charts for Dutch girls 3-20 years, deweloped by the Dutch Institute for Preventive Mediclne, were used. The Tables of the Metropolltam Life Insurance Company were used for female subjects of 18 years and older.

* To exclude physlcal Illness to explaln the light loss, anorexla nervosa patients who did not have had a prevtous physlcal oxamine*lon wers examined by a medical doctor. In addition thyrald functlon, $T_{3}$ and $T_{4}$ ' was examlned. These patllents gynerolloglcally axamined. Levells of lutelnlzing hormone (LH), folllele stimulating hormone (FSH), prolactin and 17-beta-oestradiol wore measured. 
Also those patients, who did not satisfy the necessary criteria for welght loss and menstrual cycle were selected for this study, if they had a previous history of anorexia nervosa and were still presenting the characteristic anorectic behaviour as described in Table 5.3.

Table 5.3. Criterla for Anorectlc Behavlour

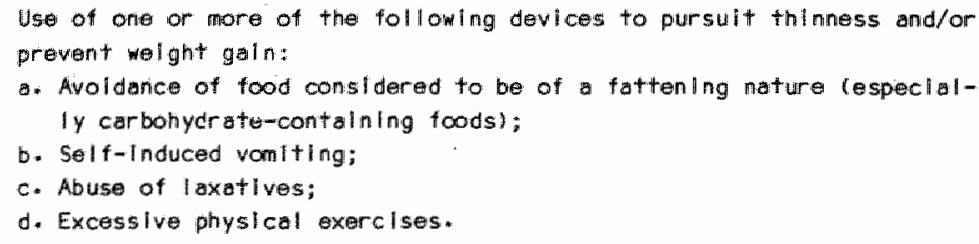

5.4.1.1. Pracedures

The request to participate in the study was made to anorexia nervosa patients attending departments of internal medicine and gynaecology by their own doctors. If the patients were willing to participate in the study, they were then asked to make an appointment with the researcher. Patients were informed by the researcher that the information obtained would be kept strictly confidential, but could be shared with their doctors at their own request.

Anorexia nervosa patients from self-help groups were contacted at their regular meetings. On these occasions information about the study was given and patients were asked to take part in the research program. Patients who were wlling to participate had to fill in an inforimed consent form.

The procedure as described, recruited 99 anorexia nerwosa (AN) patients, who volunteered for this study. Thirteen (13) were excluded: 7 patients did not satisfy the diagnostic criteria for anorexia nervosa as described previously; 2 patients were male; 3 patients were older than 40 ; and 1 patient was without anorectic symptoms at the time of the investigation. Eighty-six (86) AN patients who satisfied the criteria for diagnosis (Table 5.2. and 5.3.) and age were selected. 
All but 2 patients were outpatients. One of the patients was only temporarily hospitalized for diagnostic purposes, the other patient had to be hospitalized because of a somatic disease other than anorexia nervosa for which clinical treatment was considered to be necessary.

Five (5) patients came from 2 different departments of internal medicine; 14 patients were from 3 departments of gynaecology and obstetrics; 45 patients were from self-helpgroups; 22 patients presented themselves without referral or were referred by a general practitioner.

The AN group was heterogenuous in two aspects: 1 . they differed in respect to their stage of disease, and 2 . they differed in respect to their anorectic behaviour. Thirty-eight (38) patients were more than $25 \%$ underweight in respect to age and height. Forty-six (46) patients could be classified as 'restricters', while 40 patients accasionally had bouts of overeating.

5.4.2. Criteria for selection of the secondary amenorrhea (AM) growp

Patients with secondary amenorrhea are divided into two major groups: 1. patients suffering from organic amenorrhea and 2, patients with functional amenorrhea. The first group is beyond the scope of this study.

A characteristic feature of anorexia nervosa in females is amenorrhea, the cessation of menstruation, or the inhibition of menarche. Most research on the onset, maintenance and resumption of menses have stressed the significance of body weight (Frisch and Revelle, 1970; Frisch, 1972; Frisch and McArthur, 1974; Frisch, 1977). Frisch and her co-workers found a direct relationship between body welght and menstrual cycles: a critical amount of body fat as a percentage of total body composition was necessary for the onset or resumption of menstruation. The loss of $10 \%$ to $15 \%$ of the normal weight for age and height reduces the fat/lean ratio to less than a critical level and 
will result in the cessation of menses (Frisch, 1980).

An association of volluntary welight loss with amenorrhea has frequentiy been observed (Fries, 1974; Knuth et a1., 1977; Vigersky et a1., 1977; Graham et a1., 1979; Weeda-Mannak et a1., 1980; Wentz, 1980). These findings corroborate the hypothesis of a critical body weight for the malntenance of menstrual function. The observed association suggests that simple weight loss results in hypothalamic dysfunction, but the processes by which changes in weight alter reproductive function are st 111 unclear. Possible mechanisms whereby hypothalamic dysfunction is accomplished have been discussed by Eisenberg (1981). Stil1, the observed relation between weight loss and amenorrhea does not warrant the postulate that weight loss is the 'commonest single aetiological factor' in the pathogenesis of secondary amenorrhea in anorexia nervosa (Knuth et a1., 1977).

The observation that a significant proportion of anorexia nervosa patients experience the amenorrhea prior to weight loss (Fries, 1977; Falk and Hallmi, 1982) has led to the assumption that there may be a primary hypothalamic dysfunction, triggered by psychological stress (Russe11, 1970; Wakeling, 1977; Weiner, 1977). An alternative explanation that has been proposed is that chronic or acute psychological stress is associlated with an accumulation of dopamine in the central nervous system (Akse1, 1979). It has been shown that increased dopamine levels induce a decrease of luteinizing hormone (LH) patterns (Eisenberg, 1981, p.546) Low LH concentrations are clinically manifested in an absence of menstrual function.

An association between nutritional factors and the onset of amenorrhea in anorexia nervosa patients has also been suggested. Crisp and Stonehi11 (1971) have postulated that the onset of amenorrhea coincides with or follows a period of carbohydrate restriction. A relationship between eating behaviour and LH serum levels has been observed in several studies. Russe11 and Beardwood (1970) found that menstruating obese women became amenorrheilc on low caloric diets, even though these women were not underweight. These findings appear to support the hypothesis of carbohydrate restraint as an important factor contributing to menstrual and reproductive failure. Additional evidence to 
support this assumption has been provided in studies conducted by Katz et al. (1977) and, more recently, Falk and Halmi (1982). Their results indicated that women who regained weight but continued an anarectic eating pattern remained amenorrheic in spite of weight gain. Hence it has been suggested that amenorrhea has a stronger correlation with nutritional intake than with body weight. Considerable support to this notion has been provided by recent studies also IGraham et al., 1979; Wentz, 1981; Bates et a1., 1982). Unfortunately in studies of anorexia nervosa, nutritional, psychological and body weight factors cannot be separated.

Fries et al. (1974) in studying the epidemiolagy of secondary amenorrhea found that psychological stress was more frequently experienced by women who had secondary amenorrhea during the last year than by their age-matched controls. Although underweight was more frequently observed in the amenorrheic subjects than among the controls, dieting was not significantly more frequently reported in this anenorrheic group. A striking overrepresentation of intellectual occupations in women with secondary amenorrhea was observed. No differences with respect to psychological stress and previous menstrual irregularity have been found in women who had so-called 'postpil1' amenorrhea when compared with other amenorrheic women. Half of these women with amenorrhea related to the use of oral contraceptives reported dieting and welight 10ss. Seventy-five (75) percent of the women with amenorrhea following oral contraceptive use were judged to be underweight, mostly as a result of dieting when the medication was stopped. Recent studies give support to the hypothesis that weight loss appeared to be of more etiological importance in cases of postpill amenorrhea than the use of oral contraceptives (Wentz, 1980; Archer and Thomas, 1981).

It is not surprising that in a study by fries et al. (1974) a significant difference was found with-respect to previous menstrual irregularity. The occurrence of previous menstrual irregularity was about ten times more common in the amenorrheic group than in the control subjects. These data corroborate with the idea of a pre-existing dysfunction of the hypothalamic-pituitary-ovarian system as one of the determining factors in the development of secondary amenorrhea. Fries' 
findings suggest that the occurrence of secondary amenorrhea is related to more factors than body weight alone.

The highest incidence of spontaneous amenorrhea has been observed in women under severe stress, such as prisoners or women in concentration camps awalting execution (Drew, 1961; Whitacre and Barrera, 1944, cited in Archer and Thomas, 1981 ).

An increased incidence of amenorrhea has recently been reported in women who compete in sports or participate in strenuous physical activities such as ballet and modern dancing ISperoff and Redwine, 1980; Baker et al., 1981). Based on data from extensive studies, the occurrence of secondary amenorrhea in different subgroups suggests that the etiology of amenorrhea is diverse. Thus amenorrhea is considered to be a symptom and not a diagnosis. From previous findings one maly conclude that possible pathogenic mechanisms underlying the amenorrhea are hypothalamic changes which may be primary or secondary to weight 10ss, to caloric deprivation, or to emotional stress.

It seems obvious from previous findings that many factors effect the cessation and resumption of menstruation in anorexia nervosa.

Diagnostic criteria for anorexia nervosa consider amenorrhea a condition sine qua non for the diagnosis in female patients, however, criteria for the amenorrhea have seldom been given.

An exception is found in the criteria for diagnosis of anorexia nervosa as adopted by Dally (1969). The criteria given for secondary amenorrhea in anorexia nervosa are different from those criteria provided in studies of patients with secondary amenorrhea with regard to the duration of the absence of normal menstruation.

The criteria for secondary amenorrhea adopted in the present study are given in Table 5.4 .

Table 5.4. Criter la for Secondary Amemorrhea

A. Absemce of menstrual function for at least three cycles

B. No known organilc cause that would account for the absence of memstruel function*

* To axclude organlc causes of amenorrthe patlents were physically and gynaecologlcally examined. In addition levels of $T_{3}$ and $T_{4}$, LH, FSH, prolactin and 17-betamestradlol were aneasured. 


\subsubsection{Procedures}

Patients with secondary amenorrhea according to the criteria formulated in Table 5.4. were obtained from outpatient departments of gynaecology and obstetrics of four hospitals. The request to participate in the study was made by the gynaecologist. The patient was informed that if she agreed to take part in the study, she had to make an appointment with the researcher herself. All patients were informed by the investigator that the information obtained would be treated confidentially. Information could only be supplied to the gynaecologist at the patient's request. From the 4 outpatient departments of gynaecology and obstetrics, 89 secondary amenorrhea (AM) patients were abtained. Three (3) patients had elevated prolactine levels and were excluded from the study. Three (3) patients with secondary amenorrhea satisfied the criteria for anorexia nervosa as described in this study. Their data were omitted from the AM group. Seven (7) patients had a previous history of anorexia nervosa but did not satisfy the criterion of $25 \%$ weight loss at the first assessment. Their data were not excluded from the AM group. One had to be excluded because she was 43 years old. Eighty-two (82) patients who satisfied the criteria were selected for the comparison group of secondary amenorrhea patients (AM).

5.4.3. Criteria for selection of the asymptomatic female (AF) group

Anorexia nervosa occurs much more frequently in females than in males. The disorder predominantly affects young adolescents of upper social class and of a high educational and vocational level (Kendell et al., 1973; Crisp et al., 1976).

The development of instruments to measure anorectic and psychological features has been based upon subjects with the previously mentioned social and educational features. Therefore the instruments are of limited value and less applicability to subjects not sharing these social and educational characteristics such as young children or 
subjects of appropriate age, but who are less verbally educated. The lack of allternative less culture-related instruments determines the selection of a control group. Accordingly the control group was primarlly recrutted from a population of pupils and students attending secondary and tertiary schools. They were selected from seven educational institutes and were of different ages. Following the advice of the National Health Department, it was decided on logistical, ethical and practical grounds, that subjects under the age of 16 were only selected, when they were attending schools with guaranteed health control services.

For economical and practical reasons subjects were predominantly recruited from various educational institutions in the geographical surroundings of the University of Limburg in Maastricht.

Except for the implicit criterla such as educational level and age, which are related to the choice of measures, the only criterion for control subjects was that according to our criteria they could not be diagnosed as having anorexia nervosa or secondary amenorrhea at time of the investigation.

\subsubsection{Procedures}

A group of 316 asymptomatic females (AF) participated in the study. If the staff approved of the school's participation in the study, pupils were asked to participate and were informed about the aims of the study: to obtain data about eating behaviour, menstrual pattern and certain psychological characteristics of females between 11 and 40 years of age. Information about the methods to be used, was also supplited.

If subjects were under 18, their parents were also informed and asked to give permission. Subjects who did not want to participate or whose parents did not approve, were to return a reply form indicating that they objected to participation.

Subjects were assured that the fnformation would be treated as strictly confidential, and would only be supplied to the staff at the par- 
ticipant's explicit request.

From 7 schools of secondary and tertiary educational level and one factory, 316 female (AF) subjects were recruited. One (1) fullfilled the diagnostic criteria for anorexia nervosa, 5 other subjects met the criteria for secondary amenorrhea. In these cases of anorexia nervosa and secondary amenorrhea blood samples were taken to exclude organic illness. The anorectic and psychological data of these subjects were excluded from the comparison.

\subsection{Measures}

In the next sections a brief description of the instruments chosen to measure anorectic and psychological characteristics is presented. The endocrinological tests are also described.

\subsubsection{Measurement of the anorectic characteristics}

\subsubsection{Interview and examination}

Demographic and anorectic data were obtained using a semi-standardized interview. These data concerned age, educational/vocational level, menstrual cycle, eating behaviour, previous weight or history, present weight and height. AN and AM patients were physically examined by a medical doctor if such an examiniation had not taken place recently. Additionally, actual weight and height were also measured by the research-assistants (nurses). Before measuring the present body weight of the AN group, AN subjects were asked if they knew their actual weight and if they would like to know their body weight after measurement. It was emphasized that weight gain or loss was not significant if differences occurred between the body wight assessed at home and in the situation of the investigation as two different instruments for measuring weight were used. 
5.5.1.2. Mnorexia Nervosa Inventory for Self-Rating (ANIS)

The Anorexla Nervosa Inventory for Self-Rating was deweloped as a rellable and walid instrument for diagnostic and therapeutic purposes (Flchter and Keeser, 1980). Items for this instrument were adopted from clinical studies and experiences. Thirty-one (31) appropriate items, which were selected from a larger pool of items based on expert rating, were analyzed using factor analysis. Statistical analyses were based on self-ratings of a sample of anorexia nervosa patients and a control group comparable in sex and age. The factors identified were 1abelled:

1. Filgure consciousness (10 items)

2. Feelings of insufficiency (7 items)

3. Anacasm ( 5 items)

4. Adverse effect of meals (4 items)

5. Sexual anxieties ( 3 items)

6. But imila ( 2 items)

The factor 'Sexual anxiety' was operationally defined by three items. The operationalization of this aspect by items only referring to physical behaviours does not appear to be a valid measurement of human sexuality and has been omitted in this study.

5.5.2. Measurement of psychological characteristics

5.5.2.1. The Achievement Motivation Test

The Achievement Motivation Test (Hermans, 1967, 1968, 1969, 1970, $1980)$ was found to be a valid instrument to measure three psychological characteristics:

A. the Achlevement Motive

$B$. the Negative Fear of Faflure

c. the Positive Fear of Fallure

The Achievement Motivation Test consists of 89 items providing multiple choice items. The subscales Achievement Motive, the Negative 
Fear of Failure and the Positive Fear of Failure consist of 44, 26 and 19 items, respectively. Keys for scoring and standarized norms for interpretation of the scores were developed. These norms are based upon a representative sample of 2000 subjects in the Netherlands.

The construct 'Achievement Motive' refers not only to the need to excel in performance, but also to the need to perform well according to one's own standards. The Positive Fear of Failure refers to one aspect of the Achievement Motive - an approach motive or the motive to achieve. The second aspect, the motive to avoid fallure (an avoidance motive) has been conceptualized as the Negative Fear of Failure. (A1pert and Haber, 1960; Argyle and Robinson, 1962, 1971). The Positive Fear of Failure is viewed as a facilitating anxiety, especially in those situations which are relatively unstructured. The Negative Fear of Failure is considered as a debilitating anxiety especially in relatively unstructured situations.

\subsubsection{The Achievement Motivation Test for Children}

The Achievement Motivation Test for Children (Hermans, 1980) was developed to measure the following psycholagical characteristics of children of 10 through 16 years of age:

1. the Achievement Motive

2. the Negative Fear of Failure

3. the Positive Fear of Failure

4. the Approval Motive.

According to Crandall (1966), the Approval Motive does not primarily measure the tendency to seek positive approval for behaviours more competent than the norm, "but the person seems to attempt to avoid disapproval by moulding his behaviour to the norm and acceding to the demands of others" (p.477).

Norms for the test were derived from a representative sample of 3800 subjects aged 10-16 years. 
5.5.3. Measurement of LH, FSH and 17-beta-oestradiol

The different hospitals used different methods to measure LH, FSH and 17-beta-oestradiol.

In hospital 1 hormone levels of LH, FSH and 17-beta-oestradiol were determined by means of commercially available radio-immunoassay procedures. In case of LH and FSH, E.I.R. and Amersham kits were used. The intra- respectively inter-assay coefficient of variation, expressed in percentages, were in case of LH $5.4 \%(12.6 \%)$ and $12.2 \%$ $(13.4 \%)$ and FSH $9.4 \%(10.3 \%)$ and $10.5 \%(12.4 \%)$. In case of 17-betaoestradiol Amersham kits were used. The intra- respectively interassay coefficient of variation, expressed in percentages were in case of 17-beta-oestradiol $6.1 \%$ and $7.2 \%$.

In hospital 2 in case of LH and FSH Amersham kits, in case of 17-betaoestradiol E.I.R. kits were used. The intra- respectively interassay coefficient of variation expressed in percentages, were in case of LH $2.6 \%(3.1 \%)$ and $4.7 \%(5.6 \%)$ and FSH $0.9 \%(2.6 \%)$ and $1.8 \%(5.4 . \%)$. The intra- respectively inter-assay coefficient of variation, expressed in percentages were in case of 17-beta-oestradiol $5 \%$ and $10 \%$.

\subsection{Statistical analysis}

5.6.1. The Box-and-Whisker plot

The difference of anorectic and psychological characteristics between the groups was tested by the Box-and-Whisker plot (Tukey, 1977; Hartwig, 1979). The box-and-whisker plot is a graphical device to display differences between two or more groups. This univariate method was chosen as it adds vilsual representation to the numerical summary. Thus perception of the major characteristics of distributions may be great1y facilitated. The distribution of values is represented in a box. A horizontal line within the box represents the location of the median value in the distribution. The under and upper line of the box represent the first and third quartily respectively. Refinements have been 
used such as the presentation of 'outiliers'. Circies indicate values just outside the range and asterisks represent the values far out of range.

Further refinements are the notched intervals around the median and the adaptation of the width of the box to the sample size (McGill et a1., 1978). Differences are tested at approximately a 5\% leve1. The medians of the samples whose notched intervals do not overlap can be said to be significantiy different at approximately a $5 \%$ significance level. Instead of comparing the mean values of samples, the box-andwhisker method is based upon comparison of the median values.

\subsubsection{Discriminant function analysis}

For the purpose of an early identification of anorexia nervosa the question whether a differential diagnosis of true, mild or no anorexia nervosa can relliably be made on the basis of a set of anorectic and pychological variables is particularly relevant. To analyze the contribution of the several sets of variables to the distinction of these three categories, a multivariate method of discriminant analysis was used. This analysis takes into account the interrelations between the (psychological) variables. The primary goals of discriminant analysis are first to find the dimension or dimensions along which groups are maximally different and, secondly to predict group membership on the basis of those predictor variables used to create the dimensions. Thus the use of discriminant analysis is considered to be appropriate.

In this study a step-wise method of discriminant function analysis was chosen.

\subsubsection{Multiple regression analysis}

To assess the relationship between anorectic and psychological IIndependent) variables and the onset of anorexia mervosa (dependent variable) a multiple regression technique is used. Regression techniques 
permit the independent variables to be correlated. The regression solution takes the form of a general linear model

$$
y_{1}=A+B_{1} x_{1}+B_{2} X_{2}+\ldots \ldots \ldots B_{k} X_{k}
$$

where ${ }^{\prime} 1$ is the predicted value on the dependent variable, the $X ' s$ representing the $k^{k}$ independent variables, the $A$ is a constant representing, the $\gamma$ intercept (the value of $Y$ when all the $X$ values are zerol and the $B^{\prime} s$ are the weights assigned to each of the independent variables by the regression solution.

\subsection{Summary}

Since early identification of anorexia nervosa has been impeded by theoretical controversies about the discriminative and predictive validity of anorectic and psychological characteristics, the first step towards early diagnosis must be an empirical one. With this longterm purpose in mind, the present study was undertaken to examine the anorectic and psychological characteristics of patients with anorexia nervosa, patients with secondary amenorrhea and healthy controls. According to the continuum hypothesis, it can be assumed that only quantitative differences in the degree of the anorectic symptomatology can be found to discriminate between the groups. Second, it is expected that multiple and not single psychological characteristics predispose a person to the development of amorexia nervosa.

Alternative hypotheses, predicting that anorexia nervosa patients can be psychologically differentiated from other nonanorectic individuals in terms of the drive to achieve and the motive to avoid failure also need to be tested. According to the 'distinct entity' notion it may be expected that the presence of these psycholagical characteristics put individuals at risk of maintaining or aggravating their anorectic symptoms.

The choice of a methodological design was related to the purposes of research in this study. A transversal study method was chosen to 
examine anorectic and psychological characteristics of cases and controls. A longitudinal design was chosen to follow up the control subjects and to see if anorexia nervosa would develop and to which characteristics it was related.

The interval of time between the first and second assessment, for theoretical and logistical reasons, was 6 months and 12 months for the groups at risk and the healthy group respectively.

The arguments leading to the choice of research groups as well as the criteria that were used to select the subjects have been presented.

The instruments to measure the anorectic, psychological and endocrinological variables have been outlined and briefly discussed. Statistical procedures to analyse the data have been described. 
PART II. EMPIRICAL ASPECTS

Chapter 6. COMPARISON OF THE AN, AM AND AF GROUPS ON ANORECTIC AND PSYCHOLOGICAL CHARACTERISTICS

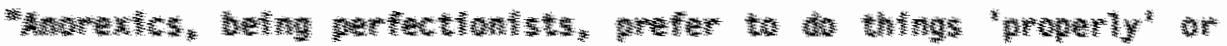

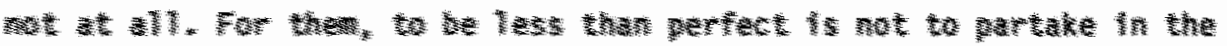

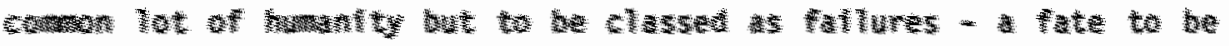

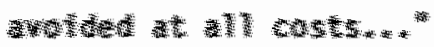

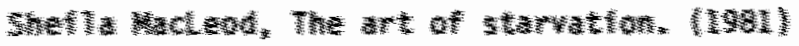


Chapter 6. COMPARISON OF THE AN, AM AND AF GROUP ON ANORECTIC AND PSYCHOLOGICAL CHARACTERISTICS

6.1. Introduction

In order to identify anorexia nervosa early it is crucial to know whether anorexia nervosa patients can be psychologically differentiated from other individuals. The results of the comparison of AN, AM and AF groups on anorectic and psychological characteristics are presented in this chapter.

\subsection{Theoretical considerations and hypotheses}

The notion that anorexia nervosa develops along the lines of a continuum has resulted in the formulation of the following theoretical proposition:

No differences may be expected to exist between AN patients, AM patients and AF subjects except for the degree of illness, as measured by the total weight loss.

The anorectic characteristics have been operationally defined in terms of weight in relation to height and the totalscore on the ANIS. The following hypotheses can be derived:

H. 1. The median ANIS score of the AN group is higher than the median ANIS score of the AM and AF group.

H. 2. The median ANIS score of the AM group is higher than the median ANIS score of the AF group.

H. 3. The median body weight in relation to height of the AN group is lower than the median body weight of the AM and AF group.

H. 4. The median body weight in relation to height of the AM group is lower than the median body weight of the AF group. 
The notion of anorexia nervosa as a distinct disease entity has resulted in the formulation of the following theoretical proposition:

A1 though there may be various stages of anorexia nervasa, anorexia nervosa can be differentiated from the more common preoccupation with weight and dieting in terms of the underlying psychological characteristics: the drive to achieve to fend off their general fear of fallure and ineffectiveness.

The psychological characteristics are operationally defined by the subscales Achievement Motive, Negative Fear of Failure and Positive Fear of Failure of the Achievement Motivation Test. Accordingly, it is expected that AN patients are characterized by a high Drive to Achieve and a high Negative Fear of Failure. In this respect the following hypotheses have been formulated:

H. 5. The median Drive to Achieve score of the AN group will be higher than the median Drive to Achieve score of the AM and AF group.

H. 6. The median Negative Fear of Failure score of the AN group will be higher than the median Negative Fear of Failure score of the AM and AF group.

H. 7. The median Positive Fear of Failure score of the AN group will be lower than the median Positive Fear of Failure score of the AM and AF group.

\subsection{Results}

Since two versions of the Achievement Motivation Test were used, the groups had to be separated into groups of subjects younger than 16 years of age and of subjects of 16 and older. Two (2) of the eightysix (86) AN patients and seventy-nine (79) of the 316 AF subjects were younger than 16 years of age. The AM subjects were all older than 16 years. The results of subjects younger than 16 will be presented in Chapter 7. 
6.3.1. Description of the AN, AM and AF groups

Tables 6.1. to 6.3. provide the descriptive data of the $A N, A M$ and $A F$ groups:

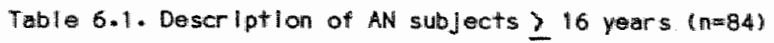

\begin{tabular}{|c|c|c|c|}
\hline Varlables & $\bar{x}$ & $\mathrm{SD}$ & $\mathrm{MD}$ \\
\hline Age & $24 \cdot 7$ & $4 \cdot 9$ & 23.0 \\
\hline Hellght & 165.7 & 6.4 & 166.0 \\
\hline Body welight & 48.9 & 9.5 & 49.0 \\
\hline ANIS & 143.0 & 30.8 & 11.2 .5 \\
\hline Drlive to Achlieve & 22.2 & 6.8 & 22.0 \\
\hline Negative Foar of Fallure & 17.9 & 5.7 & 19.0 \\
\hline Positive Foar of Fallure & 6.0 & 4.9 & 4.0 \\
\hline
\end{tabular}

Table 6.2. Descriptlion of AM subjects? 16 years $(n=B 2)$

\begin{tabular}{lrrr}
\hline & - & & \\
Warlables & $x$ & 50 & $M 0$ \\
& & & \\
\hline & 24.3 & 5.5 & 23.0 \\
Age & 165.6 & 7.0 & 166.0 \\
Hellght & 58.2 & 11.1 & 55.3 \\
Body Weight & 118.3 & 24.2 & 116.5 \\
Allis & 19.6 & 6.1 & 20.0 \\
DrIve to Achleve & 14.9 & 2.7 & 14.0 \\
Negative Fear of Fallure & 7.5 & 2.8 & 7.0 \\
Positive Fiar of Fellure & & & \\
\hline
\end{tabular}

$\bar{X}=$ Mean $\quad S D=$ Staindard dewlation $\quad M D=$ Medllan

Table 6.3. Doscrlption of Af subjects $\geq 16$ years $(n=237)$

\begin{tabular}{lrrr}
\hline & $x$ & 50 & $M 0$ \\
Varlables & & & \\
\hline & 19.4 & 2.9 & 19.0 \\
Age & 167.6 & 6.3 & 168.0 \\
Height & 59.3 & 7.9 & 59.7 \\
Body Welght & 97.3 & 17.6 & 95.0 \\
ANIS & 16.4 & 6.6 & 16.0 \\
Dr Iwe to Achleve & 14.3 & 5.5 & 15.0 \\
Negative Fear of Fallure & 7.9 & 4.6 & 7.0 \\
Positlive Fear of Fallure & & & \\
\hline
\end{tabular}


The mean age of the AF group was lower than the mean age of the All and AM group. This difference is related to the selection procedures of AF subjects described in Chapter 5.4.3. The dispersion of age in the Af group was smaller than in the two other groups. This dispersion is a consequence of the restriction of range, which results from the restriction of subject selection procedures to secondary and tertiairy educational institutions.

\subsubsection{Endocrinological characteristics of the AN and AM groups}

Table 6.4. provides the distribution of 82 AM patients (see section 5.4.2.1.), satisfying the criteria for secondary amenorrhea over the four* hospitals which participated in the study.

Tabla 6.4. Dlstributton of AM subjects ower hosp ltals $(n=82)$

\begin{tabular}{lc} 
Hospitals & Number of patients \\
\hline & 33 \\
$2^{*}$ & 44 \\
3 & 5 \\
\hline
\end{tabular}

* The departments of obstetrlcs and gyriacolagy of two hospltels are associlated

The endocrinological data of the subjects of hospitals 1 and 2 were separately analyzed due to the use of different methods of measuring levels of LH, FSH and 17-beta-oestradiol. Three (3) of the thirtythree (33) AM patients of hospital 1 were excluded due to missing data on one of the variables.

The remaining thirty (30) AM patients were compared to twenty-seven (27) AN patients, attending the same hospital (hospital 1 ).

Forty-four (44) AM subjects attended hospital 2. Fcur (4) of these patients had a spontaneous resumption of cycles prior to the time of the investigation. Their cycles were not regular, but they had been 
excluded for analysis. Two (2) AM patients used oral contraceptives and were excluded. Four (4) cases had missing data on one of the variables and were al so excluded. Of the remaining thirty-four (34) AM patients, seven (7) have had a previous history of anorexia nervosa and weighed less than $80 \%$ of standard body weight at the moment of investigation. These 7 'previous anorexia nervosa' cases were compared to the twenty-seven (27) secondary amenorrhea cases of the same hospital (hospital 2).

Tables 6.5. and 6.6. provide the data of LH, FSH and 17-beta-oestradiol of the AM and AN group of hospitals 1 and 2 .

Table 6.5. Endocrinologicol characterlstics of AN and AM subjects attendling haspltal I

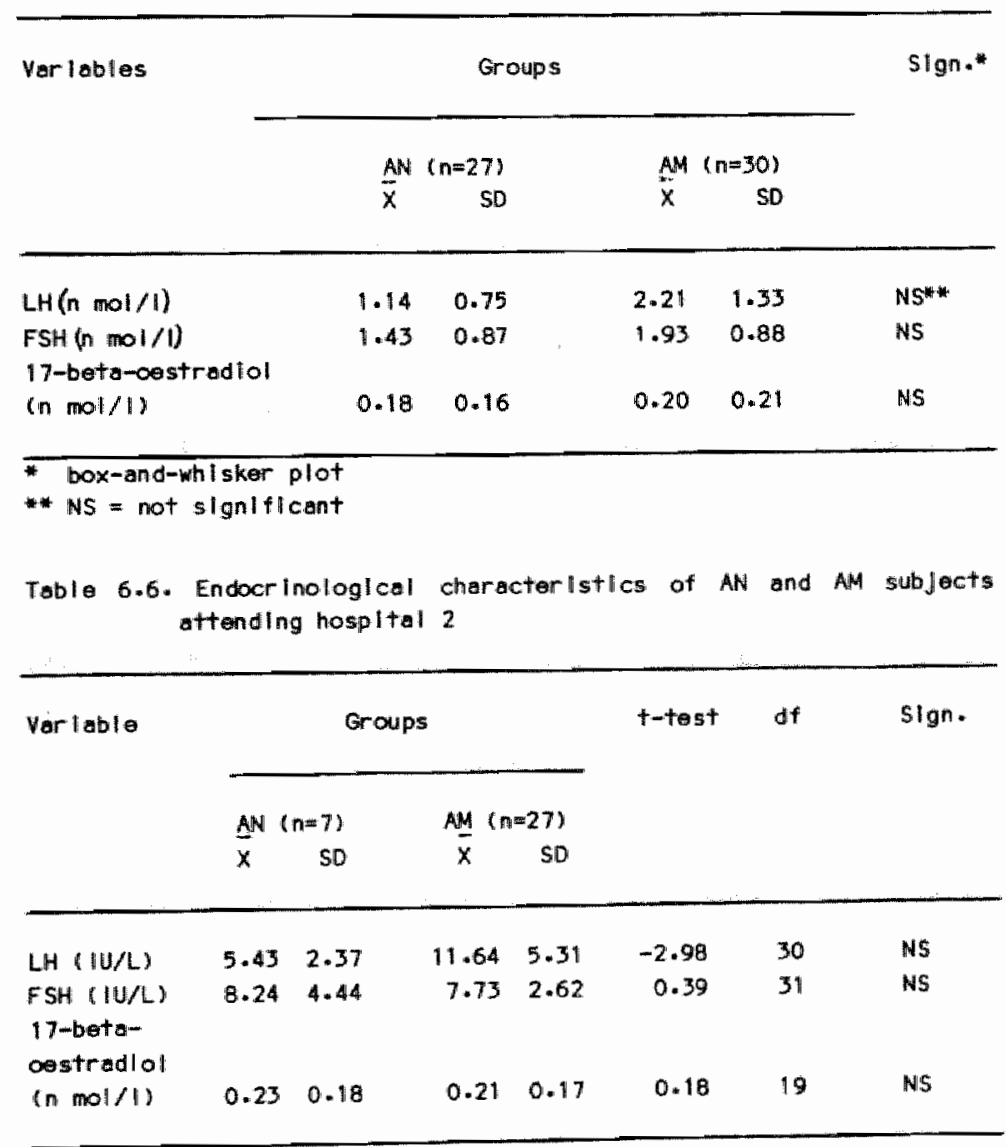


Levels of LH were decreased in AN patients compared to AM patients in both hospltals 1 and 2 " however the differences in levels of LH, FSH and oestradiol were not significant and reflect a normal variation of values. These findings confirm previous results (Kock et al., 1982) and agree with the findings of hospltal 1. No significant differences in LH, FSH and oestradiol were found between the AN and AM group. The endocrinological data of hospital 3 have been published elsewhere (Coelingh Bennink et a1., 1981; Bosch van Drakestein et al., 1981).

\subsection{Comparison of the AN, AM and AF groups}

In order to test the hypotheses with regard to anorectic and psychological differences between the groups, the box-and-whisker plot developed by Tukey (1977) was used.

6.4.1. Anorectic characteristics

The hypotheses with regard to the anorectic characteristics as measured by the ANIS; weight in relation to height have been previously formulated:

H. 1. The median ANIS score of the AN group is higher than the median ANIS score of the AM and AF group.

H. 2. The median ANIS score of the All group is higher than the median ANIS score of the AF group.

H. 3. The median body weight in relation to height of the AN group is lower than the median body weight of the AM and AF group.

H. 4. The median body weight in relation to height of the AM group is lower than the median body weight of the AF group.

Figures 6.1.a.-6.1.c. represent the comparisons between the groups on anorectic characteristics. 


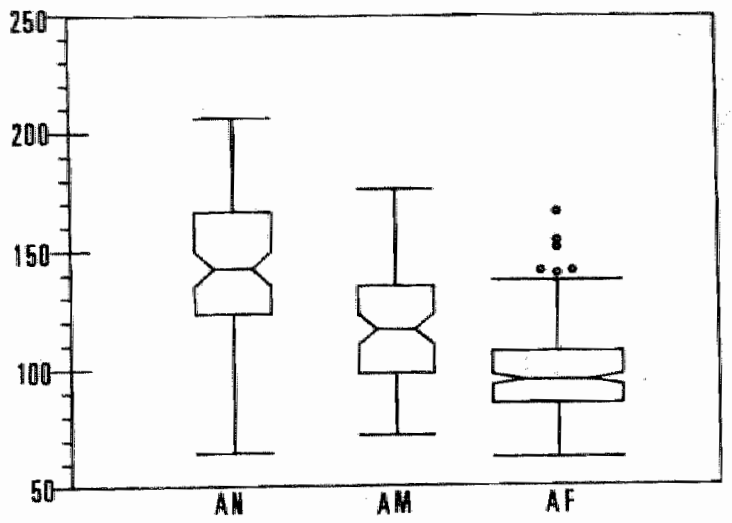

Fig. 6.1.a. ANIS scores

Comparison of the median ANIS scores of the AN, AM and AF group shows that the AN group had the most elevated score. The differences with the AM as well as the AF group were statistically significant. This result confirms hypothesis 1 .

The median ANIS score of the AM group was signficantly higher than the median ANIS score of the AF group, while significantly lower when compared to the AN group. These findings give support to hypothesis 2 .

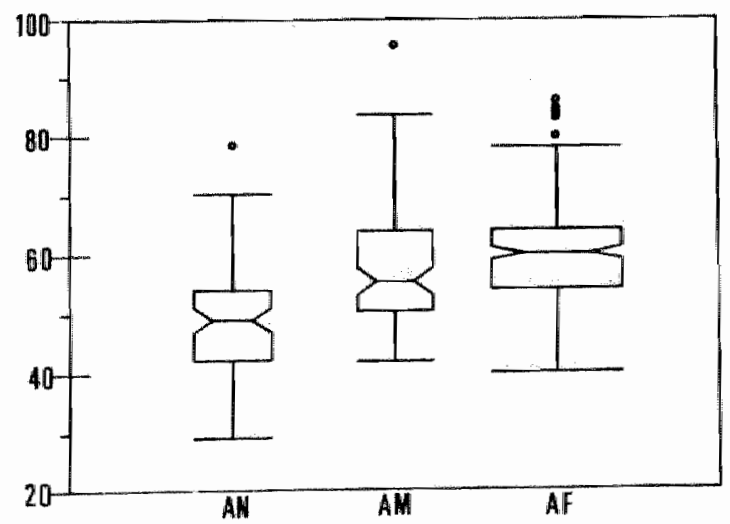

Fig. 6.1.b. Weight 


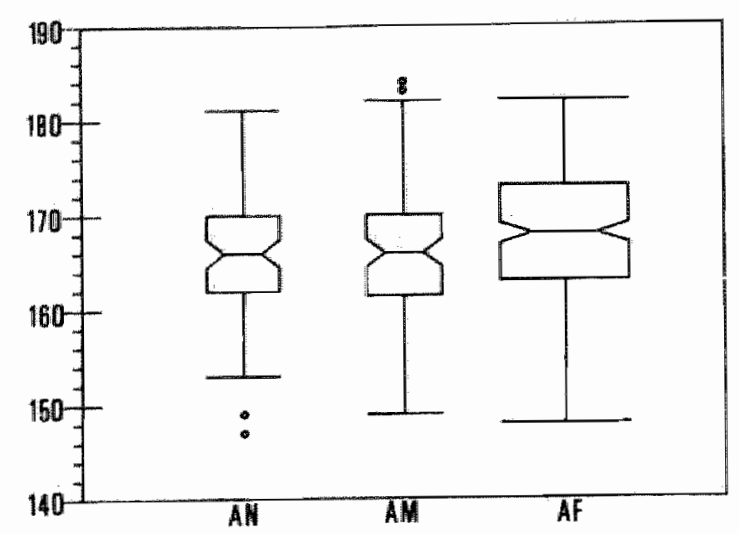

Fig. 6.1.C. Helght

Figures 6.1.b. and 6.1.c. provide the results of the comparison of the weight and height of the three groups. As expected, the AN group weighed significantly less than the AM and AF group. The body weight. difference between the AM and AF group was also statistically significant. The median heights of the three groups, however, did not differ significantly. These results provide evidence for hypotheses 3 and 4 . Moreover, Figures 6.1.a.-6.1.c. show an in-between position of the AM group when compared to the AN and the AF group. The results of this comparison of the three groups extend the previous findings in Fries" (1974, 1977) and other studies on the occurrence of anorectic behaviour in patients who satilsfied the criteria of secondary amenorrhea and self-imposed weight loss (Weeda-Mannak et a1., 1980). Since AM subjects sere sected on the criterion secondary amenorrhea only. The finding that the AM group, however, can be distinguished from the AF group by a lower body weight and an elevated ANIS score is compatible with the "continuum" hypothesis.

\subsubsection{Psychological characteristics}

The hypotheses formulated with respect to psychological differences were: 
4. 5. The median Drive to Achieve score of the AN group will be higher than the median Drive to Achieve score of the AM and AF group.

H. 6. The median Negative Fear of Failure score of the AN group will be higher than the median Negative Fear of Failure score of the AM and AF group.

H. 7. The median Positive Fear of Faillure score of the AN group wi11 be lower than the median Positive Fear of Failure score of the AM and AF group.

Figures 6.2.a.-6.2.c. provide the results of a comparison of the AN, AM and AF group with respect to their psychological characteristics.

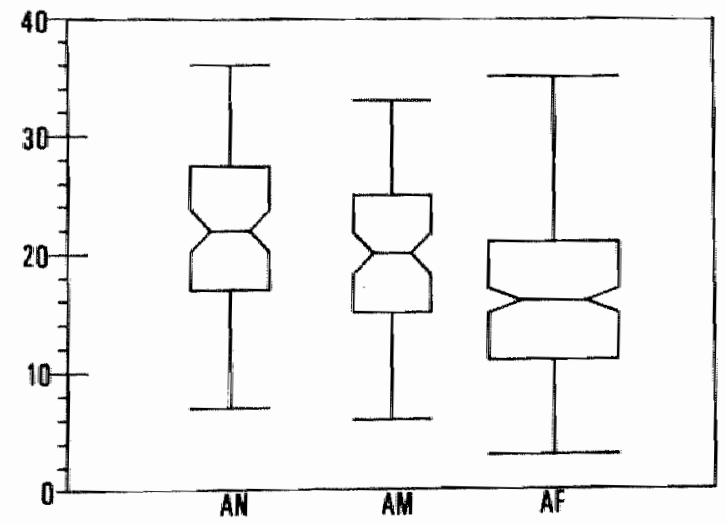

Fig. 6.2.a. The Drive to Achieve

The highest median scores on the Drive to Achieve was found in the AN group and the lowest in the AF group.

Differences with regard to the median score on the Drive to Achieve were significant between the AN group and the AF group, as well as between the AM and the AF group. Between the AN group and AM group there was no statistically significant difference in scores on the Drive to Achieve. Hypothesis 5 is partially confimed: the AN group does not differ from the AM group but differs significantiy from the AF group with respect to the Drive to Achieve. 


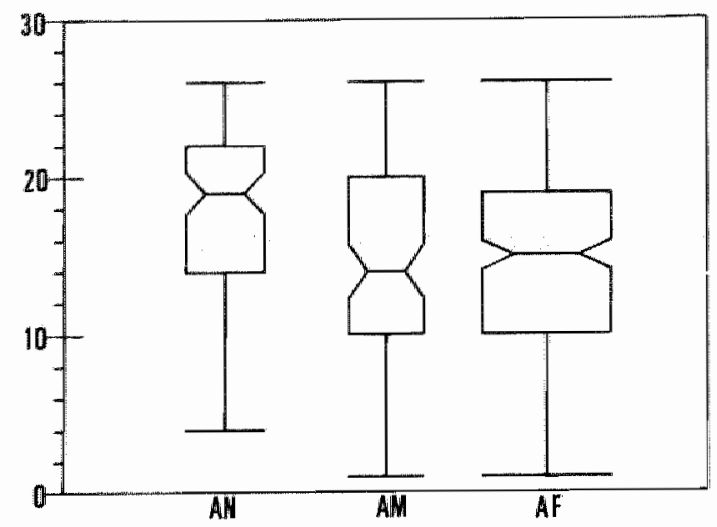

Fig. 6.2.b. The Negative Fear of Failure

The median scores of the AN group on the Negative Fear of Failure were significantly higher than the median scores of the AM and AF groups. There was no significant difference in this respect between the AM and AF group. These findings provide substantial evidence to support hypothesis 6 .

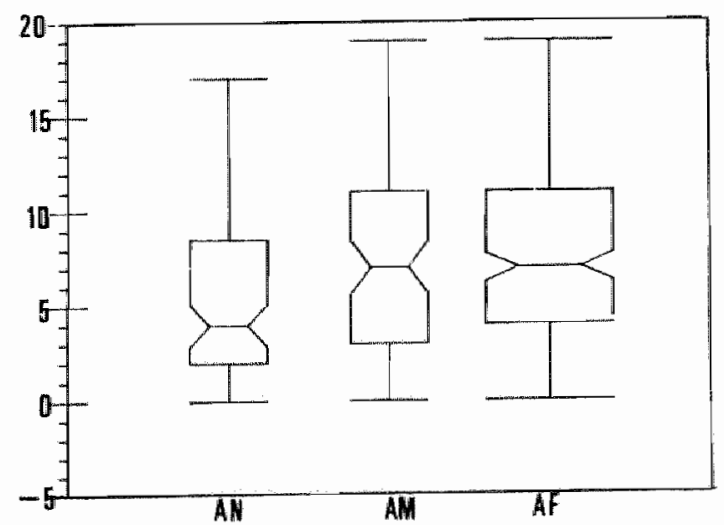

Fig. 6.2.c. The Positive Fear of Failure

In addition no significant difference was found between these two groups (AM and AF) with respect to the Positive Fear of Failure as the median value is the same for both groups. The AN group, however, has a lower median Positive Fear of Failure score, which differs signifi- 
cantly from the AM and AF group. Thus hypothesis 7 is confinned by these findings.

With respect to the psychological characteristics, the AM group also appears to have a position between the AN and AF groups with respect to the Drive to Achieve. However, with regard to both the Negative and Positive Fear of Failure the AM group tends to be similar to the AF group and different from the AN group.

When the mean scores of the groups (Tables 6.1.-6.3.) are compared to norms derived from a representative sample of the Dutch population (Hermans, 1967), the mean scores of the AN, AM and AF group on the Drive to Achieve are in the 8 th, 7 th and 5 th decile respectively. The mean scores of the $A N, A M$ and $A F$ group on the Negative Fear of Fallure are in the 9 th, 7 th and 7 th decile respectively. When compared to the AM and AF group as well as to a representative sample of the Dutch population, the AN patients can be psychologically differentiated with regard to the Drive to Achieve and the Negative Fear of Fallure. The mean scores on the Positive Fear of Fallure of the AN and those of AM and AF subjects can be placed in the 2 nd and 4 th decile respectively. The findings of the comparison on psychological characteristics are concordant with the notion that anorexia nervosa is a distinct disease entity.

If the findings of this transversal study on anorectic and psychological characteristics of $A N, A M$ and $A F$ subjects are summarized, one may state that:

1. Significant differences exist with respect to body welight and anorectic behaviour;

2. the AM group takes a position between the AN group and the AF group;

3. this in-between position of the AM group can also be found with regard to the Drive to Achieve;

4. the markedly different position of the AN group on the Negative Fear of Failure scale suggests that this Drive to Achieve is predominantiy related to the motive to avoid fallure. A high Orive to Achieve as well as a high Negative Fear of Fallure could not be found for the other two groups. 
Hence, one may conclude that the AN group can be differentiated psychologically from other subjects, including those with mild symptomatology, particularly in the motivating force of their drive to achieve.

\subsection{Discriminant function analysis}

The analysis was carried out with a BMDP7M computer program (Dixon et a1., 1981).

The variables which entered into the analysis were the following anorectic and psychological characteristics: weight, menstrual cycle, ANIS, Drive to Achieve, Positive Fear of Failure and Negative Fear of Fallure.

The same groups, anorexia nervosa patients (AN), secondary amenorrhea patients (AM) and asymptomatic female subjects (AF), were used for this analysis.

of the original 403 cases ( $\geq 16$ years), 9 were dropped from analysis owing to misising data. Missing data were randomly scattered over cases and variables with no patterning on the basis of grouping or anorectic and psychological variables. There were no outliers.

The intention of this study was to know how wll group membership can be predicted in terms of anorectic (weight, ANIS), menstrual and psychological measures. For this classification purpose, heterogeneity of variances and covariances can play an unintended role. Inspection of the scatterplots of scores on the first two canonical discriminant functions for each separate group, however, revealed that they were roughly equal in size. Thus, it may be concluded that there is some evidence for homogeneity of variance-covariance matrices.

Although the discriminant analysis itself is not influenced by groups of unequal size, the interpretation of the classification tables becomes difficult when samples are unequal. To overcome this problem it has been advised (e.g. Morrison, 1969, p.161) to split up randomly the largest group to a size about as large as the smallest group. Accordingly this resulted in three AF subgroups. A discriminant analysis has 
been carried out for each of these subgroups together with the total AN- and AM-groups. In this way three classification tables were constructed, indicating how well the classification had been done on the average.

The three statistical analyses performed - one for each AF subgroup plus the AN and AM groups - revealed that there was statistically significant discrimination among the $A N, A M$ and $A F$ groups on the basis of the 3 psychological variables alone, $F(6,478)=8.301, p<.001 ; F$ $(6,478)=7,635, p<.001$ and $F(6,476)=6.378, p<.001$.

Averaged over all three analyses at this point (jackknife classification), $48.8 \%$ of the subjects were correctly classified.

After adding the anorectic and menstrual variables, 3 discriminant function analyses were again performed which resulted in $F(12,444)=$ $28.383, p<.001 ; F(12,444)=27.360, p<.001$ and $F(12,442)=30.523, p<.001$; indicating again highly significant discriminating power.

With all six (6) predictor variables, averaged over all three analyses, $72.9 \%$ of the subjects were correctly classified.

The prior probability of group membership based on sample sizes was about 33\% (Note: the AF sample was subdivided into three almost equal parts). Averaged over the three discriminant function analyses the mean percentage correct classification in the respective groups, based on the three psychological variables, were $62 \%$ for the AN group, $24 \%$ for the AM group and $61 \%$ for the AF group.

The corresponding percentages based on the psychological and anorectic variables were $77 \%$ for the AN group, $55 \%$ for the AM group and $86 \%$ for the AF group.

Thus we may conclude that taking into account the psychological variables plus the anorectic variables leads to a far better classification than on the basis of psychological variables only.

on the basis of all six (6) predictors two discriminant functions were calculated. The two discriminant functions accounted for $89 \%$ and $11 \%$, respectively, of the between graup variability in discriminating among groups. These percentages are mean percentages averaged over the three analyses performed for each of the three AF-subgroups.

In Figures 6.3.a-c are the centroids for the three groups plotted on 
the two discriminant functions. There is a plot presented for each AF subgroup analysis.
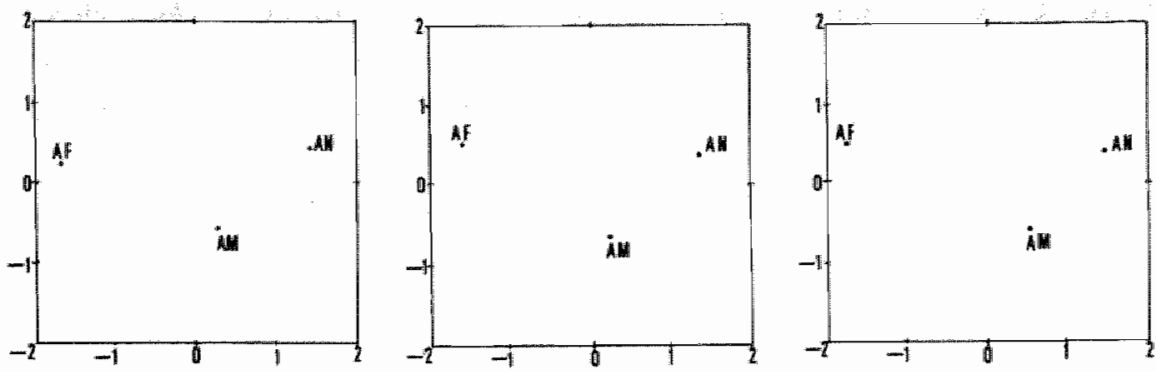

Fig. 6.3.a-c. Plots of 3 group centroids on 2 discriminant functions derived from anorectic, menstrual and psychological variables.

As shown in Figures 6.3.a-c the first discriminant function maximally differentiates the AF-group from the AN group, with AM patients situated between these two groups. The position of the AM group, however, is closer to that of the AN group than of the AF group. The second discriminant function discriminates the AM group from the other two groups.

The plots presented in Figure 6.3.a-c are based on the canonical discriminant functions evaluated at the group means. The coefficients used to compute the position of the data cases in the discriminant space are presented in Table 6.7. Because the three plots were almost identical only the coefficients of one discriminant function analysis is presented that is the analysis which resulted in Figure 6.3.a. 
Table 6.7. Unstandardized disicr im Inant coefleients

\begin{tabular}{|c|c|c|}
\hline \multirow[b]{2}{*}{ Var $1 a b l e$} & \multicolumn{2}{|c|}{ Unstendard zed coofllelents } \\
\hline & Function 1 . & Function 2 . \\
\hline constant & 0.605 & 0.308 \\
\hline Weight & -0.031 & -0.077 \\
\hline Menstrual cycle & -1.022 & 1.1115 \\
\hline ANIS & 0.026 & 0.015 \\
\hline Drlve to Achleve score & 0.029 & 0.0110 \\
\hline Pasitive Fear of Fallure & -0.029 & -0.005 \\
\hline Megat Ive Fear of Fallure & -0.025 & 0.010 \\
\hline
\end{tabular}

When the focus of attention is shifted from individual cases and group centroids to discovering the contributions of the individual variables, it is necessary to go beyond the unstandardized coefficients. The unstandardized coefficients provide information about the absolute contribution of a variable in determining the discriminant score. This information may, however, be misleading when the meaning of one unit change in the value of a variable is not the same from one variable to another. To understand the relative contribution of the variable, it is necessary to $700 \mathrm{k}$ at the standardized coefficients. These standardized coefficients are presented in Table 6.8.

Table 6.8. Standardlzed discriminant coefflclents

Standerdized coefilclents

War lable

Function 1 .

Funetion 2 .

\begin{tabular}{lrr}
\hline & -0.297 & -0.735 \\
Melighit & -0.639 & 0.697 \\
ANil S & 0.634 & 0.356 \\
Dr twe to Achleve & 0.195 & 0.067 \\
Pos. Fear of Fallure & -0.144 & -0.027 \\
Neg. Fear of Follure & -0.148 & 0.058 \\
\hline
\end{tabular}


Inspection of Table 6.8 . shows that the variables menstrual cycle and ANIS contribute most to determining scores on the first and most important discriminant function. Taking into account that the variables menstrual cycle and ANIS have opposite signs, the role of the variables body weight and psychological characteristics becomes more Important in determining the first discriminant function (accounts for 89\%). The second discriminant function is dominated by the variables weight and menstrual cycle.

Thus we may conclude that menstrual cycle is an important factor in discriminating between the $A N, A M$ and $A F$ groups and second that the psychological variables also contribute to the classification of groups.

\subsection{Discussion}

In view of the hypotheses which have been tested it seems evident that anorexia nervosa is a multidetermined disorder, characterized by anorectic and menstrual as well as psychological features. The disorder may present itself in varying degrees of severity of anorectic behaviour and related weight loss and hence will develop along the lines of a continuum (Garner et al., 1983). This may also be illustrated in this study, where the AM group has an in-between position with respect to the aspects of body weight and anorectic characteristics as measured with the ANIS. Furthermore the dispersion of body weights combined with elevated ANIS scores in the AM group suggests a heterogenelty of dietary behaviour. The results of this study indicate that preoccupation with weight and dieting may occur unrelated to the psychological characteristics of anorexia nervosa. At the same time the findings of this study provide evidence that anorexia nervasa patients can be psychologically differentiated from other individuals, including subjects sharing anorectic and menstrual weight 10ss. The crucial feature that enables us to discriminate between anorexia nervosa and extreme preoccupation with weight and dieting is the Negative Fear of Failure, indicating that the motivating force of the 
need to achieve and performance behaviour is significantly different. The finding that the Negative Fear of Failure is typical for the AN group confirms the clinical descriptions of anorexia nervosa patients that their perfectionism and their excelling in performance can be interpreted as compensations for their general fear of failure. Thus way conclude that anorexia nervosa is a distinct disease entity with important psychological differences underlying preoccupation with weight and dieting.

Since increased preoccupation with weight and dieting was found in the AM group, attention to nutritional factors and eating behaviour may lead to an early recognition of dietary disorders.

For an early identification of anorexia nervosa, however, neither psychological characteristics nor anorectic characteristics independently are sufficient to discriminate between $A N$, AM and AF subjects. In order to identify anorexia nervosa early in its course anorectic and menstrual as well as psychological characteristics have to be evaluated.

\subsection{Summary}

The purpose of this study was to provide empirical evidence that psychological differences exist between anorexia nervosa patients, patients with secondary amenorrhea and heal thy control subjects. For this purpose, hypotheses refering to anorexia nervosa as a distinct disease entity or an extreme point on a continuum were tested in a case-control design.

84 AN patients, 82 AM patients and 237 AF subjects older than 16 years of age were compared with respect to their anorectic and psychological characteristics. These data were analyzed with the box-and-whisker plot. A step-wise discriminant function analysis on anorectic, menstrual and psychological variables was performed. Results of these statistical analyses reveal that:

- significant differences exist in respect to anorectic characteristics between the AN, AM and AF subjects 
- with regard to these anorectic aspects, the AM group appears to have an in-between position

- the AN group has the most elevated score of the groups on the Drive to Achieve, although this score is not significantly different from the score of the AM group

- the AN group has the most elevated score on the Negative Fear of Fallure, significantly different from the scores on this scale of the AM and AF groups

- the AN group has the lowest score on the Positive Fear of Failure, and also significantly differs in this respect from the AM and $\mathrm{AF}$ groups

- AN, AM and AF subjects can be classified correctly in 73\% of the cases on the basis of both anorectic, menstrual and psychological characteristics

AN patients and AM patients could not be differentiated with respect to the endocrinological characteristics.

The results of this study provide substantial evidence that anorexia nervosa patients can be psychologically differentiated from other subjects, including individuals who can be characterized by an increased focus on dieting and weight.

Moreover, it has been found that an extreme preoccupation with weight and dieting may occur unrelated to the psychological characteristics of anorexia nervosa. It may be concluded that to identify anorexia nervosa early attention must be pald to early anorectic and menstrual as well as psychological characteristics. 
Chapter 7. SOME FURTHER EVIDENCE FOR THE DISCRIMINATIVE VALUE OF THE FEAR OF FAILURE. COMPARISON WITH BALLET DANCERS

"Ze leren vroeg, die kleine danseresjes. Ze worden snel volwassen, ze moeten wel, want hun carrière begint midden in hun jeugd, wanneer de rest van de wereld nog spelletjes speelt en leert hoe te leven".

Toni Bentley, Winterseizoen. Dagboek van een danseres. (1983) 
Chapter 7. SOME FURTHER EVIDENCE FOR THE DISCRIMINATIVE VALUE OF THE FEAR OF FAILURE. COMPARISON WITH BALLET DANCERS

7.1. Introduction

There is a growing awareness that young females committed to highly competitive sports or participating in strenuous activities such as professional ballet dancing have a high incidence of menstrual irregularity and amenorrhea (Feicht et al., 1978; Malina et al., 1978; Fishman, 1980; Frisch et al., 1980; Speroff et al., 1982; Keizer, 1983). The pressure to reduce fatness to maximize strength and endurance as well as the strong positive aesthetic connotation of thinness may lead to extreme voluntary weight reduction associated with a fear of fatness, anorectic behaviour and amenorrhea. The weight loss and anorectic symptomatology may be so severe as to satisfy the major diagnostic criteria for anorexia nerrosa (Garner and Garfinke1, 1980; Smith, 1980; Yates et al., 1983). It has also been noted that ballet dancers also share social and psychological characteristics with anorexia nervosa patients such as similar upper or middle class social background, self-discipline and the drive to achieve. This drive to achieve has been observed in a comparative study of young female ballerinas and anorexia nervosa patients (Druss and Silverman, 1979) as a 'strong desire to excel in every aspect of live, including academics and sports'. However, it has been postulated in this study that the intense drive to achieve in ballet dancers appears to be toward some inner goal, rather than to gain approval from others: "Their continuous hard work was to achieve something within themselves, not applause, fame and stardom' (p.118). This finding suggests that ballet dancers, in addition to other anorectic, social and psychological characteristics, also share with anorexia nervosa patients the drive to achieve but can be psychologically differentiated from anorexia nervosa patients with respect to the underlying positive fear of fallure. To test the hypothesis that the drive to achieve to avoid 
fallure is characteristic of anorexia nerwosa, a comparative study of the anorectic and psychological characteristics of female ballet students was carrfied out.

Accordingly, the following hypotheses were tested:

H. 1. The median Drive to Achieve score of anorexia nervosa (AN) patients will not differ from the median Drive to Achieve score of female ballet dancers (BA).

H. 2. The median Negative Fear of Failure score of the BA group is lower than the median Negative Fear of Failure score of the AN group.

H. 3. The median Positive Fear of Failure score of the BA group is higher than the median Positive Fear of Failure score of the AN group.

The hypotheses with regard to psychological differences were tested in a group of anorexila nervosa patients (AN) and female ballet students $(B A)$.

\subsection{Methods}

7.2.1. Subjects

Ballet students of two national schools for professional dancing participated in the study. This group consisted of four categories of $B A$ students attending the following educational programs:

1. the preparation of aspirant-students for the professtonal program

2. dance-expression

3. the teaching of ballet

4. the preparation of dancers for membership in professional dance compantes

A total of $194 \mathrm{BA}$ students volunteered to take part in the study. Seventeen (17) male ballet dancers also participated, but for the 
purpose of this study, the data collected from male subjects were not inciuded in the comparison. One student satisfied the criteria for anorexia nervosa and one for bul imia nervosa. The data of these were two excluded. Of the remaining 175 BA students, 70 were younger than 16 years of age. The results of subjects younger than 16 will be presented separately in the sections 7.6. and 7.7.

\subsubsection{Procedures}

Two national schools of professional ballet dancing were approached with the request to take part in a comparative study of AN patients, AM patients and AF subjects. Information was provided about the data to be collected as well as the methods to be used. The staff of both schools were familiar with the syndrome of anorexia nervosa and considered the possibility of having some doubtful cases at school. As the staff approved participation in the study, a circular letter was sent to the parents of $B A$ students younger than 16 years of age. If the parents did not approve, they were to return a reply form.

\subsubsection{Measures}

Actual body weight and height of BA students were measured. The ANIS and Achievement Motivation Test were administered and all subjects were interviewed. These measures have been previously outlined in Chapter 5.

All subjects filled in their questionnaires in small groups of a maximum of five students. A menber of the research team was present at the time of the assessment procedure, while teachers were absent. 
7.3. Results

7.3.1. Description of the BA group of 16 years and older

Table 7.1. provides the descriptive data of the BA group.

Toble 7.1. Description of the BA sibjects $\geq 16$ years $(n=105)$

\begin{tabular}{lrrr}
\hline Warlables & $\bar{x}$ & SD & MD \\
\hline & & & \\
\hline Age & 19.4 & 2.7 & 19.0 \\
Height & 168.0 & 6.5 & 169.0 \\
Body Welght & 55.9 & 5.6 & 56.0 \\
Allis & 106.0 & 19.7 & 104.0 \\
Drive to Achleve & 21.0 & 6.9 & 21.0 \\
Negative Fear of Fallure & 13.0 & 5.3 & 12.0 \\
Positive Fear of Fallure & 11.0 & 2.8 & 12.0 \\
\hline
\end{tabular}

$\bar{X}=$ Mean $\quad$ SD $=$ Standard devlation $\quad$ MD $=$ Medlan

The mean age of the BA group was 19.4 years. The mean age of the AN group was 24.7 years (see Table 6.1.). The difference in age is related to the procedure for selecting educational institutions. The mean height of the BA group is 168.0 , while the mean height of the AN group is 165.7. The AN group has a lower body weight (48.9) than the BA group (55.9).

7.4. Comparison of the AN and BA group of 16 years and older

7.4.1. Psychological characteristics

To test the hypotheses, the AN and BA group were compared in respect to their psychological characteristics. For this purpose the box-andwhisker plot (Tukey, 1977; McGill et al., 1978) was used. Figures 7.1.a.-7.1.c. provide the results of the comparison of the Drive to Achieve, the Negative Fear of Failure and the Positive Fear of Fail- 
ure, respectively. To consider the findings in view of the findings of the control subjects, the data of the AF group were included in the box-and-whisker plots.

The median Drive to Achieve score of the AN group was not significantly different from the Drive to Achieve score of the $B A$ group. Thus, the hypothesis that AN patients will not differ from $B A$ students with respect to the Drive to Achieve is confirmed.

When the mean scores on the Drive to Achieve of the BA and AN group are compared to the standardized norms of the Dutch population, the mean scores of both groups are situated in the 8 th decile. Hence, the $\mathrm{BA}$ and AN group scores are higher than the scores of a representative sample of the Dutch population with respect to the Drive to Achieve. Their Drive to Achieve scores are also significantly higher than the score of the AF group.

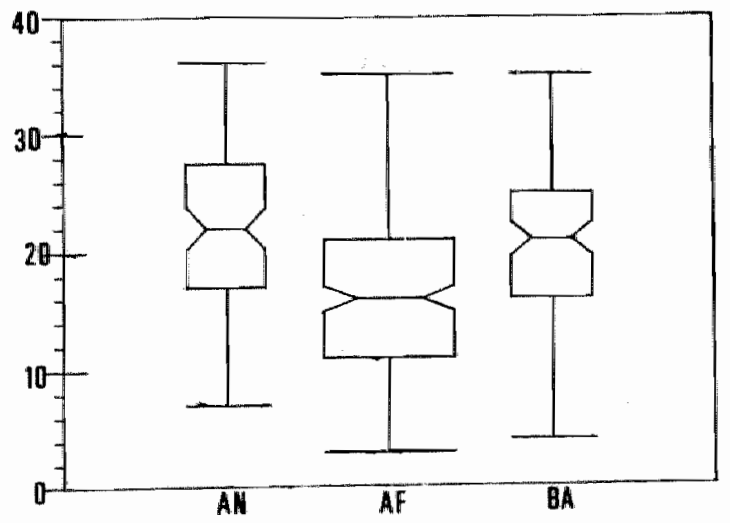

Fig. 7.1.a. The Drive to Achieve

As $c$ an be seen from Figure 7.1.b. the median score of the Negative Fear of Failure was significantly higher in the AN than in the BA group. The results confirm the second hypothesis on differences between the $A N$ and $B A$ group with respect to the Negative Fear of Failure. 


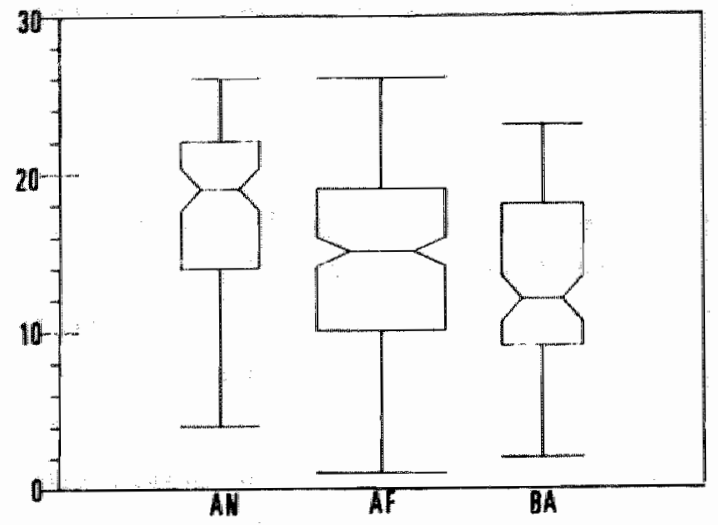

Fig. 7.1.b. The Negative Fear of Failure

The mean score of the Negative Fear of Failure of the BA group is in the 6 th decile, while the score of the AN group is found in the 9 th decile.

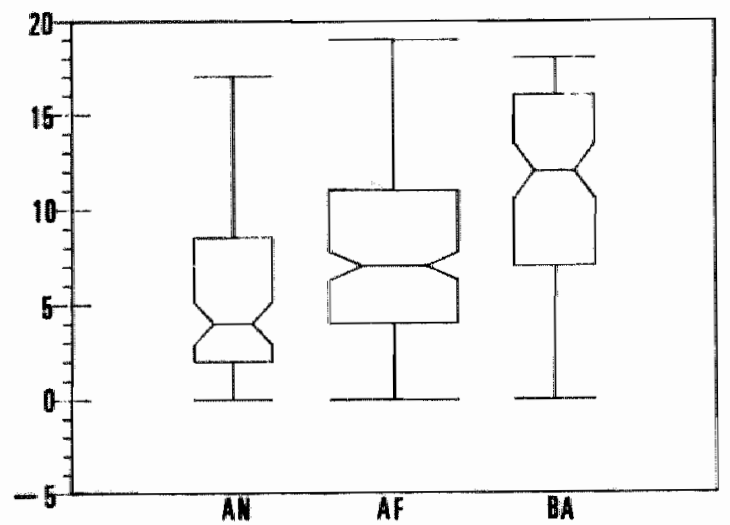

Fig. 7.1.c. The Positive Fear of Fallure

The difference with respect to the Positive Fear of Failure score between the AN and BA group was also statistically significant. The mean Positive Fear of Fallure score of the BA and AN group is in the 6 th and 2 nd decile respectively. The difference between the $B A$ and the AF group was statistically significant. Thus hypothesis 3 is confirmed by these findings. 
The $B A$ and AN group did not differ significantly with respect to the Drive to Achieve. However, a high Drive to Achieve and a high Negative Fear of Failure is found to characterize the AN group. A high Orive to Achieve and a high Positive Fear of Failure was found to typify the BA group. These findings provide substantial support to the hypothesis that the BA group can be differentiated from the AN group with respect to different underlying motives to achieve.

\subsubsection{Anorectic characteristics}

It has been generally assumed and confirmed that ballet dancers have a preoccupation with weight and dieting in common with anorexia nervosa patients (Garner et al., 1981, 1983; Meermann, 1983). Ballet dancers must focus on slimness to meet professional expectancies. Hence, it may be concluded that the underlying motive to pursue thinness is different for ballet dancers when compared to anorexia nervosa patients: the reduction of body weight is not a virtue in itself but an essential prerequisite to succeed in competition and performance.

Accordingly we can postulate that the preoccupation with weight and dieting of ballet dancers may be increased when they are compared to heal thy females, while at the same time less exaggerated when compared to anorexia nervosa patients. The hypotheses to be tested were:

H. 4. The median ANIS score of the BA group is higher than the median ANIS score of the AF group and lower than the median ANIS score of the AN group.

H. 5. The median body weight in relation to height of the BA group is lower than the median body weight in relation to height of the AF group and is higher than the median body weight in relation to height of the AN group.

Hence, the anorectic characteristics of the $B A$ group will be compared with the previous findings on anorectic features of the AN as well as the Af group (see Chapter 6).

Figures 7.2.a.-7.2.c. provide the comparison of the ANIS score, height and body wight of the BA, AN and AF groups. 
Figure 7.2.a. compares the groups on the ANIS. The ANIS score of the AN group is significantly higher than the ANIS score of the BA group. The BA group, however, scores significantly higher on the ANIS when compared to the AF group.

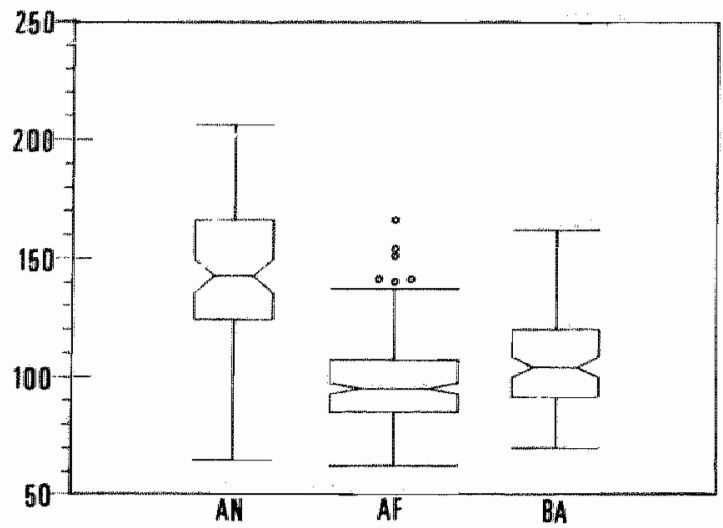

Fig. 7.2.a. ANIS

The hypothesis that BA subjects have higher ANIS scores when compared to control subjects and lower ANIS scores when compared to AN patients is confirmed. One may conclude from these findings that the BA group shares with the AN group the preoccupation with weight and dieting.

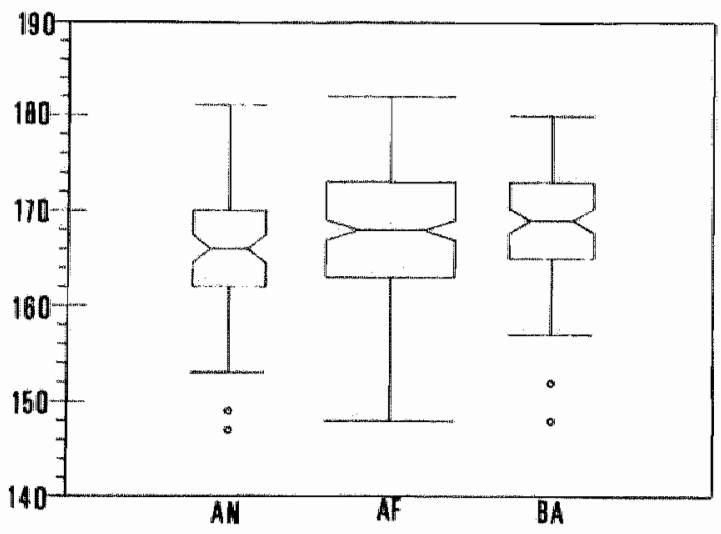

Fig. 7.2.b. HEIGHT 


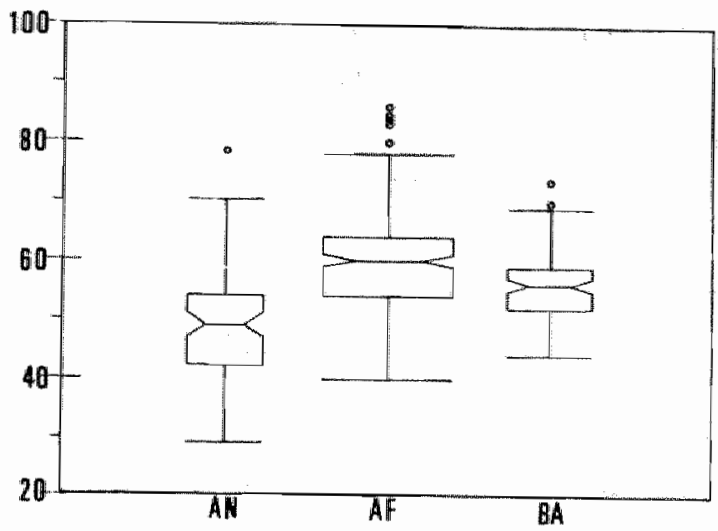

Fig. 7.2.c. WEIGHT

Figures 7.2.b. and 7.2.c. Show that, while the height of the three groups does not differ, the median body weight differs significantly. AN subjects meigh significantly less than the BA group. The BA group weighs significantly less than the AF group. Thus, hypothesis 5 . is a) so confirmed.

Summarizing the results of the comparative study, one may state that:

1. the $B A$ group has an increased preoccupation with weight and dieting when compared with AF subjects

2. the BA share with the AN group the pursuit of thinness

3. despite the common difference in anorectic symptoms of the $B A$ and AN group when compared with AF subjects, significant differences can be found between the BA and AN group in the intensity of preoccupation with weiaht and dieting

4. the accurrence of a case of anorexia nervosa and a case of bulimia nervosa in the BA group when compared with the AF group indicates that 'anorexic like' symptoms are overrepresented in the $B A$ group.

These findings suggest that the BA group shares to some degree anorectic symptoms with the AN group.

The results of the comparison on psychological characteristics of the $B A$ and $A N$ group, however, suggest that a significant psychological difference exists between the groups. Although the BA and AN subjects 
are characterized by a strong Drive to Achieve, this drive seems to originate in a different motive. While the orive to Achieve in the AN group is associated with the Negative Fear of Fallure, in the BA group this drive is associated with a Positive Fear of Failure.

\subsection{Theoretical considerations and hypotheses}

Most studies comparing female ballet dancers with anorexila nerwosa patients have concerned samples of ballet dancers of 18 years of age and older at the time of investigation (Garner and Garfinke1, 1980; Meermann, 1983). Druss and Silverman (1979) reported on a sample of female ballet dancers whose ages ranged from 15-21; however, the mean age of the sample studied is not given. Frisch et a1. (1980) reported on the occurrence of dellayed menarche and amenorrhea in a sample of 89 young ballet dancers; the mean age of this sample was 16.8 years.

Anorexia nervosa has its onset predominantly in adolescence. It is postulated that the onset of the disorder is related to the onset of changes in weight and body shape. If the onset of puberty, especially the changes in weight and body shape, are considered prerequisites for the onset of anorectic symptoms (Crisp, 1980), this assumption will also be justified in all cases of dieting also in the case of female ballet dancers. Accordingly one may postulate that:

young pre-pubertal female ballet dancers differ from controls, with respect to a low body weight, since thinness is also required for young ballet dancers, but do not differ with respect to increased concerns about weight and dieting.

Since studies on the development of motives, especially the studies on the Achievement Motive have shown that the Achievement Motive is a relatively stable characteristic from the age of 10 , one may expect to find a psychological difference with respect to the Drive to Achieve between young ballet dancers and asymptomatic females.

In view of these findings the following hypotheses were formulated and were examined in a comparison of BA and AF subjects younger than 16 years of age: 
1. The median body weight of the young BA group is lower than the median body weight of the young AF group;

2. The median score on the ANIS of the young BA group does not differ from the median score on the ANIS of the young AF group;

3. The median score on the Drive to Achieve of the young BA group is higher than the median score on the Drive to Achieve of the young AF group;

4. The median score on the Negative Fear of Faifure of the young BA group is lower than the median score on the young AF group;

5. The median score on the Positive Fear of Failure of the young BA group is higher than the median score on the Positive Fear of Failure of the young AF group.

\section{6. $\quad$ Results}

7.6.1. Description of the BA and AF group younger than 16 years

Tables 7.2. and 7.3. provide the descriptive data of the BA and the AF group respectively.

Table 7.2. Description of the BA subjects ( 16 years $(\mathrm{nm}=70)$

\begin{tabular}{|c|c|c|c|}
\hline Varlables & $\bar{x}$ & SD & MD \\
\hline Age & 13.1 & 1.4 & 13.0 \\
\hline Helght & 159.0 & 8.5 & 160.0 \\
\hline Body" Welght & 43.4 & 7.4 & 44.0 \\
\hline ANIS & $90 \cdot 2$ & $23 \cdot 3$ & $86 * 4$ \\
\hline Drl we to Achlleve & 20.2 & 5.9 & 21.0 \\
\hline Negat Ive Fear of Fallura & 8.1 & 3.0 & 8.0 \\
\hline Positive Fer of Fall ure & 8.5 & 3.5 & 9.0 \\
\hline
\end{tabular}


Tobl 7.3. Description of the Af subjects $<16$ years $(n=79)$

\begin{tabular}{|c|c|c|c|}
\hline Harlables & $\bar{x}$ & so & 10 \\
\hline Agg & 13.4 & 1.1 & 13.0 \\
\hline Helght. & 162.0 & 8.0 & 161.0 \\
\hline Body hellght & 51.9 & 11.0 & 51.0 \\
\hline ANIS & 91.4 & 18.9 & 91.3 \\
\hline Drll to Achlewe & 8.9 & 5.4 & 7.0 \\
\hline Nagatlive Fear of fallure & 6.9 & 3.4 & 6.0 \\
\hline Posltive Fear of Fallure & 5.3 & 3.2 & 5.0 \\
\hline
\end{tabular}

The median age of the BA group as well as the AF group was 13. Fortyfour (63\%) of the BA group did not have their menarche yet, compared to 10 AF subjects (13\%). The mean height of the BA group was 159.0; the mean height of the AF group was 162.0.

\subsection{Comparison of the BA and AF group younger than 16 years}

Figures 7.3.a.-7.3.c. provide the results of the comparison of anorectic and Figures 7.4.a.-7.4.c., psychological differences.

7.7.1. Anorectic characteristics.

The BA group did not differ significantly from the AF group with respect to height. The difference in median body weight between the two groups, however, was significant: young female ballet dancers weigh significantly less than young controls. Hence, hypothesis 1 is confirmed. 


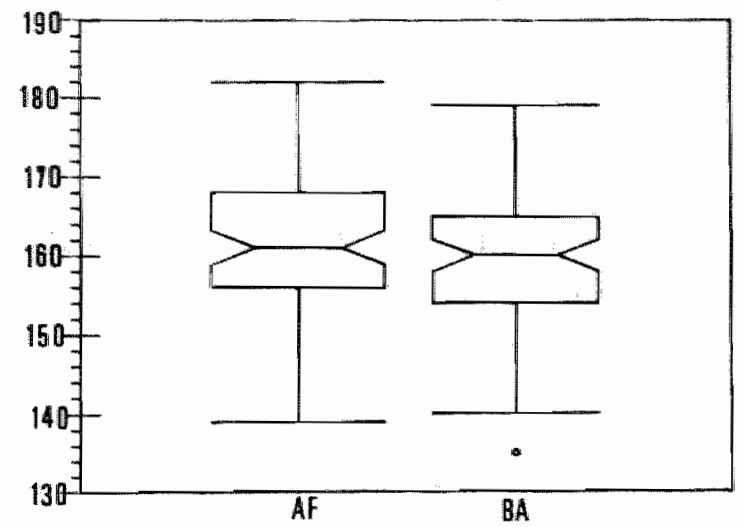

Fig. 7.3.a. HEIGHT

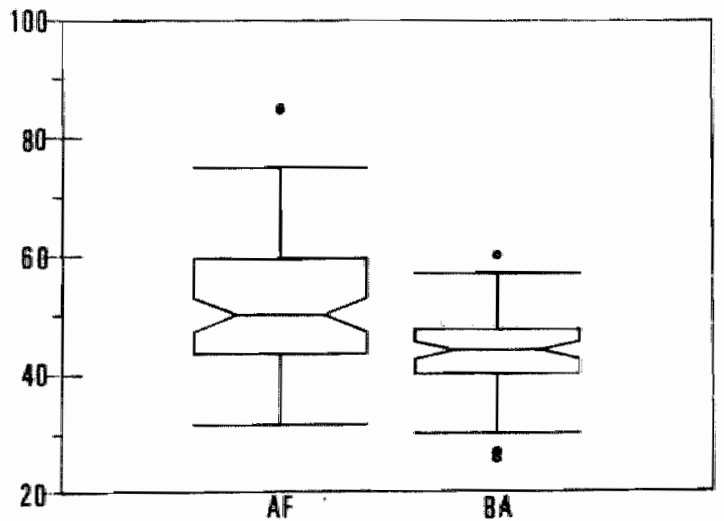

Fig. 7.3.b. WEIGHT

Despite the difference in weight considering age and height, the BA group did not score statistically different on the ANIS than the AF group (Figure 7.3.). The hypothesis that young BA dancers could not be differentiated from asymptomatic female controls with respect to preoccupation with weight and dieting is thus supported.

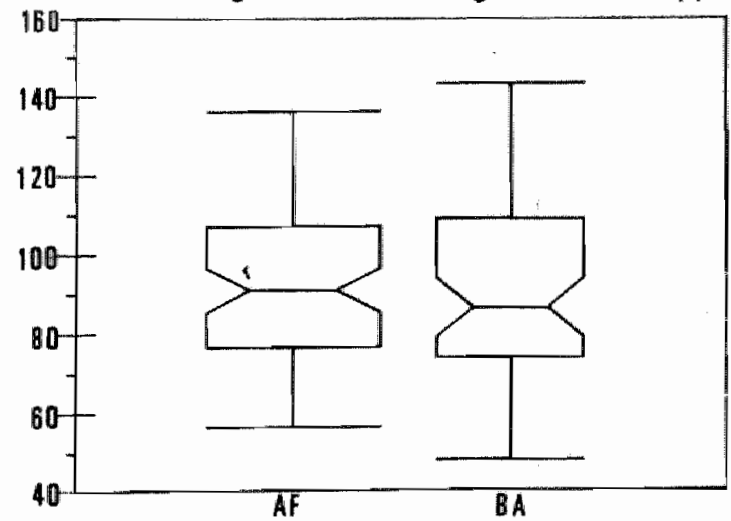

Fig. 7.5.c. ANIS 


\subsubsection{Psychological characteristics}

Figures 7.3.a.-7.3.c. show the results of the comparison between the $B A$ and AF group on the psychological characteristics "Orive to Achieve', 'Negative Fear of Failure' and 'Positive Fear of Failure" respectively.

A high Drive to Achieve, considered to be characteristic of ballet dancers, was also found for the young BA group. Their score on the Drive to Achieve was significantly higher than that of the AF group (Figure 7.4.a.).

Thus the hypothesis that BA students are characterized by a stronger Drive to Achieve is confirmed.

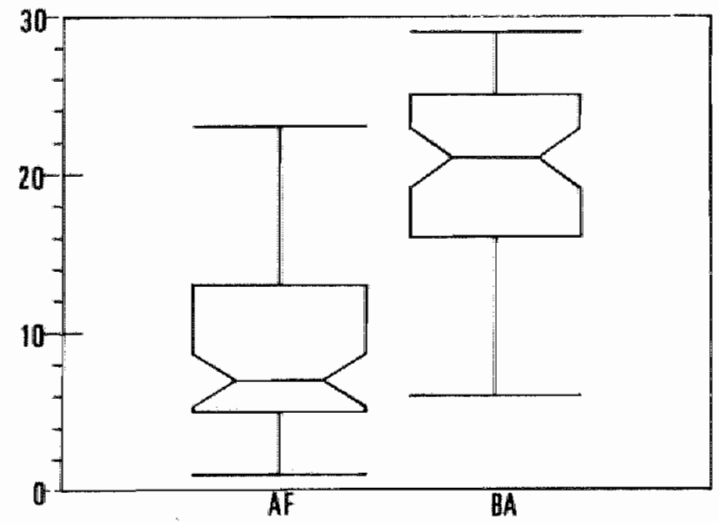

Fig. 7.4.a. Comparison of the Drive to Achieve of subjects $<16$ years

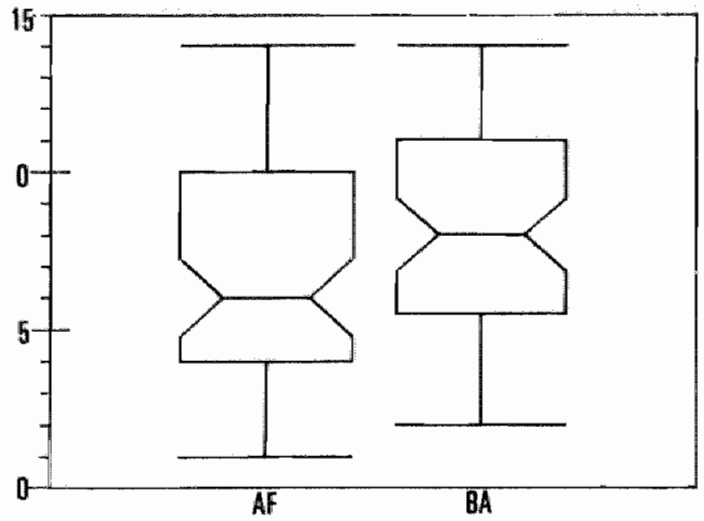

Fig. 7.4.b. The Negative Fear of Failure of subjects $<16$ years 


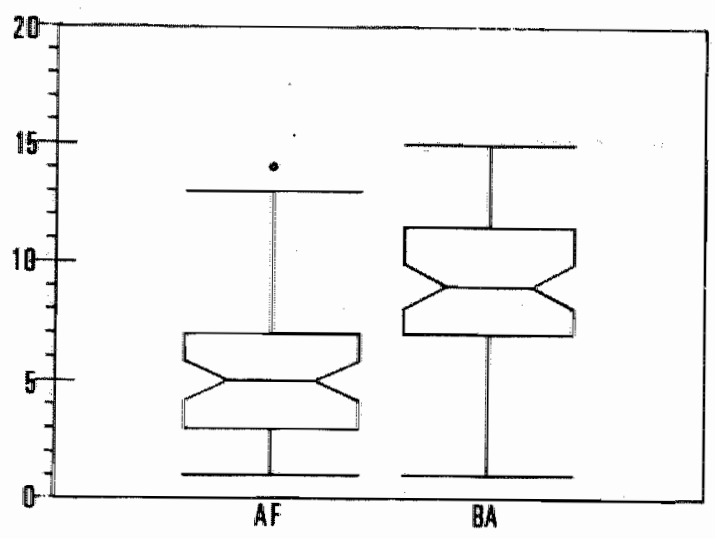

Fig. 7.4.c. The Positive Fear of Failure of subjects $<16$ years

The BA group also had a higher median score on the Negative Fear of Failure, when compared to the AF group, this difference is not statistically significant. Hypothesis 4 is not confirmed. The BA group scored significantly higher on the Positive Fear of Failure than the AF group. Thus hypothesis 5 is confimed.

As has been postuiated the Drive to Achieve associated with the Positive Fear of Failure, is characteristic also of young female ballet dancers. The presence of differences in weight and the absence of differences in concern about weight and dieting between the BA and AF group suggest that preoccupation wilt weight and dieting is related to the onset of physical changes in weight and body shape.

\subsection{Discussion}

The results of the comparative study of female ballet dancers with anorexia nervosa patients and asymptomatic female subjects suggest that female ballet dancers are characterized psychologically by a Drive to Achieve, reflecting a strong basic need to excel. Evidence was found in high scores on the scales 'Drive to Achieve' and 'Posttive Fear of Fallure'.

These findings have been found for the young group of ballet students 
as well as for the group of ballet dancers of 16 years of age and older.

The results of the comparison on psychological characteristics of ballet dancers and anorexia nervosa patients confirm previous findings that anorexila nerwosa patients can be psychologically differentiated in terms of the Negative Fear of Fallure. A high Drive to Achieve characterizes both ballet dancers and anarexia nervosa patients. However, a difference was found with respect to the underlying fear of faillure.

Anorexia nervosa patients (16 and older) show more anorectic behawiours and attitudes as indicated by the score on the ANIS and body weight than female ballet dancers. However, the ballet dancers have lower bady welghts and higher scores on the ANIS when compared to asymptomatic females. These findings are concordant with previous results that female ballet dancers have an increased emphasis on a thin body shape (Garner et a1.. 1979). The finding of low body weights unrelated to concern about weight as manifested in the ANIS score is observed in the ballet dancers younger than 16 years of age. Al though the ballet students weigh significantly less than the controls, the scores on the ANIS do not differ from those found in the AF group. One may conclude from the comparison of young female ballet dancers with asymptomatic females that, concerns about weight and dieting are likely to occur after the onset of puberty with a change of body shape. Psychological differences as indicated by a strong Drive to Achieve and a high Positive Fear of Failure has found to typify both the balletdancers of 16 years of age and older as well as those younger than 16 years of age.

These results support the notion that anorexia nerwosa patients can be psychologically differentiated from other subjects who to some degree share the anorectic and menstrual characteristics.

\subsection{Surmmary}

The present study extends previous findings by comparing the anorectic 
and psychological characteristics of ballet dancers with anorexia nervosa patients and controls. The results of this study indicate that:

- Female ballet dancers cannot be distinguished from anorexia nervosa patients with respect to the psychological characteristic Drive to Achieve.

- Female balletdancers show less preoccupation with weight and dieting than anorexia nervosa patients. Compared with asymptomatic females they show an increased focus on weight and dieting.

- Concern about weight and dieting is found to occur after the onset of changes in weight and body shape at puberty and is considered to be related to age.

- The presence of psychological differences however, does not seem to be related to the age factor.

It may be concluded from the findings of this study that despite simi1 arities in anorectic and psychological characteristics of ballet dancers and anorexia nervosa patients, the crucial difference is found in the meaning of these similarities. The Drive to Achieve and the need to exce 1 in performance in anorexia nervosa patients have been found to originate in the avoidance of failure. This Negative Fear of FaiTure can be considered a typical characteristic of subjects with anorexia nervosa. 
Chapter 8. THE ROLE OF ANORECTIC AND PSYCHOLOGICAL CHARACTERISTICS IN THE DEVELOPMENT OF ANOREXIA NERVOSA

"Anorexia nervosa should be seen as evolving from a concatenation of circumstances, both past and present, rather than appearing suddenly and for no sufficiently good reason, as a particular response to a particular stimulus".

Sheilla MacLeod, The Art of Starvation, 1983, p.171. 
Chapter 8. THE ROLE OF ANORECTIC AND PSYGHOLOGICAL CHARACTERISTICS IN THE DEVELOPNENT OF ANOREXIA NERVOSA

8.1 .

\section{Introduction}

The vifew that anorexia nerrosa is a psychobiosocial disorder is predicated on the hypothesis that biological and psychological as well as social factors play a role in the onset and sustaining of the disease. In the present study emphasis has been laid on examining the discriminative value of anorectic as well as psychological characteristics of anorexia nervosa patients.

The results of this transversal study have shown that anorexia nervosa patients are characterized psychologically by a strong motive to achieve originating in a negative fear of failure. At the same time anorexia nervosa patients can also be differentiated from other subjects sharing to some degree anorectic and menstrual characteristics with respect to an increased preoccupation with weight and dieting and a lower body weight.

For the purpose of an early identification of anorexia nervosa it is crucial to know the contributory role of anorectic as well as psychological characteristics in the onset and development of the disorder. A longitudinal prospective study was carried out to determine the role of anorectic and psychological characteristics in the development of anorexia nervosa. For this purpose the anorectic and psychological characteristics of secondary amenorrhea patients (AM), asymptomatic females (AF) and ballet students (BA) group were assessed for a second time.

\subsection{Theoretical considerations and research questions}

Previous studies on the Achievement Motive have shown, that the drive to achieve is a relatively stable psychological characteristic from 
the age of 10 (Kagan and Mass, 1962; McClelland, 1966; Skollnick, 1966). Individuals with strong achieve motives tend to conform more to soctally prescribed standards (Hermans, 1978).

If soc10-cultural standards emphasize a thin body shape, as presently is the case, subjects with a strong drive to achieve will tend to develop more concern about weight and dieting than subjects with a low drive to achieve.

A1 though anorexia nervosa may have its onset in dieting, common dieting to improve external appearance and anorexia nervosa are not identical. Common dieting can be interpreted as conforming to socially prescribed standards.

Little research has been done on the development of other motives such as the fear of failure. From these findings (Chapter 9.) one may conclude that the fear of failure results from the continuous interaction with a social environment and is a less stable psychological characteristic compared to the drive to achieve.

From the findings from the transversal study one may expect that the Negative Fear of Fallure play a role in the development of anorexia nervosa.

However, the effect of anorectic characteristics in particular the role of starvation contributing to the development of anorexia nervosa has also been stressed.

The onset of anorexia nervosa usually is manifested by loss of weight and increased preoccupation with weight and dieting.

To determine the predictive value of weight, anorectic behaviour, menstrual cycle as well as the Drive to Achieve, the Negative and Positive Fear of Failure on weight loss and increased concern about wellght and dieting multiple regression analysis were carried out.

As three groups were studied the data of the groups were analyzed separately. 


\section{3.}

\section{Procedures}

A11 subjects were sent a circular letter one month prior to the second assessment. If the reply form to confirm their participation was not received within three weeks, a reminder was sent.

since at first the drop-out rate was particularly high in the AF group, it was decided to provide a small financial compensation for the second participation. A delay in the planned second assessment resulted from this and the mean time-interval between the first and second assessment for the AF group was 14 months, instead of the scheduled 12 months. The time-interval for the AM and the BA group are 6 and 9 months respectively.

Eigthy-two (82) AM, $237 \mathrm{AF}$ and $105 \mathrm{BA}$ subjects of 16 years and o1der participated in the first assessment.

Fifty (50) AM, $171 \mathrm{AF}$ and eighty-six (86) BA subjects took part in the second assessment. The drop-out rate of the AM, AF and BA. groups of 16 and older was $39 \%, 28 \%$ and $18 \%$ respectively.

\subsection{Comparison of the drop-outs and participants}

To determine whether the drop-outs and participants sere significantly different from each other, the two subgroups in the $A M, A F$ and $B A$ group were compared with regard to age, anorectic and psychological characteristics, using a t-test.

Tables 8.1., 8.2., and 8.3., provide the results of the comparison of drop-outs and participants in the $A F, A M$ and $B A$ group respectively.

8.4.1. AF group

The AF drop-outs differ significantly in respect to age, helght and the Drive to Achileve (Table 8.1). As the AF subjects were recruited from a schoolpopulation, drop-outs consisted of individuals, who gra- 
duated as 11 as individuals who did not continue their education. The Drive to Achieve is a reliable predictor for educational and vocational success. A lower Drive to Achieve score may underly the drop-out of school and hence the drop-out of this investigation.

\begin{tabular}{|c|c|c|c|c|c|}
\hline \multirow[t]{2}{*}{ Varlables } & \multicolumn{2}{|c|}{ Drop-outs $(n=56)$} & \multicolumn{2}{|c|}{ Partliclpants (nख171) } & \multirow[b]{2}{*}{$\operatorname{sig} n}$. \\
\hline & $\bar{x}$ & SD & $\bar{x}$ & $\mathrm{SD}$ & \\
\hline Age 1 & 20.4 & 4.7 & $19 \cdot 1$ & 1.7 & $p<0.05$ \\
\hline Helght 1 & 166.2 & 7.4 & $168 \cdot 2$ & 5.9 & $0 \times 0.05$ \\
\hline Body walght 1 & 58.1 & 10.0 & 59.9 & 7.0 & NS \\
\hline Drlwa to Achlowa 1 & 14.9 & 6.7 & 17.0 & 6.6 & $0 \times 0.05$ \\
\hline Nog.Far of Fallura 1 & $1 \quad 14.1$ & 5.9 & 14.5 & 5.5 & NS \\
\hline Pos four of Fallure 1 & 4.5 & 0.6 & 4.6 & 0.4 & NS \\
\hline ANIS 1 & $102 \cdot 3$ & 17.9 & 95.5 & 17.3 & $p<0.01$ \\
\hline
\end{tabular}

In the AF group the drop-outs had significant higher ANIS scores, if compared to the participants who participated in the second assessment.

\subsubsection{AM group}

As can be seen from Table 8.2. the AM drop-outs did not differ significantly from the participants, except for body weight and the Negative Fear of Fallure. The AM subjects who dropped out, had lower body weights and significant higher scores on the Negative Fear of Failure when compared to the participating AM subjects. It is noteworthy that in this 'anorectic and menstrual' risk group, the psychologically at risk individuals dropped out predominantly. This selective drop-out may affect the results of this study. 
Table 8.2. Deserlptive data of the AM subjects $\geq 16$ years $(n=82)$

\begin{tabular}{|c|c|c|c|c|c|}
\hline \multirow{2}{*}{ War fablos } & \multicolumn{2}{|c|}{ Drop-mouts $(n=32)$} & \multicolumn{2}{|c|}{ Particlpant's (n=150) } & \multirow[b]{2}{*}{ Silgn. } \\
\hline & $\bar{x}$ & SO & $\bar{x}$ & 50 & \\
\hline Age 1 & $25 \cdot 3$ & 6.5 & 23.7 & 4.7 & NS \\
\hline Helght 1 & 164.8 & 5.7 & $\| 66.2$ & 7.6 & NS \\
\hline Body Wolght 1 & 55.5 & 11.0 & 60.1 & 11.0 & $p<0.10$ \\
\hline Dr l ve to Achleve 1 & 19.8 & 6.7 & 19.5 & 5.9 & NS \\
\hline Neg. Fear of Fallure 1 & 16.8 & 6.5 & 13.7 & 5.5 & $0 \times 0.05$ \\
\hline Pos.Fear of Fallure 1 & 7.8 & $5 \cdot 2$ & $7 \cdot 4$ & 5.2 & NS \\
\hline ANIS 1 & 121.6 & $26 \cdot 4$ & 116.2 & 22.7 & NS \\
\hline
\end{tabular}

Table 8.3. Descr Iptl we date of the BA subjacts _ 16 years $(n=105)$

\begin{tabular}{|c|c|c|c|c|c|}
\hline \multirow[t]{2}{*}{ Varlablas } & \multicolumn{2}{|c|}{ Drop-outs $(n=19)$} & \multicolumn{2}{|c|}{ Particlpants $(n=86)$} & \multirow[b]{2}{*}{$\operatorname{sign}$} \\
\hline & $\bar{x}$ & $S D$ & $\bar{x}$ & $S D$ & \\
\hline Age 1 & 19.5 & 2.4 & $19 \cdot 4$ & 2.8 & NS \\
\hline Helght is & 168.1 & 7.9 & 168.5 & 6.3 & NS \\
\hline Welght 1 & 55.4 & 7.0 & 56.11 & 7.0 & WS \\
\hline Dr lve to Achleve 1 & 23.6 & 7.0 & 20.5 & 7.0 & NS \\
\hline Neg.Fear of Fallure : & 13.3 & 6.9 & $\$ 3.0$ & 5.1 & WS \\
\hline Pos.Fear of Fallure 1 & 11.0 & 5.8 & 11.0 & 5.0 & NS \\
\hline ANIS 1 & 105.7 & $22 \cdot 3$ & 106.0 & 19.3 & NS \\
\hline
\end{tabular}

Table 8.3. shows, that there were no significant differences between $B A$ drop-outs and BA participants.

The drop-outs in the AM and the AF group can be considered as individuals who were psychologically respectively, anorectically at an increased risk when compared to the AM and AF participants.

\subsection{Results}

To determine the contribution of anorectic, menstrual and psychologi- 
cal characteristics to the development of anorexia nervosa, the data were analyzed by multiple regression analysis. Separate multiple regression analyses were conducted with 'weight loss' and 'increased preoccupation with weight and dieting' as dependent variables. Weight loss was defined as: Body weight 2 minus Body weight $1<0$. Increased preoccupation with weight and dieting was defined as: ANIS 2 minus ANIS $1>0$.

Table 8.4. provides the number of subjects of the AF, AM and BA group, satisfying the criteria for weight loss and increased preoccupation with weight and dieting.

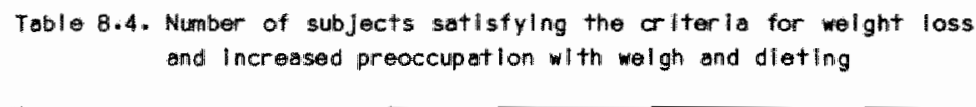

\begin{tabular}{|c|c|c|c|}
\hline \multirow[t]{2}{*}{ Varlables } & \multicolumn{2}{|c|}{ Groups } & \multirow[b]{2}{*}{$B A \quad(n=B 6)$} \\
\hline & AF $(n=171)$ & $A M(n=50)$ & \\
\hline Bw $2-B w 1<0$ & 65 & 20 & 32 \\
\hline ANIS 2 - ANIS $1<0$ & 61 & 16 & 34 \\
\hline
\end{tabular}

For the multiple regression analyses a set of anorectic, menstrual and psychological characteristics was used as predictor variables.

Separate multiple regression analyses were conducted for each of the three groups. The multiple regression analyses were corrected for the effect of regression to the mean. This effect is related to repeated measurements and the occurrence of extreme scores (Lord, 1963; Durinck and Munnik, 1978).

The multiple regression analysis in the AF group was the basis for the estimation of the regression whight which was used on a correction coefficient for the so-called 'regression to the mean effect'. This coefficient was estimated to be about 0.068 . In the regression equations of the AM and BA groups this coefficient was used as a correc- 
tion for the variable Body Weight 1 .

The following procedures were carried out to correct for the effect of regression to the mean in each group:

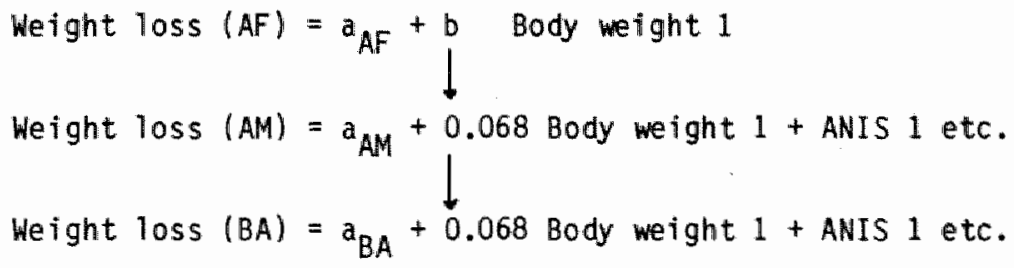

8.5.1. Multiple regression analysis with AF subjects with weight loss

Sixty-five (65) subjects of the total group of 171 AF subjects satisfied the criterion for weight loss. Elght (8) subjects were excluded due to missing data on one of the variables. Hence the multiple regression analysis was based upon the data of fifty-seven (57) subjects.

Table 8.5. provides the descriptive data of these subjects on the variables used for multiple regression analysis.

Table 8.5. Descriptive date of AF subjects with welght loss ( $n=57)$

\begin{tabular}{|c|c|c|}
\hline Varlables & $\bar{x}$ & 50 \\
\hline Body welght I & 60.5 & 6.4 \\
\hline Body lght 2 & 58.2 & 6.2 \\
\hline ANIS : & 98.2 & 19.3 \\
\hline ANIS 2 & 91.7 & 18.4 \\
\hline Dr lwe to Achlewe I & 16.4 & 6.2 \\
\hline Nag.Fear of Fallure I & 14.9 & 5.2 \\
\hline Pos-Fear of Fallure 1 & 7.5 & $4 \cdot 4$ \\
\hline
\end{tabular}

Table 8.6. provides the results of the multiple regression analysis of body wight, ANIS, menstrual cycle and psychological characteristics as predictor variables and weight loss as dependent variable. 
Table 3.6. Multiple regression analysis of body whigh, ANIS, menstrual cycle and psychologlcal character istlics as predictor varlables and whelght loss as independent varlable

\begin{tabular}{lll}
\hline Vorllables & Unstandardized & Standardized \\
regr. coeff. & regr. coeff.
\end{tabular}

\begin{tabular}{|c|c|c|c|}
\hline Intercept & -1.46 & - & \\
\hline Body welght 1 & 0.08 & 0.33 & $p \times 0.05$ \\
\hline ANISI & -0.01 & -0.18 & NS \\
\hline Menstrual cycle 1 & 0.95 & 0.20 & NS \\
\hline Dr lwe to Achlowe & 0.05 & 0.18 & NS \\
\hline Nag.Fear of Follure & -0.04 & -0.12 & NS \\
\hline Poss.Fear of Fallure & -0.03 & -0.08 & NS \\
\hline
\end{tabular}

It can be seen from Table 8.6. that the variable body weight 1 contributes significantly to the prediction of the degree of weight loss. Body weight 1 accounts for $15 \%$ of differences in weight loss of the AF group. The percentage of accounted variance amounts $15 \%$ (Multiple $R=$ 0.391 .

8.5.2. Multiple regression analysis with AF subjects with an increased preoccupation with weight and dieting

Sixty-one (61) AF subjects satisfied the criterion of increased preoccupation with weight and dieting. Eight $(8)$ subjects were excluded due to missing data on one the variables.

Table 8.7. presents the descriptive data of the subjects on the variables used for multiple regression analysis. The mean ANIS score increased, while the mean weight did not change. 
Table 8.7. Descriptlive data of AF subjects with Incraased preoccupsthon with weight and theting $(n=53)$

\begin{tabular}{lrr}
\hline Varlables & $\bar{x}$ & SD \\
\hline Body ght 1 & 59.3 & 6.5 \\
Body ght 2 & 59.6 & 6.8 \\
ANIS & 90.0 & 15.5 \\
ANis 2 & 99.0 & 18.6 \\
Drive to Achleve 1 & 15.9 & 7.2 \\
Neg.Foar of Fallure 1 & 13.0 & 5.4 \\
Pos.Fear of Fallure & 8.5 & 5.0 \\
\hline
\end{tabular}

Multiple regression analysis with the anorectic, menstrual and psychological characteristics produced no significant predictors. The percentage of accounted variance amounts $6 \%$ (Multiple $R=0.24$ ) and may reflect a fluctuation of chance.

8.5.3. Multiple regression analysis with AM subjects with weight loss

Of the total group of fifty (50) AM subjects, twenty (20) satisfied the criterion for weight loss. There were no missing data and the analysis was performed on twenty $(20)$ cases.

In Table 8.8. the descriptive data of these subjects on the variables used for multiple regression analysis are presented. Also in the AM group a decrease of mean body weight is accompanted by a decrease of the mean ANIS score. 
Table 8.B. Descriptlye date of AM subjects with lignt loss $(n=20)$

\begin{tabular}{|c|c|c|}
\hline Varlables & $\bar{x}$ & SD \\
\hline Body wht I & $6 \cdot 4 \cdot 0$ & 15.1 \\
\hline Body light 2 & $61: 2$ & 14.3 \\
\hline ANES 1 & 125.0 & 22.0 \\
\hline ANIS 2 & $109 \cdot 5$ & 19.4 \\
\hline Or lwe to Achleve 1 & $18 \cdot 9$ & 5.7 \\
\hline Heg.Fear of Fallure 1 & 13.0 & $4 \cdot 3$ \\
\hline Pos.Fear of Fallure : & 7.4 & 4.5 \\
\hline
\end{tabular}

The results of the multiple regression analysis produced no significant predictors. The percentage of accounted variance is $27 \%$ (Multiple $R=0.52$ ) and may reflect a fluctuation of chance.

8.5.4. Multiple regression analysis with AM subjects with an increased preoccupation with weight and dieting

af the total group of fifty (50) AM subjects, sixteen (16) subjects satisfied the criterion for increased preoccupation with weight and dieting. One (1) subject was excluded due to missing data on one of the variables. The descriptive data of these fifteen (15) AM subjects are presented in Table 8.9. An increase of mean ANIS score is accompanied by an increase of body weight.

Table 8.9. Descirlptive dat of AM subjects with Increased preoccupatlon whelgint and deting $(n=15)$

\begin{tabular}{|c|c|c|}
\hline Vorllables & $\bar{x}$ & so \\
\hline Bady welght 1 & 61.6 & 13.6 \\
\hline Body lght 2 & 62.7 & 12.3 \\
\hline ANIS 1 & 119.3 & 24.8 \\
\hline ANIS 2 & 1134.0 & 32.6 \\
\hline Drlve to Achlove 1 & 20.4 & 6.7 \\
\hline Nag. Foar of Fallure & 16.5 & 5.8 \\
\hline Pos.Feor of Fallure 1 & 6.0 & 6.0 \\
\hline
\end{tabular}


Table 8.10. provides the results of the multiple regression analysis of anorectic, menstrual and psychological characteristics as predictor variables and increased preoccupation with welght and dieting as dependent variable.

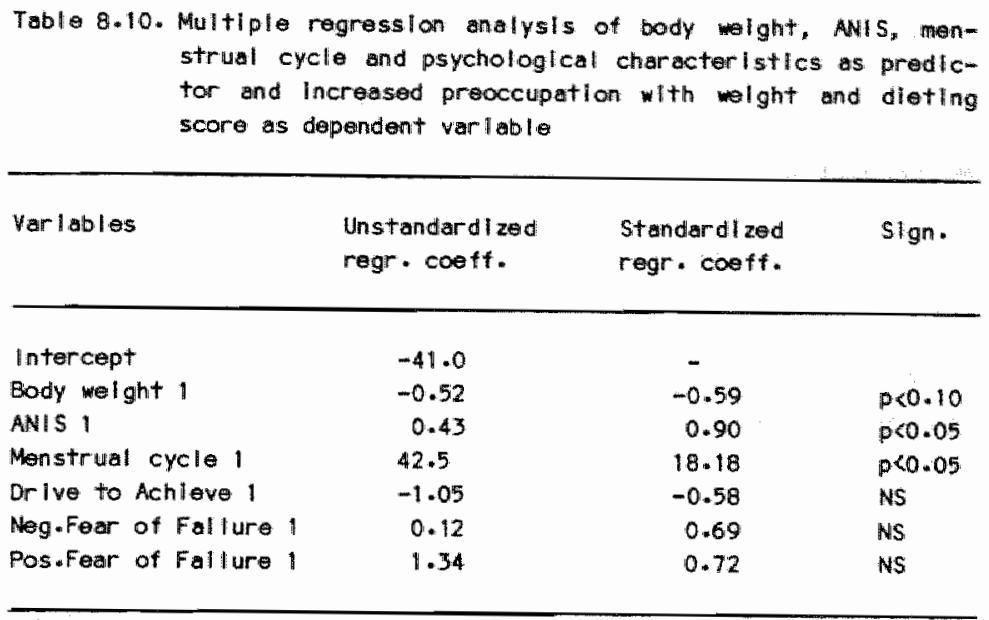

The results of this multiple regression analysis indicate that ANIS 1 and menstrual cycle 1 contributed significantly to the prediction of the degree of increased preoccupation with weight and dieting. The percentage of accounted variance amounts $66 \%$ (Multiple $R=0.81$ ).

Differences in the increase of preoccupation with weight and dieting are related to an elevated ANIS 1 score as well as to the presence of menstrual disorders.

8.5.5. Multiple regression analysis with BA subjects welght loss

Of eighty-six (86) BA subjects, thirty-two (32) satisfied the criterion of weight loss. Four (4) were excluded due to missing data on one of the variables. The descriptive data of the remaining twenty-eight (28) BA subjects are presented in Table 8.11. 
Table 0.11 . Deserlptiva data of BA subjects with welght loss (n=28)

\begin{tabular}{|c|c|c|}
\hline Varlables & $\bar{x}$ & $\mathrm{SD}$ \\
\hline Eody welght 1 & 55.4 & 5.0 \\
\hline Body whight 2 & 53.1 & 4.8 \\
\hline ANIS I & $108 \cdot 3$ & 25.2 \\
\hline ANVIS 2 & 101.5 & 25.9 \\
\hline or ll we to Achleve 1 & $19 \cdot 0$ & 5.9 \\
\hline Neg.Fear of Fallure 1 & $13 \cdot 0$ & $5 \cdot 2$ \\
\hline Pos. Foar of Fallure I & 11.0 & 4.8 \\
\hline
\end{tabular}

Multiple regression analysis with the anorectic, menstrual and psychological characteristics produced no significant predictors. The percentage of accounted variance amounts $23 \%$ (Multiple $R=0.48$ ) and is not significant.

8.5.6. Multiple regression analysis with $B A$ subjects with an increased preoccupation with weight and dieting

Thirty-four (34) BA subjects satisfied the criterion of increased preoccupation with weight and dieting. Four (4) cases were excluded; due to missing data on one of the variables. The descriptive data of the remaining thirty (30) BA subjects are presented in Table 8.12.

\begin{tabular}{|c|c|c|}
\hline Varlablos & $\bar{x}$ & SD \\
\hline Body welght i & 55.2 & 4.2 \\
\hline Bodly wolght 2 & $56 \cdot 1$ & 5.0 \\
\hline ANIIS 1 & 103.2 & 20.5 \\
\hline ANHS 2 & 112.6 & $25 \cdot 2$ \\
\hline Drllve to Achleve 1 & 21.2 & 6.3 \\
\hline Nag. Foar of Fallure & 13.1 & 4.8 \\
\hline Pos.Fear of Fallure 1 & $11 \cdot 4$ & 5.2 \\
\hline
\end{tabular}


Table 8.12. provides the results of anorectic, menstrual and psychological characteristics as predictor variables and increased preoccupation with weight and dieting as independent variable.

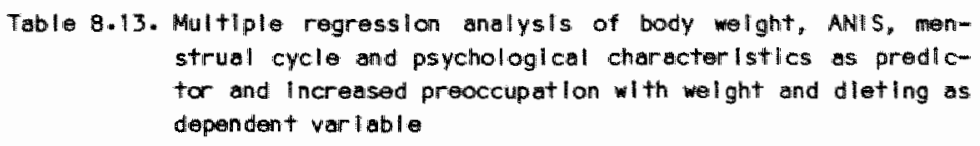

\begin{tabular}{lccl}
\hline Varlable & $\begin{array}{c}\text { Unstandardlized } \\
\text { regr. coeff. }\end{array}$ & $\begin{array}{c}\text { Standardized } \\
\text { regr. coeff. }\end{array}$ & Sign. \\
\hline Intercept & -5.66 & - & \\
Body welght & 0.18 & 0.12 & NS \\
ANIS 1 & 0.05 & 0.16 & NS \\
Menstrual cycle 1 & 8.14 & 2.54 & p 0.05 \\
Drlve to Achleve 1 & -0.47 & -0.46 & PKo.05 \\
Neg.Fear of Fallure 1 & 0.05 & 0.04 & NS \\
Pos.Fear of Fallure 1 & 0.04 & 0.03 & NS \\
& & & \\
\hline
\end{tabular}

As can be seen from Table 8.13. menstrual cycle and the Drive to Achieve contribute significantly to the prediction of the degree of increased preoccupation with weight and dieting. The percentage of accounted variance is $39 \%$ (Multiple $R=0.63$ ). Menstrual disorders and anorectic characteristics contribute significantly to the degree of increased preoccupation with weight and dieting.

\subsection{Interpretation of the findings}

Mul tiple regression analysis performed separately on each of the AF, AM and BA groups produced different predictor variables for each group. The results with regard to the predictor variables for each group are provided in Table 8.14 . 


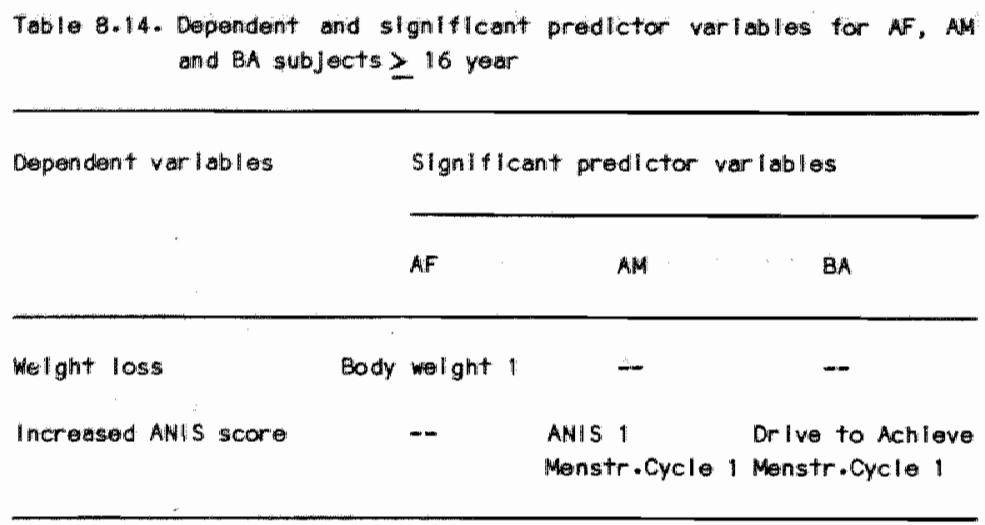

It can be concluded that anorectic, menstrual and psychological factors play a role in the onset of weight loss and increased preoccupation with weight and dieting and that the contribution of these factors may vary.

One may conclude that menstrual cycle contributes significantly to predicting degree of increased preoccupation with weight and dieting in subjects at risk in the AM as well as the BA group. An increase of preoccupation with weight and dieting combined with an increase of weight was observed in the $A M$ and $B A$ group the combination of the weight gain and an increased ANIS score do not indicate an onset of anorexia nervosa but may reflect an onset of a related eating disorder such as bulimia or bulimia nervosa. The analysis of the AM participating subjects and AM drop-outs indicated that the drop-out group could be characterized with respect to a significantly higher score on the Negative Fear of Failure. From this group with anorectic and menstrual characteristics the group with the psychological characteristic Negative Fear of Failure could be considered to be at risk of developing increased preoccupation and weight and dieting with decrease of weight. Unfortunately this group dropped out.

The results of the analyses indicate that the amounts of accounted variance of anorectic, menstrual and psychological characteristics are satisfactory to explain $66 \%$ respectively $39 \%$ of an increase of preoccupation with weight and dieting of the AM and BA group. The fact 
that during and shortly after the period of study three (3) subjects were diagnosed as anorexia nervosa by medical doctors they have consulted, stressed the need to qualitatively reconsider the data obtained. The data of these subjects with regard as well as three subjects with extreme weight loss are presented for illustration.

\subsection{Illustrative cases}

All subjects participating in the study were interviewed at the first and the second assessment. The personal data provided, were collected by the interview.

Weight changes of 5 kilograms or more, occurring within a year, is generally considered as one of the criteria for the presence of disturbed eating behaviour. Accordingly those individuals with a minimum weight loss of $5 \mathrm{~kg}^{\prime} \mathrm{s}$ between the first and second measurement of body weight were selected.

8.7.1. Selection of individuals with significant meight loss

Significant weight loss is operationally defined as: Body weight 1 minus Body weight $2 \geq 5 \mathrm{kgs}$.

Nineteen (19) individuals satisfied this criterion of weight loss. Four (4) subjects belonged to the AM group, 6 to the AF group and 9 subjects to the BA group. Table 8.15. provides the anorectic, menstrual and psychological characteristics of this group. 
Table 8.15. Ancractlc, menstrua and psychologlcal characterlstics of subjects wth wht loss $\geq 5 \mathrm{kgs}$ *

Case Age Welght AHIs Menstr. Drlve Heg. Pos. History
loss 1

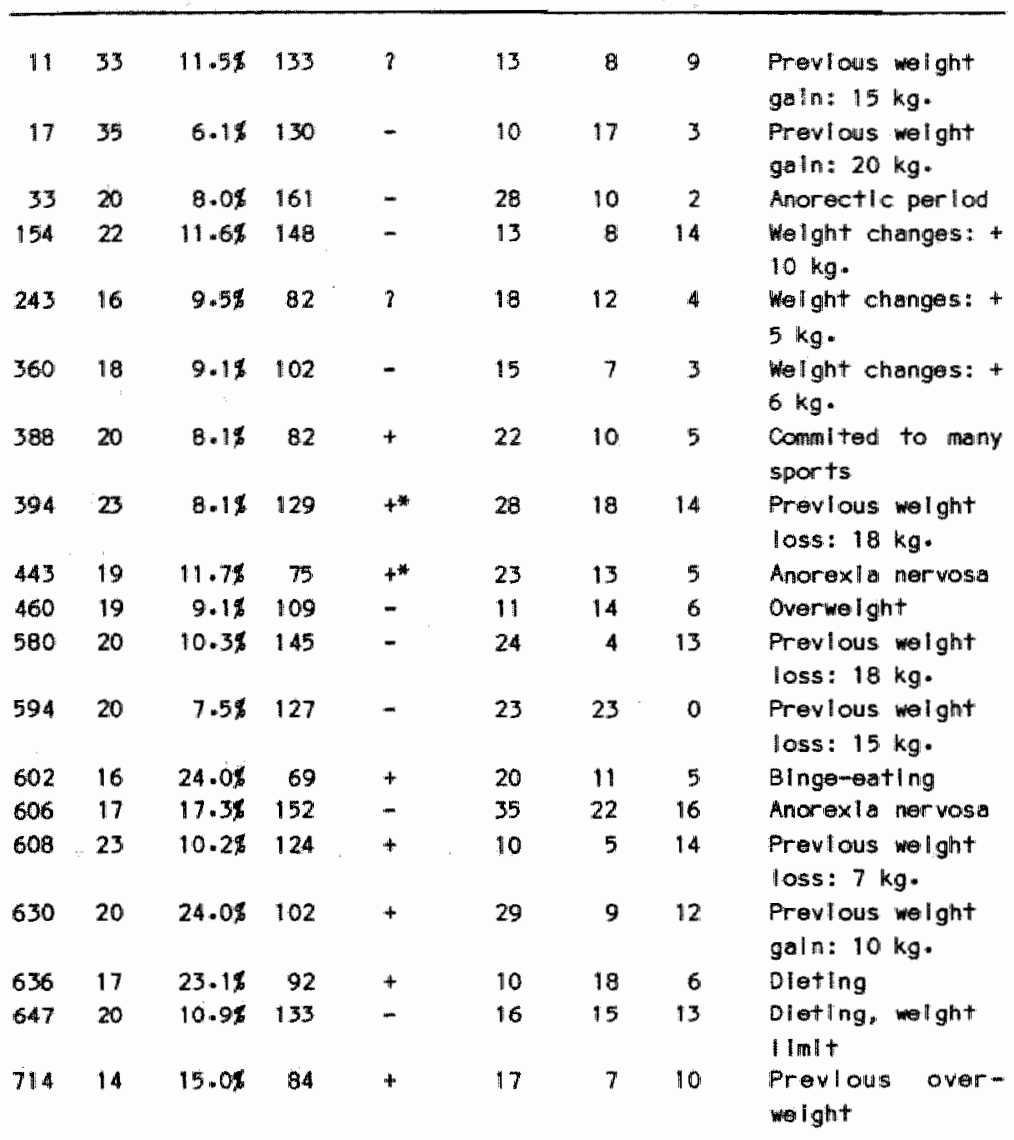

- use of orel contraceptive

This table indicates that preoccupation with weight and dieting need not also be manifested in an elevated ANIS scare. It is not clear if a low value can be interpreted as a form of denial of symptoms since four of the five individuals with low ANIS scores and significant welght loss did not mark the item 'always' but 'often' when asked if they had filled in this self-inventory honestly. 
At the first interview all nineteen subjects reported to be involved in dieting or to have experienced sudden weight gain or weight loss. But dieting was also commonly reported by other subjects $133 \%$ of the AF group reported 'regularly dieting"). Seven (7) of the nineteen (19) subjects remain to have menstrual cycles, while ten (10) subjects are suffering from secondary amenorrhea. Two (2) subjects used oral contraceptives.

One of the subjects who had been diagnosed as having anorexia nervosa four months after the second assessment is not included in the table. Her loss of body weight accounted to $2 \mathrm{kgs}$ at the second assessment.

The three anorexia nervosa cases will be further discussed.

The findings indicate that 11 of the nineteen subjects with significant weight loss at second assessment had also experienced a period of significant weight changes at first assessment. The fluctuations of weight may be considered indicators for the presence of dietary disorders.

8.7.2. Illustrative cases of subjects developing anorexia nervosa

To 11 lustrate how different psychological, anorectic and menstrual characteristics are involved in the onset of anorexia nervosa the following three cases will be presented.

Case 1.

The first girl is 19 years of age and has had a boy friend for two years.

The amount of information obtained on the first case is limited, due to the limited information that was provided by the subject. Important details were "forgotten' such as the names of the doctors she consulted for 'psychogenic weight loss and vomiting", resulting in extreme weight loss and her 'original body weight'.

At the time of the second assessment this girl was recelving psychiatric treatment and had gained some wight when compared to her lowest recent body weight. The percentage of weight lass of a "guessed ori- 
ginal body ight" and 'lowest body weight during treatment' is $22 \%$. Her cycles were absent but she used oral contraceptive medication. There were amenorrheic perfods of two months when contraceptive medication was stopped.

The scores of the Drive to Achieve, Negative Fear of Failure and Positive Fear of Fallure are in the $8 \mathrm{th}, 6 \mathrm{th}$ and $3 \mathrm{rd}$ decille respectively.

The NIS score on the first assessment was 10w (75), when compared to the mean ANIS score of the AF group (97.3). She regularly vomited and she had cut out fat food: she said she did both things because she could not tolerate 'heavy' food.

\section{Case 2.}

The second woman is a 23 year old a teacher. She was dilagnosed as having 'anorexia nervosa' by a medical doctor four months after the second assessment. Previously (4 years ago) she had experienced a perfod of significant weight loss ( $18 \%$ of original body weight) and amenorrhea when she had to do her final examination in secondary schoo1. While having 'better than average' grades in school, she was afrald of failing the examination. After this period she received dietary control and gained weight. Although she was still amenorrheic at first assessment.

The first investigation took place in the last year of her academic education. At that time she was living with her parents but reported at the interwiew that she intended to live independently from her parents after passing her examination and becoming financially independent.

The second measurement took place after she had graduated and had an occupation. She reported that 'practical reasons' made her decide to stay with her parents.

The score of the ANIS 1 is 133, but may be inflated, since she indicated on the item asking whether all questions have been answered truly: "often" and not "always".

Four months after the second measurement her weight loss had reached more than $20 \%$ of her original body weight. Her scores on the Drive to 
Achieve, the Negative and Positive Fear of Fallure are in the 6th, 7th and 8 th decile respectively. After a series of four interviews she admitted that her position as the only daughter in the row of five children made it difficult to leave home. Her parents had persuaded her not to leave home for several reasons. As these reasons appeared understandable to her, and she felt responsible for her parents, she could not leave.

Case 3.

This girl is 17 years old and developed anorexia nervosa during the time-interval of the investigation. She had experienced a weight loss of more than 25\%, secondary amenorrhea and had been diagnosed as 'anorexia nervosa' by an internitst.

Although she was not fat, she clailmed to feel fat. The ANIS score on the first assessment was high (152) compared to the norm of the AF group (97.3). The scores on the Drive to Achieve, the Negative and Positive Fear to Fail are in the 10 th, 8 th and 3 rd decile respectively.

She is the only child at home and was living with her parents. Although she preferred to live independently, she was not allowed to do so by her parents, who were convinced that not living home would result in less concentration and devotion to her studies. According to her standards she failed in her educational career. An actual failure as well as a threatening weight gain made her decide to go on a diet. She was determined not to fail in dieting this time. Increasing weight loss and emaciation has made her feel superior ('best of al1').

The three subjects can be classified as individuals with a strong Drive to Achieve and a high Negative Fear of Fallure.

A11 three subjects have experienced a perfod which can be qualified as stressfu1. It can be inferred that at least two subjects have been confronted with a situation in which they had to cope with an external stressful situation: they had to make a choice of wich the implications were unclear. They did not choose as they feared that

1. chosing was leading to fallure or could be considered as fall- 
ure:

2. chosing for themselves was to be disloyal to other responsibillties.

They did not express their anxiety and ambivalence to others but tried to cope by striving to be good and not to fail.

One may conclude that they might have denied their feelings in the threatening situation, but they did not deny their illness as they had actively tried to seek treatment.

\subsubsection{Illustrative cases of subjects with extreme weight lass}

The following three subjects satisfied the criterion of weight loss of body weight. Desplte remarkable weight loss they had not sought treatment for their weight loss.

They all had a prior history of eating problems, which they typified as '1 ack of control over eating'.

One of them reported at the first interview a recent weight fluctuation of 10 kilos. She was preoccupied with weight and dieting, felt guilty when she ate too much, and had used laxatives because of constipation.

A second subject reported during the interview at the second assessment a dally food-intake which was far below that reported at the first assessment. She also reported the second time not to have had weight $10 \mathrm{ss}$ but a stable body weight and to have regular menses. Yet she had consulted her general practitioner because she was experiencing an emotional stressful period. Her ANIS score on the first assessment was low (69). However, she also reported the first time not to be able to stop eating once started. She also marked the position 'often" and not 'always" when asked if the answers were honest.

The third girl also had restricted her food-intake when the foodintake of first and second assessment are compared. However, she reported not to have had weight loss and to have regular cycles. Although she admitted at the first interview being weight-conscious, 
counting calories and frequently attempting to change her eating behaviour, her ANIS score was not very high (92). She also indicated that her answers given on the ANIS were 'often' and not 'always' true. The change of dieting behaviour and weight loss was accompanied by an elevated Drive to Achieve and an increasing trust and confidence as measured by a decrease of the Negative Fear of Fallure and an increase of the Positive Fear of Failure.

This phenomenon has often been hypothesized to occur: (Bruch, 1973; Crisp, 1981) restrained eating is associated with a sense of control and confidence. Since the second assessment also was a momentary evaluation of the psychological and biological status of these subjects one cannot state that these individuals had developed anorexia nervosa as they did not satisfy the $25 \%$ weight loss of original body weight.

\subsection{Discussion}

Multiple regression analyses separately performed on the $A M$ and $B A$ group with weight loss or increased preoccupation with wheight provided that menstrual and anorectic as well as psychological characteristics (the drive to achieve) contribute to the degree of an increase of preoccupation with weight and dieting. Original body weight explained 15\% of the differences in weight loss in the AF group.

A decrease of weight was accompanied by a decrease of preoccupation with weight and dieting in AF subjects. An increase of preoccupation with weight and dieting was accompanied by an increase of body weight in the BA and AM group.

The occurrence of both phenomena does not reflect the onset of anorexia nervosa rather the onset of a related dietary disorder such as bulimia or bulfimia nervosa. The fact that the psychological risk group with elevated ANIS scores and lower body weights in the total AM group dropped out of the study may have contributed to the results. Since one might expect that this group was at risk of anorexia nervosa manifested in weight loss and increased preoccupation with weight and 
dieting.

One could argue that the 1 imited numbers of subjects and the relatively short observation time may also have contributed to the previous findings.

However, the number of subjects was based upon present knowledge about the incidence and prevalence of anorexia nervosa, which has been estimated as 1\% for severe anorexia nervosa (Crisp et a1.. 1976) and $5 \%$ for mild cases of the disorder (Button and Whitehouse, 1981; Mann et al., 1983). The occurrence of increased anorectic behaviour with slight weight loss in four subjects and the frequency of sixteen (16) cases of significant weight loss (6\%) does not seem incompatible with the previously mentioned $5 \%$ prevalence of mild forms of anorexia nervasa. The incidence of anorexia nervosa estimated at $1 \%$ is also concordant with previous findings.

The main reason for restriction to a minimum number of subjects is related to the choice of our measures: all subjects were personally interviewed and their actual body weight and height were measured. The results indicate that 4 of the 5 individuals with extreme weight loss would have been unidentified if the evaluation had only been based upon reported body weight and ANIS score. One of the three individuals with anorexia nervosa had been diagnosed within four months of the second assessment. Her change of weight between the first and second assessment is slight. All three cases were diagnosed by medical doctors, who were consulted for weight loss and vomiting, secondary amenorrhea and extreme loss of welight respectively. The duration of the disease in these three cases has been relatively short when compared to the duration of the disease of the AN group (mean duration of disease: 6 years). Interviews with these three individuals indicated that external stressful events had played a significant role. Coping with these externals demands had seemed impossible as reported by two individuals: chosing for theilr autonomy had been perceived as not being loyal, not being responsible and a lack of concern about others. The fallure to cope with these demands seems to have contributed to the onset or aggravation of symptoms.

knowledge of predisposing factors helps explain why a particular $111-$ 
ness is chosen. It does not, however, account for the timing of the disease (Weiner, 1977). Diseases coincide with events in an individual's life and with his emotional state. The failure to cope with a situation from which there seems no escape may result in a sense of hopelessness. This sense of hopelessness is generally considered to precipitate and determine the onset of disease.

Risk factor models in mental illness tend to fall into two types (Schwartz et al., 1982): 1. models which permit predictions about prognosis once someone has been diagnosed as having a given disorder and 2. models which attempt to predict who is at high risk premorbidly for developing anorexia nervosa, given a set of predisposing factors. Amorectic and menstrual as well psychological characteristics had been suggested to make individuals at risk of developing anorexia nervosa. The findings of this prospective study confirmed these postulations. The presence of menstrual, anorectic and psychological factors explained the degree of increased preoccupation with weight and dieting without weight loss in $66 \%$ of the AM and $39 \%$ of the BA group. The fact that a group considered to have an increased risk, due to the presence of secondary amenorrhea, the presence of the Negative Fear of Failure, an elevated ANIS score and a low body wht dropped out may have contributed to the absence of increased preoccupation with weight accompanied with loss of weight.

\subsection{Summary}

Multiple regression analysis of the anorectic, menstrual and psychological characteristics on weight loss and increased preoccupation with weight and dieting were performed. The results of each group indicate that the amount of explained variance that contributed to the onset of anorectic symptoms varied within a selectod group of AF. AM and $B A$ individuals. Body weight is a significant variable to explain the degree of weight loss in the AF group. Menstrual and anorectic characteristics contributed significantiy to the degree of increased preoccupation with ight and dieting in the AM group. Menstrual cycle 
and the drive to achieve explained at a satisfactorily level an increase of preaccupation with weight and dieting in the BA group. It seems evident that multiple factors, such as constitution, previous 1 iffe experiences, psychological and social factors which have not been investigated in our study contribute to the development of anorexia nervosa and related disorders.

Another factor that hampers the study of anorexla nervosa is inherent to the nature of the disorder: facts, thoughts and feelings may be denied or may contribute to the drop-out. The use of direct measures such as measuring boy weight instead of self-report of weight are recommended to study in anorexia nervosa. Early diagnosis of eating disorders is possible by focussing on the presence of anorectic behavlour in menstrual disorders. The $1 \%$ incidence of anorexia nervosa and 6\% incidence of eating disorders indicate that these eating disorders are very prevalent. The findings allso suggest that studying the occurrence of anorexia nervosa and related dietary disorders must not be carried out without adding direct and personal methods to obtain information, such as an interview and the measurement of actual body weight. 
PART III. IMPLICATIONS

Chapter 9. DISCUSSION

"Self-esteem, or lack of it, it of great importance in matters of achievement and fallure.

Ann Dal1y, Why women fail, 1979. 
Chapter 9. DISCUSSION

\subsection{Introduction}

The empirical findings of the transversal study are consistent with previous clinical descriptions and autobiographic accounts of anorexia nervosa, linking the excelling performances and great achievements of these patients to an underlying fear of incompentence and ineffectiveness. The results provide an illustration of what Macleod (1981, p.83) described in her autobiographic notes that anorexia nervosa patients are 'driven towards success by anxiety and the fear of failure'. The results of the longitudinal study indicate that on the basis of anorectic, menstrual and psychological characteristics the development of increased preoccupation with weight can be predicted satisfactorily. In view of the results of this study a number of methodologicai and theoretical issues concerning the contributory role of psychological factors in the development of anorexia nervosa are discussed. The purpose of this chapter is to reconsider the evidence that psychological variables, within the context of other predisposing factors, may play a role in the pathogenesis of anorexia nervosa. The methodological as well as practical implications of this study will also be discussed.

9.2. Methodological 1 imitations

One of the methodological issues of the present study concerns the generalizibility of the findings for other anorexia nervosa patients. One of the criteria to participate in this study was the informed consent of all subjects, including anorexia nervosa patients. In addition to ethical reasons this criterion was also chosen to eliminate the effect of denial in anorexia nervosa, as this factor may undermine the external validity of the findings. Moreover to eliminate 
the effect of hospltalization, only those anorexia nervosa patients who were not hospltallized for treatment were selected for study. so the data may be based on a selection of anorexia nervosa patients who can be considered "relatively good": except in two cases the anorectic symptoms were not so severe to be socially and educationally or vocationally debllitating. The question rises whether the data accumulated are generalizable to extreme, severe hospitalized anorexia nervosa patients. Bruch's (1978) clinical obserwation that "anorexia nervosa patients' during the height of the illness are constantly absorbed in proving their superiority or camoufllaging their inferiority' suggests that the findings in this study may also be extended to other more severe stages of anorexila nervosa. Moreover it may be expected that these psychological characteristics tend to aggrevate with the aggrevation of disease.

Another methodological problem concerns the use of quantitative measures to assess more objectively and at a larger scale the presence of features of anorexia nerwosa. The results of the findings of the comparison of the AN, AM and AF groups based on the ANIS score is not incompatible with the conclusions of Fichter and Keeser (1980) that the ANIS is a reliable and valid instrument to differentiate between anorexia nervosa patients, mild and non-anorectic subjects who had been already diagmosed. These findings provide a measure of sensitivity.

In this study other weight-preoccupied individuals of both nomal and overweight and not satisfying the criterila for weight loss of anorexia nervosa had elevated scores on the ANIS. The presence of 'false pasitives" suggest that the ANIS lacks specificity.

It is unclear whether the fact that 'false negatives' have been found Is related to the lack of sensitivity or the denial of 111 ness in anorexia nervosa. The issule of 'dental of 111 ness' in anorexia nervosa has been recently discussed by Vandereycken and Vanderlinden (1983). The authors administered the Eating Attitude Test (EAT) (Garner and Garfinke1, 1979) in forty (40) hospitalized, mostly severe cases of anorexia nervosa. They found that thirteen (13) patients could be classified as 'deniers', eleven (11) as 'admitters" and sixteen (16) 
as "nomal" scorers on the EAT and questioned the use of self-report In anorexia nervosa. However, 'denial' had not been operationally defined and the generalization of these results based upon severe hospitalized cases may not be justified since the authors do not menthon that their patients gave 'informed consent" to participate in the study.

Moreover the findings in our study indicated that denial of symptoms may also affect other methods of obtaining information such as an interview. Hence the tendency to deny is by no means unique to selfreporting questionaires.

A third methodological issue refers to the representativeness of the remaining subjects who took part in the second assessment of the longitudinal study. However, much of the drop-out rate in the AF group is related to the expected percentage of pupils leaving or finishing their school. Analysis of respondents and non-respondents of each group indicated that the at risk AM subjects dropped out and may be of significance to the results of this study. It is also advisable in order to minimize the drop-out rate to compensate subjects financially for their participation in longitudinal studies.

\subsection{Theoretical inferences}

The onset of disease is related to actual or percelved threatening circumstances and the success or failure to cope with these changing demands.

The observed combination of a high drive to achieve and a high negative fear of fallure in anorexia nervosa patients can be interpreted as an indicator for the need to be competent and a sense of incompetence. From a psychosomatic point of view individuals who can be psychologically characterized by a low sense of competence are supposed to be sensitized to changing external demands or life-events (Alexander, 1950). The central concept that the disease is a consequence of the fallure to adapt to various life situations and not a direct consequence of these situations has come from wolff 11950 ; 
cited in Weiner, 1977, p.11). From his study Wolff (1950) postulated that persons who feel threatened actually long for emotional care and support but they repress this longing and 'cover' it with insistent assertions that they can manage and are strong and able to cope. In the face of these threats, the person protects and defends himself with an 'organismic' response. According to Wolff blological, psychological and environmental factors are involved, since he asserted that "the bodfly responses are dictated by such factors as natural endowment, past experience and the specific situations, perceived as stressful '. From Wolff's studies one may conclude that these emotional reactions and defense mechanisms commonly occur in all diseases. Manifestations of this psychological and bodily defense mechanisms have also been mentioned for anorexia nerwosa: the hyperactivity in athletics or other sports, intellectual activities and the occurrence of amenorrhea have been emphasized as symptoms preceding the anorectic behaviour and weight loss. However, the psychological defense mechanisms of anorexia nervosa were not the issue of this study. The interviews with the three subjects developing anorexia nervosa revealed that these subjects had previous weight loss and had been preoccupied with dieting and weight: one had started dieting and continued this successful attempt to lose weight. One had tried to diet several times and, according to her standards, had failed to lose weight and to control her weight at a minimum level. The third individual did not intentionally go on a diet the first time, but did not feel hungry during stressful times. The fact that initial weight loss received social approval, made her start dieting in order to lose weight. In all three cases amenorrhea was an early symptom preceding significant weight loss.

The quantitative results also indicate that menstrual disorders can be considered a significant early symptom explaining an increase of concern about weight and dieting. Thus, the absence or irregularity of menstrual cycle as a crucial and early feature offers the opportunity to identify disturbed eating behaviour early, including early anorexia nervosa, mild anorexia nervosa and bul imia nervosa.

Minuchin et a1. (1978, 1983) emphasized the role of the parents and 
the family as to modeling coping behaviour of the child with conflictuous external demands. However, parents' characteristics and patterns of family interaction had not been examined in this study. Yet the presence of both the drive to achieve and the negative fear of fallure as characterizing features of anorexia nervosa stresses the need to reconsider the factors and processes which lead to the development of a negative fear of failure.

\section{9:3.1. The development of the negative fear of faiture}

The excellent performances and great achievements of anorexia nervosa patients can be understood as efforts directed toward hiding a basic sense of incompetence and reflect the general fear of fallure. According to Fromm (1963), the fear of failure in men can be described as a fear of failure to pass a test, whille in women 'the fear of failure is inextricably bound up with her anatomy and the role in the sexual act' (Fromm, cited in MacLeod, 1981, 1982). According to Erikson (1952) the fear of fallure in women reflects the fear of being left alone (Erikson, 1952) or, in other words the fear of rejection. In view of these theoretical assumptions it can be postulated that the fear of failure in anorexia nervosa patients will also be demonstrated in particular in an interpersonal relationship.

An interesting theory on the development of the fear of fallure was provided by Birney et al. (1961) (Chapter 8.2.) who defined failure as the nonattainment of a prescribed standard'. However, according to these authors the negative fear of fallure is not directly resulting from nonattainment, rather than from the negative implicatians of nonattainment such as lowered self-estimate or social devaluation. By referring to the implications of nonattainment, Birney et al. emphasized the role of consequent factors particularly social devaluation in the development of the negative fear of fallure.

If the experience of failure is associated with social devaluation, then the fear of failure may reflect a fear of social disapproval. In a recent study (Weeda-Mannak et al., 1983) it was found that the Drive 
to Achieve is positively correlated with the Approval Motive, a tendency to seek social approval. Boskind-Lodah1 (1976, 1977) postulated that anorexia and bulimia nervosa patients mainly see achievement in terms of what rewards it could provoke from others. Thus the fear of failure in women is considered to reflect basically the fear of rejection.

The fear of rejection had not been operationally defined and systematically examined in this study. However, fear of rejection in personal contact has been frequently acknowledged and mentioned by clinicians who treated many anorectic patients and stated that this fear of rejection usualiy is masked by an strong negativism and indifference (Selvini Palazolli, 1974; Bruch, 1978; Garner et al., 1982) in the social contact.

Since situations or demands, perceived as threatening usually generate langings for emotional care and support, in anorexia mervosa patients, this longing may trigger their basic fear of failure in an interpersonal relationship. This need for care may be covered up with demonstrations that the patient is capable and independent.

9.3.2. The role of parent-child interaction in the development of the negative fear of failure

The presence of both the motive to achieve and the motive to avoid failure is characteristic for anorexia nervosa patients. As the combination of the drive to achieve and the negative fear of failure did neither occur frequently in a representative sample of Dutch population nor in the groups studied it is necessary to comment on the development of the negative fear of fallure in anorexia nervosa patients. Psychological characteristics like motives are learned (McClelland, 1961, 1971); accordingly the role of parent-child interaction is reviewed and discussed in this section.

Hermans (1980) observed the social interaction of parents of 9 to 10 year old children with high Achievement Motive scores (AM) and high Negative Fear of Fallure scores $(\mathrm{F}-)$. He found that parents with 
children with a strong Negative Fear of Failure failed to react to expressions of insecurity of their child manifested in the child's asking if 'what he did was good". Hermans interpreted this lack of response as the 1 ack of providing prescribed standards for the chlld. Moreover these parents did not give feedback by providing reinforcements when the child gave a correct solution. In view of these findings Hermans criticized Birney's et al. postulation that only negative reinforcement (social devaluation) rather than the deprivation of positive reinforcement contributes to the development of the negative fear of faiture. Hermans' pastulation seems to agree with previous findings of Teevan and McGhee (cited in Birney et al.. 1969) that parents of children with a high negative fear of failure do not positively reinforce successful performances of their children, and gave negative reinforcement to failure in performing. Hermans postulated that the lack of parental response co child"s insecurity as well as the 1 ack of confïmation of attainment of prescribed standards lead to a deficient cognitive and affective structure of the child. This lack of structure results in a negative fear of failure that makes a child inadequatiy equipped to cope with situations which are relatively unstructured; in situations which are structured, however, children with a negative fear of faillure manage to cope well.

In relation to anorexia nervosa, Bruch (1977, p.4) has emphasized the developmental deficits of anorexia nervosa patients in relation to the lack of parental confirmation of child-initiated clues early in childhood.

In a Dutch study (Tak, 1971, cited in Hermans, 1978) on the relationship of the three scales of the Achievement Motivation Test with the psycho-social stages of human development (Erikson, 1952), the highest correlation $(-.40)$ was found between the fear of fallure and the aspect 'basic trust'. A high score on the Negative Fear of Fallure was associated with less basic trust, a low score with more basic trust. chlidren with a strong positive fear of fallure showed more bastc trust when compared with chlldren with less strong positive fear of fatlure scores.

Selvini Palazolli (1974, p.58) pointed at the fundamental importance 
of the primary interpersonal relationship for the perceptive and cognitive development of children. If a parent is emotionally blind to the individual needs of their child, the child will not learn to perceive and satisfy its own needs appropriately. Three major and closely connected factors are considered of primary importance for the Interpersonal and social development: the need for satisfaction, the search for security and the implenentation of the power motive (Sullivan, cited in Selvini Palazolli, 1974). The power motive, represent an evolutionary impetus to test one's own capacity and ability and has al so been referred to as an individual's 'third dimension' (Langeveld, $1969 \mathrm{a}, \mathrm{b})$.

The power motive is consolidated on the one hand by the attainment of satisfaction and security (basic trust) and on the other hand by the successful attempts to establish the validity of one's own actions (attainment of prescribed standards). According to this theory, the development of basic trust and self-esteem depends on the infant's discovery of its own power to attain desirable ends with the means at his disposal. If this fundamental discovery is lacking, a child will feel insecure, incompetent and incapable. If the prescribed standards of patients and adopted by the child are ambitiously high, then the risk of nonattainment will increase and hence favor the development of a feeling of inadequacy.

Bruch stated that in the early childhood of anorexia nervosa patients things were done according to the mother's decisions and feelings and not according to the child's needs. By not providing appropriate responses to a child's needs, the parent prevents the child from developing a stable inner affective and cognitive structure.

Yet, one cannot infer causation that parents' lack of appropriate responses and not affective and cognitive structure cause the negative fear of failure. Yet, one may hypothesize that the lack of parental structure may lead to a lack of affective and cognitive structure in the child. This lack of inner structure increases the risk of failure, or perception of failure in situations where an outer structure is not provided.

Summarizing the findings one may conclude that 
- demonstration of inappropriate behaviour neglecting the child's needs

- the ambiguity of prescribed standards, and

- the absence of confirmation of appropriate responses in the child are determining factors in the development of the negative fear of failure.

The feeling of competence is the result of an individuals capacity to interact effectively with its environment (White, 1959; cited in Hermans, 1980), while The development of an effective ego is primarly effected by successful and gratifying experiences (Kardinar and Spiege1, 1947). Thus a child who is deprived of reinforcement either by parents or significant others will lack a crucial form of feedback and is likely to develop a negative fear of failure and a sense of incompetency.

In literature this sense of incompetency is considered a predisposing factor in developing anorexia neryosa. Accordingly subjects with a negative fear of failure are considered to have an increased risk of developing anorexia nervosa. Unfortunately this group at risk dropped out of this study, but prospective studies must be carried out in the future to determine the predictive value of the negative fear of fallure. The development of the fear of failure is not exclusively due to parents' interaction but to educational and socio-cultural factors as well. The social factors which may also contribute to the development of this fear will be discussed.

9.3.3. The role of society in the development of the negative fear of failure

In western-industrialized countries the phases of puberty and adolescence are characterized by many developmental tasks, one which is adaptation to a new body shape and new social demands. The entrance to puberty and adolescence confronts an individual with his own resources to cope with new external demands. For young women an explicit and 
clear external structure is lacking due to change in expectancies and roles. It has been postulated that this wider range of choices is overwhelming for adolescent wo depends on external structure due to a lack of inner structure (Garner et a1., 1983). The dependency on an external structure in anorexia nervosa patients was empirically validated as a strong negative fear of failure in anorexia nervosa patients. The change in expectancies for the role of women can be interpreted as an ambiguity of the prescribed standards. Moreover despite an increasing number of choices, the choice of another role than the traditional feminime one is (in fact) difficult since other choices are contradictory and conflicting.

Since soctal expectancies are irreconcilable and may lead to conflicts of fallure (Birney, 1950) prescribed standards will not be attained or attainment may not be socially reinforced. It may not be surprising that anorexia nervosa and other related dietary dilsorders such as bulimia and bulimarexia occur predominantly in females who are high achievers academically and above average in intellect (Boskind-Lodahl, 1976, p.254), women who are considered at an increased risk of failure (Dally, 1979).

\subsection{Implications}

\subsubsection{For research}

The drop out of the group who had "secondary amenorrhea, concern about welght and dieting and a strong negative fear of fallure' is a serious methodological problem, since this fact may have significantly influenced the results of this study.

Future research must be aimed at following such a group at risk to determine if anorexila nervosa or a related dietary disorder develops. To guarantee that data will be obtained in case of drop-out, other individuals, such as relatives or a husband, must, in addition, also be approached to participate in the study.

Future studies must also be directed at obtaining data on the role of 
social and interactional factors in the development of the fear of faillure.

\subsubsection{For practice}

It has been found that menstrual, anorectic and psychological characteristics account for a satisfactory amount of variance in the development of increased preoccupation with weight and dieting.

As the increase of preoccupation with weight and dieting was accompanied by an increase of weight gain it can be concluded that these characteristics contribute to the early identification of eating disorders other than anorexia nervosa alone.

The findings of this study stress the importance of what has been recommended earlier: in case of secandary amenorrhea attention should also be paid to nutritional (Wentz, 1980) and psychological factors (Akse1, 1979). It implies that hormonal treatment may not be effective as long as the amenorrhea is related to the presence of nutritional and psychological factors.

An important factor that may hamper the early identification and diagnosis of anorexia nervosa is the denial of symptoms. This denial may lead to detecting false negatives when only self-reporting measures are used.

It is evident that the ANIS is developed for diagnostic purposes in research and not for making diagnoses in practice. No diagnosis of anorexia nervosa or any other disorder can be based upon the sumscore of a questionaire only. Additional information such as the measurenent of body welght is necessary.

The results of this study indicate that anorectic symptoms are relatively stable characteristics. The opinion that anorectic symptoms are only "temporarily" and spontaneously wi11 disappear is not confirmed.

The fact that three females who develop anorexia nervosa had sought treatment for their problems suggest that prevention of anorexia nervosa at a secondary or tertiary level is possible.

Secondary prevention of other eating disorders than anorexta nervosal 
is necessary since it has been found that anorectic symptoms tend to be consistent. Prolonged starvation is a facilitating factor of extreme preoccupation of weight and dieting. Starvation factors have been found to predispose to development of anorexia and bulimia nervosa.

\subsubsection{For intervention}

To elicit information of an anorexia nervosa patient may be difficult due to the psychological characteristic negative fear of failure. Individuals with a strong negative fear of fallure are characterized by a insufficient affective and cognitive inner structure. It is important to provide a high degree of external structure for the interview as a high degree of structure is needed to experience a sense of confidence and security.

Hermans (1980) provided practical guidelines to provide an appriate situational structure. These guidelines are specified to the situation with anorexia nervosa patients:

1. Use relevant questioning rather than 'wait and see' what the patient will tell.

2. Use questioning to know 'what' is experienced rather than asking and interpretating "why' is it experienced.

3. Provide feedback and information.

The affective structure of the interview can be best qualified as the establishment of 'rapport' (Beck et a)., 1979) which refers to a harmonious emotional and intellectual accord between people. Rogers (1971) has also outlined the necessary and sufficient conditions to establish 'rapport' in a human relationship.

\subsection{Summary}

Anorexia nervosa patients are characterized by a strong motive to achieve and high negative fear of failure. 
The role of social factors which predispose a person to develop anorexia nervosa or a related dietary disorders need to be studied in the future.

Future research must also be concerned with following groups at risk. To minimize the effect of the drop-out on the collection of data, relatives must also be approached to participate in such a prospective study.

The results indicate that to identify early anorexia nervosa or a related dietary disorder attention must be paid to nutritional and psychological factors rather than focussing on biological factors only in menstrual disorders.

General, practical guidelines are provided for providing a necessary affective and cognitive structure for the interview. 
167

\section{SUMMARY}


SUMMARY

This dissertation describes the results of a study on the early identification of anorexia nervosa.

It consists of three parts:

1. Theoretical aspects of anorexia nervosa

2. Empirical results of this study

3. The implications of the results

Rationale of the study

Comparing the long-term outcome of treated and untreated anorexia mervosa patients leads to the conclusion that the benefits of medical treatment are marginal. As long as the pathogenesis of anorexia nervosa is not understood, treatment remains symptomatic and the longterm outcome may reflect its natural course as well as the effect of therapeutic treatment.

The fact that a short duration of symptoms is associated with a favourable prognosis indicates that efforts must be made to identify anorexia nervosa early. Vet due to the incomplete understanding of the disorder it is difficult to diagnose anorexia nervosa early in its course.

It is still unknown whether severe anorexia nervosa differ from mild anorexia nervosa in other aspects than the amount of weight loss and secondary effects of severe starvation. If other than anorectic differences exist, it is unclear whether menstrual or psychological features contribute to the onset and course of anorexia nervosa. In order to examine the discriminative value of anorectic, menstrual and psychological characteristics a transversal study comparing anorexia nervosa patients, patients with secondary anenorrhea, fenale ballet dancers and control subjects was carried out. Determination of the predictive value of anorectic, menstrual and psychological characteristics on the development of anorexia nervosa was done in a followup study of secondary amenorrhea patients, ballet dancers and control 
subjects.

Chapter 2 reviews the present understanding of anorexia nervosa that has evolved since the earlifest medical account in 1694. The characteristic somatic, psychological and behavioral features of amorexia nervosa are described.

The common clinical impression is that anorexia nervosa and related dietary disorders have become more prevalent. Recent epidemiological studies on severe anorexia nervosa and subclinical anorexia nervosa are reviewed. There is insufficient epidemiological evidence to decide with certainty that the increase of admissions of anorexia nervosa patients reflect an actual increase of the disorder. However, it is not very likely that an increase of anorexia nervosa diagnoses may only be related to improved public and medical awareness.

The prognosis of anorexia nervosa is usually not favourable as has been found in several follow-up studies. Despite methodological differences between prognostic studies, it is generally found that longterm recovery is more related to patients' characteristics than to the different way they have been treated. Attention is paid to factors which favor the prognosis of anorexia nervosa.

Despite methodological differences prognostic studies have obtained similar results indicating that the long-term outcome of anorexia nervosa is favored by a short duration of disease, as measured by the time of duration between onset of symptoms and treatment.

Studies of anorexia nervosa are frequently characterized by methodological difficulties and shortcomings. First the criteria for diagnostic have varied widely. Second, the status of anorexia nervosa as a distinct disease entity has been disputed. Reference is made to the disagreements of anorexia nervosa as an extreme point on a continuum of preoccupation with wight and dieting rather than a distinct disease entity.

Chapter 3 reviews the methodological difficulties of psychosomatic research and the clinical approach. The major methodological shortcomings of research on anorexia nervosa are summarized. 
Chapter 4 reviews the biological, psychological and environmental factors that have been considered to predispose a person to anorexta nervosa. Special attention is paid to the psychological risk factors. The early parent-child relationship and patients of family interaction as well as socio-cultural influences are discussed.

Chapter 5 the study provides an outline of the present. The purpose of research are described. Hypotheses were generated from both points of view on anorexia nervosa as an extreme point on a continuum or a distinct disease entity steming from psychological deficits.

The choice of the transversal and longitudinal study design was related to the research questions. The criteria for selection of groups and subjects are presented. The measures, procedures and statistical methods which were used are described.

Chapter 6 presents the results of a comparison of the anorectic and psychological characteristics of anorexila nervosa patients, secondary amenorrhea patients and asymptomatic females. It is show that secondary amenorrhea patients share to some degree the anorectic characteristics of anorexia nervosa patients. However, anorexia nervosa patients can be psychologically differentiated from secondary amenorrhea patients and asymptomatic females with respect to a striving to excel in performance in order to avoid failure. Endocrinological differences between anorexia nervosa and secondary amenorrhea patients were not significant.

The hypothesis that anorexia nervosa patients can be psychologically differentiated from other subjects, including those individuals who to some degree share the anorectic symptoms was confirmed.

Chapter 7 provides the results of a study on the presence anorectic and psychological differences comparing anorexia nervosa patients. Ballet dancers of sixteen years of age and older were compared with anarexia nervosa patients and ballet dancers younger than sixteen years were compared to controls of the same age.

The emphasis on thinness in female ballet dancers may lead to extreme 
voluntary weight reduction with a fear of fatness, anorectic behaviour and amenorrhea. The welght loss and anorectic symptoms may be so severe as to satisfy the major diagnostic criteria for weight loss and fear of fatness of anorexia nervosa. It has also been found that ballet dancers share the striving for perfection with anorexia nervosa patients. Previous studies, however, have suggested that perfectionism in ballet dancers stems from a basic drive to achieve, rather than an avoidance of fallure. The hypothesis that a strong drive to achieve to compensate for the fear of fallure is characteristic for anorexia nervosa patients was confirmed. A strong drive to achieve originating in the positive failure appears to characterize young ballet dancers of a11 ages.

Chapter 8 presents the results of multiple regression analyses of the role of anorectic, menstrual and psychological characteristics in the onset of anorectic symptoms.

Anorectic, menstrual and psychological characteristics have been chosen as independent variables, weight loss and increased preoccupation with ight and dieting as dependent variables. The statistical analyses performed indicate that the percentages of variance are sufficient to predict which individuals who are at high risk in the secondary amenorrhea group and the ballet group, given a set of predisposing factors will develop increased preoccupation with wight and dieting.

It was found that menstrual cycle, anorectilc symptoms and the drive to achieve contributes to the degree of increased preoccupation with weight and dieting in the selected subjects.

Three cases of subjects who were diagnosed as anorexia nervosa patients during the period of study and three cases with extreme whight loss are presented for 111 lustration.

Chapter 9 concerns the methodological issues of our own study, such as the generalizibility of the findings; the effect of drop out and the denial of symptoms in anorexia nervosa patients.

The theoretical implications of the findings, especially in relation 
to the negative fear of fallure are discussed. Reference is made to the development of the negative fear of failure in relation to the parent-child interaction and socio-cultural demands. Attention is also paid to the practical implications of the research findings for future research, clinical practice and intervention. 
SAMENVATT ING 
SAMENVATTING

Dit proefschrift heeft tot doel de resultaten wan een onderzoek naar de vroege herkenning van anorexia nervosa te beschrijuen. De motivatie voor dit onderzoek wordt in een inleidend hoofdstuk beschreven. Na deze introductie is het proefschrift opgebouwd uit drie onderdelen:

\section{Deel 1. Theoretische aspecten}

Het eerste deel bestaat uit 5 hoofdstukken. In deze hoofdstukken wordt een overzicht gegeven van de huidige stand van zaken met betrekking tot onderzoek en theorievorming van anorexia nervosa.

De belangrijkste theoretische controversies en methodologische problemen die een belemmerende rol hebben gespeeld bij het onderzoek en de theorievorming met betrekking tot anorexia nervosa, worden in een afzonderl ijk hoofdstuk 3 beschreven.

De theoretische vooronderstellingen van het onderzoek en de uitwerking in de opzet van dit onderzoek worden in de hoofdstukken 4 en 5 gepresenteerd.

\section{Deel 2. Empirische aspecten}

Het empirische deel omvat de hoofdstukken 6,7 en 8 .

Het eerste onderzoek, beschreven in hoofdstuk 6 , had tot doel na te gaan of er behalve kwantitatieve verschillen in de mate van preoccupatie met gewicht en daarmee samenhangend gewichtsverlies, psychologische verschillen aanwezig zijn tussen anorexia nervosa patienten, patienten met menstruatiestoornissen en een controlegroep.

Het tweede onderzoek wordt in hoofdstuk 7 beschreven. In dit hoofdstuk worden de psychologische verschillen uit het eerste onderzoek nader getoetst bij vrouwelijke ballet leerlingen. De resultaten van het longitudinale onderzoek, dat tot doel had na te gaan wat de rol van anorectische en psychologische 
kenmerken is op de ontwikkeling van anorexia nervasa, worden beschreven in hoofdstuk 8 .

Deel 3. Implicaties

De implicaties van dit onderzoek voor toekomstig onderzoek, de vroege diagnostiek en interventie van anorexia nervosa worden in het laatste hoofdstuk 9 nader uitgewerkt.

Hoofdstuk 1. Inleiding

De behandeling van anorexia nervosa is langdurig en intensief. Onderzoek naar duurzame genezing bij anorexia nervosa is in Nederland niet verricht. Onderzoek dat in het buitenland werd verricht, geeft weinig reden tot optimisme over de prognose van het ziektebeeld: $40 \%$ van de patienten geneest, $30 \%$ verbetert niet, maar verslechtert ook niet en $30 \%$ verslechtert of overifjdt. Vergel ijkt men deze resultaten met het percentage herstel bij niet-behandelde anorexia nervosa patienten ( $40 \%$ herstelt spontaan, $30 \%$ herstelt niet en verslechtert niet en $30 \%$ verslechtert of overlijdt), dan kan men slechts concluderen dat het effect van behandeling marginaal is.

Het feit, dat de prognose van anorexia nervosa bovendien een sterkere samenhang vertoont met z.g. patienten-kenmerken (met name 'ziekteduur') dan met de gebruikte therapeutische methode, vormde de aanleiding tot dit onderzoek naar de vroege herkenning van anorexia nervosa. De meeste studies over anorexia nervosa zijn gebaseerd op opgenomen patienten met een ernstige vorm van anorexia nervosa. Deze gegevens bieden echter weinig mogelijkheden om anorexia nervosa in een vroege fase te herkennen. In studies over milde vormen van anorexia nervosa is nagelaten deze proefpersonen te volgen om te onderzoeken of deze 'subclinische' anorexia nervosa patienten zich later inderdaad tot 'echte' anorexia nervosa patienten ontwikkelden.

Anorexia nervosa wordt algemeen opgevat als een psychosomatisch ziektebeeld. Dit betekent dat anorexia nervosa wordt gekarakteriseerd door een verscheidenheid aan lichamelijke en psychische symptomen. Dit betekent ook dat de ontwikkeling van anorexia nervosa het resultaat 
wordt geacht van een samenspel tussen biologische, psychologische en sociale factoren. Hoewel in het onderzoek vooral de nadruk is gelegd op gedrags - en psychologische variabelen, is ernaar gestreefd ook aan de biologische en socio-culturele factoren aandacht te schenken. Met het oog op de vraagstelling was het onderzceksteam multi-disciplinair samengesteld.

Het onderzoek vond van 1981 tot 1984 plats aan de Rijksuniversiteit Limburg. De proefpersonen waren afkomstig uit heel Nederland.

\section{Hoofdstuk 2. Anorexia Nervosa}

Anorexia nervosa betekent letterlijk 'verijes van eetlust door nerveuze oorzaak'. Deze diagnostische benaming is echter onjuist, aangezien gevoelens van eetlust zelden afwezig zijn. Anorexia nervosa patienten gedragen zich alsof ze geen honger hebben, uit angst de controle over het eten te verliezen als ze aan hun eetlust toegeven. Anorexia nervosa wordt gekenmerkt door een aantal lichamelijke symptomen: vermagering, het uitblijven van de menstruatie (amenorrhoe), kouwelijkheid, trage hartslag, lage bloeddruk en soms een fijne donsachtige beharing. De meeste lichamelijke symptomen zijn een rechtstreeks gevolg van het hongeren en de sterke vermagering, en verdwijnen weer als het gewicht is hersteld. Er is echter geen duidelijke causale relatie tussen gewichtsverlies en het optreden van de amenorrhoe. De amenormhoe kan voorafgaande aan het gewichtsverlies optreden en kan ook blijven na gewichtsherstel.

vaak zijn de psychische gevolgen van het hongeren b.v. preaccupatie met voedsel en afname van sexuele gevoelens en emoties ten onrechte beschouwd als de typerende psycholagische kenmerken van anorexia nervosa. Als de belangrijkste psychologische karakteristiek van anorexia nervosa werd echter het gevoel van ineffectiviteit en incompetentie genoemd, d.w.z. dat de patient het gevoel heeft dingen te doen omiat de ongeving ze verwacht en niet ondat ze dat zelf wil.

Er wordt veelvuldig gesignaleerd dat anorexia nervosa toeneemt in de westerse geindustrialiseerde lianden. Uit het feit dat anorexia nervosa 
nu vaker wordt gediagnosticeerd dan vroeger, mag, gelet op het tekort aan epldemiologische gegevens, niet zonder meer worden geconcludeerd dat anorexia nerwosa toeneemt. Het lijkt echter onwarschijnlijk dat de toename van gediagnosticeerde patienten alleen een gevolg is van een betere herkenning en diagnostiek.

Hoofdstuk 3. Methodologische aspecten van anorexia nervosa onderzoek.

Anorexia nervosa onderzoek wordt vaak gekenmerkt door methodologische onvolkomenheden. Sommige methodologische onvolkomenheden zijin inherent aan het gegeven dat anorexia nervosa wordt bepald door een groot aantal lichamelijke, psychische en sociale factoren, warvan slechts een deel kan worden onderzocht. Andere problemen zijn terug te leiden op belangrijke theoretische controversies.

Enkele van de theoretische controversies zijjin $0 . \mathrm{m}$. het verschil in definitie en de diagnostische criteria van anorexia nervosa. Een aantal auteurs omschreven anorexia nervosa als 'extreem gewichtsverlies door psychische oorzaak'. Aangezien gewilchtsverlies eveneens voor kan komen bij andere psychische of emotionele stoornissen, b.v. depressie of schizophrenie, werd deze 'ruime' diagnose ernstig becritis seerd.

Een onderzoek dat aan de Rijksuniversiteit Limburg werd uitgevoerd in 1977 en 1978 bij huilsartsen en andere medisch specialismen, toonde aan dat deze slechts ten aanzien van het criterium 'gewichtsverlies bij afwezlgheld van een lichamelijke oorzaak" een unaniem oordeel hadden. Een tweede theoretische controversie heeft betrekking op de status van anorexia nervosa als een zelfstandig ziektebeeld.

Recente onderzoeken hebben aangetoond, dat milde vormen van anorexia nervosa frequent voorkomen. Deze onderzoekers hebben op basis van hun resultaten het standpunt ingenomen, dat anorexia nervosa een extreem punt is op een continuum van gedragingen, dat gericht op vermagering en consequent gewlchtsverlies. Andere auteurs daarentegen hebben gepostuleerd dat anorexia nervosa $\mathrm{kwal}$ itatief meer is dan een uit de hand gelopen dieet, gezien de ernstige psychologische defecten die aan 
het dieet houden ten grondslag liggen.

Met name deze theoretische uitgangspunten over anorexia nervosa als een extreem punt op een continuum versus anorexia nervosa als een kwallatief te onderscheiden ziektebeeld op grond van psychologische kenmerken, zijn voor het onderzoek naar de vroege herkenning van cruciaal belang.

Hoofdstuk 4. De vroege herkenning van anorexia nervosa.

Onderzoek naar mogelijke etiologische factoren bij anorexia nervosa vond doorgaans plaats bij ernstige, gehospitaliseerde patienten met een lange ziekteduur. Op basis van deze gegevens worden in de literatuur een aantal predisponerende factoren genoemd, die biologisch, psychologisch en sociaal van aard zijn. Deze factoren zullen worden toegelicht in hoofdstuk 4 .

Biologische factaren.

Het feit dat anorexia nervosa bij moeder en kind of bij meerdere kinderen in éēn gezin kan voorkomen, werd beschouwd als bewïjs, dat anorexia nervosa een genetische oorzaak had. ook het gegeven, dat hypothalame afwijkingen, die manifest worden in het uitblijven van de menstruatie, bij anorexia nervosa voorkomen, werd ten onrechte gebruikt ter staving van de theorie dat een afwijking in het hypothalame functioneren primair is.

Momenteel wordt niet uitgesloten dat er sprake kan zijn van een specifieke biologische kwetsbaarheid, bijvoorbeeld in de hypothalamus; men veronderstelt echter dat deze kwetsbaarheid pas manffest wordt onder psychilsch stressvalle omstandigheden.

Psychologische factoren

Psychologische defecten m.n. het gevoel van incompetentie bij anorexia nervosa patienten zijn vaak minder herkenbaar door de uitstekende prestaties die worden behaald en het aangepaste gedrag dat wordt gedemonstreerd.

Het aangepaste gedrag en het streven naar perfectie, waren in die gevallen evenwel slechts middelen om gevoelens van incompetentie en 
minderwatrdigheid te compenseren.

Gezins-en maatschappelijk factoren

De psychologische tekorten, $m . n$. het gevoel van incompentie werden verondersteld samen te hangen met de vroege ouder-kind interacties. Als gevolg van het felt dat ouders, in het bijzonder de moeder, de zorg voor het kind bifna uifsluitend baseerde op wat zij dacht dat goed was en minder op de behoeften van het kind, werden de eigen gevoelens en behoeften wan het kind niet bevestigd en gesanctioneerd. omdat het kind niet leerde ap zijn efgen gevoelens, gedachten en impulsen te vertrouwen, blijft de ontwikkeling van een sterk ik-gevoel anvol doende.

De wijze waarop gezinsleden met elkaar omgaan, is eveneens genoemd als predisponerende factor voor de ontwikkeling van psychosomatische zlekte in het algemeen en anorexia nervosa in het bijzonder.

Bovendien, zo werd verondersteld, wordt dit zwakke zelfgevoel ook niet gestimuleerd door de culturele en matschappelijke opvattingen over de rol van de vrouw. Met name is gewezen op de specifieke nadruk die de matschappij legt op het slankheidsideal voor vrouwen.

Wat de invloed van deze risico-factoren op het ontstaan van anorexia nervosa is, kan niet worden nagegaan met de bestaande, transversale onderzoeksmethoden. Met name epildemiologische methoden waarbij personen met milde anorexia nervosa en gezonde personen worden gevolgd om na te gaan öf, en in relatie tot welke kenmerken, de ziekte ontwikkelt, zijn nodig.

Voor een vroege herkenning van anorexia nervosa dienen de volgende onderzoekswragen te worden beantwoord:

1. Kunnen anorexia nervosa patienten, behalve in de mate van preoccupatile met gewicht en gewichtsverlies, psychologisch worden onderschelden van controle proefpersonen, door hun streven naar hoge prestaties om falen te vermijden?

2. Kunnen anorexia nervosa patienten, behalve in de mate van preoccupatie met gewicht en gewichtsverlies, van personen met milde symptomen psychologisch worden onderscheiden, door hun streven naar hoge prestaties om falen te vermijden?

3. Is er een relatie tussen de aanwezigheid van anorectische symptomen 
en het ontstaan van anorexia nervosa?

4. Is er een relatie tussen de aanwezigheid van menstruatie-stoornissen en het ontstaan van anorexia nervosa?

5. Is er een relatie tussen psychologische kenmerken, met name de drang tot hoge prestatie en het vermijden van falen en het ontstaan van anorexia nervosa?

Hoofdstuk 5. De opzet van de studie.

Uitgaande van de vraagstellingen van het onderzoek is, om de eerste twee vragen te beantwoorden, gekozen voor een transversaal onderzoek. Voor de vragen 3,4 en 5 werd voor een longitudinaal onderzoek opgezet.

A1s te onderzoeken groepen werden gekozen:

1. Anorexia nervosa patienten (AN),

2. Patienten met secundaire amenorrhoe (AM),

3. Een controlegroep (AF),

Door het criterium 'uitblijven van menstruatie" kwamen uiteraard siechts vrouwen in aanmerking voor het onderzoek. De leeftijdscriteria waren minimaal 11 en maximaal 40 jaar.

Om de anorectische (streven naar vermagering, laag lichaamsgewicht), de menstruele (amenorrhoe) en psychologische kenmerken (het streven naar prestatie en faalangst) te kunnen meten, werd gebruik gemaakt van de vol gende methaden:

1. Interview

2. Lichamelijk onderzoek (bepalen van lengte, gewicht en kniebreedte)

3. Vragenlijsten,

a. een zelfbeoordelingshijst voor anorectische kenmerken (ANIS)

b. Prestatie Motivatie Test (PMT en PMT-k).

om lichamelijke oorzaken voor ernstig gewichtsverlies en amenorrhoebij AN- en AM-patienten uit te sluiten, werd door een arts een lichamelfjk onderzoek verricht en endocrien onderzoek uitgevoerd, als dit nog niet had plaatsgevonden.

Verschillende statistische methoden werden gebruikt on de gegevens te bewerken. 
Hoofdstuk 6. Vergelljking van de AN, AM en AF groep.

De proefpersonen van 16 jaar en ouder werden vergeleken met betrekking tot hun anorectische en psychologische kenmerken.

84 AN-patienten, 82 AM-patienten en 237 AF-proefpersonen van 16 jaar en ouder werden vergeleken op de mogelijke significante verschillien. ook werd een discriminant-analyse uitgevoerd.

Dit leidde tot de valgende bevindingen:

1. AN-patienten wogen significant minder dan AM-patienten; AM-patienten wogen significant minder dan de AF-groep.

2. AN-patienten vertoonden significant sterkere anorectische symptomen dan AM-patienten; AM-patienten vertoonden significant sterkere anorectische symptomen dan de AF-groep.

3. AN-patienten vertoonden een significant sterkere drang tot presteren dan de AF-groep; de AM-patienten vertoonden eveneens een significant sterkere drang tot presteren dan de AF-groep. De AM- en AN-patienten verschilden in dit opzicht echter niet van elkaar.

4. AN-patienten vertoonden een significant sterkere tendens om fallen te vermijden dan AM-patienten en AF-personen. De verschillen in deze tussen AM- en AF-groep waren niet significant.

5. AN-patienten konden endocrinologisch niet worden onderscheiden van AM-patienten.

Deze gegevens bevestigden de vooronderstelling dat AN-patienten, behalve wat betreft de ernst van de anorectische symptomen, ook psychologisch verschillen van een controle groep en wan een groep met milde anorectische symptomen. De AM-patienten nemen een tussenpositie in wat betreft gewlicht en anorectisch gedrag.

Hoofdstuk 7. Vergel 1,jking met ballet danseressen.

Balletdanseressen streven, vaak beroepshalve, naar een zo slank mogelijk lichaam. Soms kan de angst on dik te worden als ook het ondergewicht zo extreem worden, dat $z i j$ in dit opzicht aan de diagnostische criteria van anorexia nervosa voldoen. 
Het is echter de vraag of ballerina's, hoewel zij anorectische kenmerken gemeenschappelijk hebben, ook psychologische kenmerken gemeenschappel ijk hebben met anorexia nervosa patienten.

In tegenstelling tot anorexia nervosa patienten lijkt hun streven om te presteren voort te komen uit de behoefte on de dingen perfect te willen doen en niet uit angst om te falen.

175 BA leerlingen werden onderzocht. Twee (2) studenten bleken aan de criteria voor anorexia en bulimia nervosa te voldoen.

Een vergelijking tussen AN-patienten en balletstudenten (BA) toonde aan, dat AN-patienten niet verschillen in hun streven naar hoge prestaties van BA-leerlingen. BA-leerlingen verschilden echter wel van AN-patienten in de daaraan ten grondslag liggende motivatie. De drang tot presteren ging niet samen met de angst om te falen.

Een vergelijking van BA-leerlingen en AF-proefpersonen jonger dan 16 toonde aan dat ook jonge BA-leerlingen psychologisch te karakteriseren waren door een sterke behoefte tot presteren, vergeleken met de AFgroep. Hoewel de BA minder wogen, waren zij op jongere leeftijd niet met hun gewicht en streven naar vermagering bezig.

Deze gegevens bevestigen eerdere onderzoeksgegevens dat, ondanks gemeenschappelijke kenmerken tussen AN-patienten en BA-leerlingen, AM-patienten kunnen worden getypeerd door een sterke drang tot hoge prestaties, ter compensatie van hun angst te falen.

Hoofdstuk 8. De voorspellende waarde van anorectische en psychologische kenmerken voor de ontwikkeling van anorexia nervosa.

DE AM-, BA- en AF-groep werden na respectievelijk 6,6 en 12 maanden opnieuw onderzocht. In totaal 426 proefpersonen deden met de tweede meting mee waarvan 307 personen van 16 jaar en ouder. Voor de statistische bewerking werd een multiple regressie-analyse uitgevoerd met personen met gewichtsverlies en een toegenomen preoccupatie met gewicht en eten. Voor de AM-groep bleken vooral de anorectische en menstruele kenmerken van invloed te zijn op een toegenomen preoccupatie met gewicht en dieet houden. Voor de BA groep bleken met name de 
menstruele en psychologische kenmerken van invloed te zifn op een toename van anorectisch gedrag.

Van de 307 onderzochte personen bleken 3 proefpersonen anorexia nervosa te hebben ontwikkeld gedurende de looptijd van het project. Drie (3) proefpersonen hadden een extreem gewill chtsverlies maar voldeden let aan het criterlum 25\% gewichtsverlites. Deze personen worden ter $\$$ 11ustratie gepresenteerd.

Tevens werd nagegaan of de uitval uit het onderzoek selectief was en werden verschillen tussen uitvallers en deelnemers op significantie getoetst.

\section{Hoofdstuk 9. Discusste.}

De bevindingen van het onderzoek bevestigen het bestaan van psychologische verschillen tussen anorexia nervosa en extreme preoccupatie met gewicht en eten en gewichtsverlies. Op basis van menstrule en anorectische kenmerken enerzijds en menstruele en psychologische kenmerken anderzijds blijkt met een voldoende percentage zekerheid te voorspellen of eetstoornissen zich zullen ontwikkelen.

Voor de vroege diagnostiek van anorexia nervosa en andere eetstoornissen betekent dit dat vooral aandacht dient te worden besteed aan menstruele en anorectische symptomen als ook aan het psychologische kenmerk, de drang tot presteren. De vaak gehoorde opvatting dat lijnen 'vamzelf' voorbij gaat, is in combinatie met de menstruele en psychologische kenmerken niet gerechtvaardigd.

Het motief om falen te vermijden is typerend voor anorexia nervosa patienten. Dit motief, negatieve faalangst genoemd, is het resultat van leerervaringen in het gezin en op school.

De ontwikkeling van negatleve falangst wordt echter ook beĩnvloed door matschappelfjke factoren. Als het niet-beantwoorden aan sociale verwachtingen wordt gevolgd door een sociale devaluatie en een verminderde zelfwaardering kan dit negatieve faalangst tot resultaat hebben. Negative faalangst wordt echter befnvloed door het gebrek aan duidelijkheid en de tegenstrijdigheid van verwachtingen waaraan moet 
worden voldaan.

Wellicht vormt het gegeven dat de huidige onduidelijke en conflictuerende verwachtingen over de rol van de vrouw een van de factoren, die bijdragen tot negatieve faalangst, een angst die typerend is voor patienten met anorexia nervosa. 
REFERENCES 


\section{REFERENCES}

Akse1. S.: Psychogenic amenorrhea: diagnosis by exclusion. Psychosomatics, 1979, 20, 5, 357-359.

Alexander, F.: Psychosomatic Medicine. New York, Norton, 1950.

Alpert, R. and Haber, R.N.: Anxiety in academic achievement situations. Journal of Abnormal and Social Psychology, 1960, 61, 207 215.

Archer, D.F., Ronald, L.Th.: The fallacy of the postpill amenorrhea syndrame. Clinical obstetrics and Gynaecology, 1981, 24, 943-950.

Argyle, M. and Robinson, P.: Two origins of achievement. British Journal of Social and C1inical Psychology, 1962, 1, 107-120.

Argyle, M. and Robinson, P.: Origins of achievement motivation. In: Southwe11, E.A. and Merbaum, M.: Personality: Readings in theory and research. Belmont, Wadsworth Publishing Company, 1971, 385397.

Atkinson, 3.H. and Feather (Eds.): A theory of achlevement motivation. New York, Wiley, 1966.

Baker, E.R., Mathur, R.S., Kirk, R.F. and Williamson, H.0.: Female runners and secondary amenorrhea: correlation with age, parity, mileage, and plasma hormonal and sex-homone-binding globulin concentrations. Fertility and Sterility, 1981, 36, 183-187.

Ballot, N.S., Dellany, N.E., Erskine, P.J., Langridge, P.J., Smit, K., Van Niekerk, H.S., Winters, Z.E. and Wright, N.C.: Anorexia Nervosa - a prevalence study. SA Medical Journa1, 1981, 59, 992-993.

Bates, G.W., Bates, S.R., Neil, M., Whitworth, S.: Reproductive failure in women who practice weight control. Fertility and Sterility, $1982,37,373-378$.

Beck, J.C. and Bröchner-Mortensen, K.: Observations on the prognosis in anorexia nervosa. Acta Med. Scand., 1954, 149, 409-430.

Beck, A.T., Rush, A.J., Shaw, B.F. and Emery, G.: Cognitive therapy of depression. Chichester, John Wiley and Sons, 1980.

Berkman, J.M.: Anorexia nervosa, anterior-pituitary insuffiency, Simmonds" cachexia and Sheehan's disease; including some observations in disturbances in water metabolism associated with starvation. Postgrad. Med., 1948, 3, 237-246. 
Beumont, P.J.W., Gearge, G.C.W. and Smart, D.E.: 'Dieters' and "womiters and purgers" in anorexia nervosa. Psychological Medicine, $1976,6,617-622$.

Beumont, P.d.V.: Further categorization of patients with anorexia nervosa. Australian and New Zealand Journal of Psychiatry, 1977, 11, 223-226.

Beumont, P.J.V., Abraham, S.F., Arglall, W.J., George, G.C.W., Glaun, D.E.: The onset of anorexia nerwosa. Australian and New Zealand Journal of Psychilatry, 1978, 12: 145-149.

Bhanji, 5. and Mattingly, D.: Anorexia Nervosa: Some observations on 'Dieters" and 'Vomiters', Cholesterol and Carotene. British Journal of Psychilatry, 1981, 139, 238-241.

Birney, R.C., Burdick, H., Teevan, R.C.: Fear of Fallure. New York, Van Nostrand, 1969.

Bliss, E.H. and Branch, C.H.: Anorexia Nervosa. New York, Hoeber, 1960.

Bosch van Drakestein, J.L.P., Coelingh Bennink, H.J.T., Weeda-Mannak, W.L.: Het falen van een dopamine-antagonist (pimozide) en het succes van psychotherapie bij de behandeling van vroumen met 'wellght loss related" amenorrhoe. Tijdschrift voor Psychiatrie, 1981, 23/speciaal nummer, 41-48.

Boskind-Lodah1, M.: Cinderella's stepsisters: A feminist perspective on anorexia nervosa and bulimia. Signs: Journal of Women in culture and Society, 1976, 2,342-356.

Boskind-Lodah1, M. and Sirlin, J.: The gorging-purging syndrome.

Psychology Today, 1977,50,50-85.

Bruch, H.: Perceptual and conceptual disturbances in anorexia nervosa.

Psychosomatic Medicine, 1962, 24, 187-194.

Bruch, H.: Eating disorders. New York, Basic Books, 1973.

Bruch, H.: Psychological antecedents of anorexia nervosa. In: R.A.

Vigersky, (Ed.): Anorexia Nervosa. New York, Raven Press, 1977.

Bruch, H.: The Golden Cage. Cambridge, Harvard University Press, 1978. Bruch, H.: Developmental deviations in anorexia nervosa. Isr. Ann. Psychiatry, 1979, 17, 255-261.

Bruch, H.: Preconditions for the development of anorexia nervosa. The American Journal of Psychoanalysis, 1980, 40, 169-172. 
Buhrich, N.: Frequency of presentation of anorexia nervosa in Malaysia. Australlian and New Zealand Journal of Psychiatry, 1981, 15, $153-155$.

Button, E.J., Fransella, F. and S1ade, P.D.: A reappralisal of body perception disturbance in anorexia nervosa. Psychological Medicine, $1977,7,235-243$.

Button, E.J. and Whitehouse, A.: Subclinical anorexia nervosa. Psychological Medicine, 1981, $11,509-516$.

Cantwe11, D.P., Sturzenberger, S., Burroughs, J., Salkin, B. and Green, J.K.: Anorexia Nerwosa: An affective disorder? Arch. Gen. Psychiat, 1977, 34, 1087-1093.

Casper, R.C. and Davis, J.M.: On the course of anorexia nervosa. American Journal of Psychiatry, 1977, 134, 947-978.

Casper, R.C., Eckert, E.D., Halmi, K.A., Goldberg, S.C. and Davis, J.M.: Bulimia. Its incidence and clinical importance in patients with anorexia nervosa. Arch. Gen. Psychiatry, 1980, 37, 1030-1034. Casper, R.C.: Some provisional ideas concerning the psychologic structure in anorexia nervosa and bulimia. Paper presented at the Closed Conference on Anorexia Nervasa, Toronto, September 1981.

Chatterjee, R., Banerjee, S., Ghosh, K.K., Chaudhuri, N.: A study of postpil1 amenorrhea. International Journal of Gynaecology and obstetry, $1980,18,113-114$.

Coelingh Bennink, H.J.T., Heeda-Mannak, W.L., Bosch van Drakestein, J.L.P. en Mommersteeg-F1ipse, E.: Failure of a dopamine antagonist and success of psychotherapy in weight loss related amenorrhea. Neuro-endocrinology Letters, 1981, 3, 119.

Crandall, V.C.: Personality characteristics and social and achievement behaviors associated with children's social desirability response tendencies. Journal of Personality and Social Psycholgy, 1966, 4, $477-486$.

Cremerius, J.: Zur Prognose der Anorexia nervosa 113 fünfzehn bis achtzehnjährige Katamnesen psychotherapeutisch unbehandeter Fälle. Arch. Psychosomatische Zeitschrift Neurologie, 1965, 207, 378-393. 
Cremerius, J.: Zur Prognose der Anorexila Merwosa 111 sechsundzwanzig bis neunundzwanzigjährige Katamnesen psychotherapeutisch unbehandelter Fällel. Zeitschrift für Psychosomatische Medizin und Psychoanalyse, 1978, 24, 56-69.

Crisp, A.H.: Premorbid factors in adult disorders of weight, with particular reference to primary anorexia nervosa (weight phobia). Journal of Psychosomatic Research, 1970, 14, 2-22.

Crisp, A.H. Stonehill, E.: Relation between aspects of nutritional disturbance and menstrual activity in primary anorexia nervosa. British Medical Journa1, 1971, 3, 149-151.

Crisp, A.H., Palmer, R.L. and Kalucy, R.S.: How common is anorexia nervosa? A prevalence study. British Journal of Psychiatry, 1976 , $128,549-554$.

Crisp. A.H.: Some psychobiological aspects of adolescent growth and their relevance for the fat/thin syndrome (anorexia nervosa). International Journal of Obesity, 1977, 1, 231-238.

Crisp, A.H., Kalucy, R.S., Lacey, J.H. and Harding, B.: The long-tem prognosis in anorexia nervosa: Some factors predictive of outcome. In: R.A. Vigersky (Ed.), Anorexia Nervosa, New York, Raven Press, $1977,55-65$.

Crisp, A.H.: Anorexia nervosa - A disease of our time. The need to make provision for $i t$. Health and Hygiene, 1979, 2, 149-152.

Crisp, A.H.: Early recognition and prevention of anorexia nervosa. Developmental Medicine and Child Neurology, 1979, 21, 393-395.

Crisp, A.H.: Hsu, L.K.G., Harding, B., Hartshorn, J.: Clinical features of anorexia nervosa. A study of a consecutive series of 102 female patients. Journal of Psychosomatic Research, 1980, 24. 179-191.

Crisp, A.H.: Anorexia Nervosa. Let me be. London, Academic Press, 1980.

Dally, P.: Anorexia Nervosa. London, Willlam Heineman Medïcal Books Limited, 1969.

Dal1y, P.J. and Gomez, A.J.: Anorexia Nervosa. London, Willitam Heineman Medical Books Limited, 1979. 
Darby, P.L., Garfinkel, P.E., Vale, J.M., Kirwan, P.J. and Brown,

G.M.: Anorexia Nervosa and Turner syndrome: Cause or coincidence? Psychol. Med., 1981, 11, 141-145.

Diagnostic and Statistical Manual of Mental Disorders. Third Edition, Washington DC., American Psychiatric Association, 1980.

Dickens, J.A.: Concurrence of Turner's syndrome and anorexia nervosa. British Journal of Psychiatry, 1970, 117-237.

Dixon, W.J. and Brown, M.B.: BMDP-79: Biomedical Computer Prograns

P-series. Berkeley, University of California Press, 1979.

Drew, F.L.: The epidemiology of secondary amenorrhea. Journal of Chronic Diseases, 1961, 14, 396-407.

Druss, R.G. and Silverman, J.A.: Body image and perfectionism of

ballerinas: Comparison and contrast with anorexia nervosa. General Hospital of Psychiatry, 1979, 2, 115-121.

Duddle, $M_{.}$: An increase of anorexia nervosa in a university population. British Journal of Psychiatry, 1973, 123, 711-712.

Ehrensing, R.H. and Weftzman, E.L.: The mother-daughter relationship

in anorexia nervosa. Psychosomatic Medicine, 1970, 32, 201-208.

Eisenberg, E.: Toward an understanding of reproductive function in anorexia nervosa. Fertility and Sterility, 1981, 36, 5, 543-550.

Enge1, G.L.: A psychological setting of somatic disease: The "giving up-given up" complex. Proc. R. Soc. Medicine, 1967, 60, 553-555.

Erikson, E.H.: Childhood and society, New York, Norton, 1952.

Fairburn, C.G., Cooper, P.J.: Self-induced vomiting and bulimia nervosa: an undetected problem. British Medical Journal, 1982, 284 , 1153-1155.

Falk, J.R., Halmi, K.A.: Amenorrhea in anorexia nervosa: Examination of the critical body weight hypothesis. Biological Psychilatry, $1982,17,7,799-806$.

Feicht, C.B., Johnson, I.S., Martin, B.J.: Secondary amenorrhea in athletes. Lancet, 1978, 1, 1145-1146.

Feighner, J.P., Robins, E., Guze, S.B., Woodruff, R.A.J., Winokur, G. and Munoz, R.: Dlagnostic criteria for use in psychiatric research. Arch. Gen. Psychiatry, 1972, 26, 57-63. 
Fichter, M.M. and Keeser, W.: Das Anorexia Nerwosa Inventor zur Selbstbeurteflung: (ANIS). Archiv für Psychlatrie und Nervenkrankheiten, 1980, 67-89.

Fishman, J.: Fatness, puberty, and ovulation. New England Journal of Medicine, $1980,303,42-44$.

Fox, K.C., James, N.: Anorexia nervosa: A study of 44 strictly defined Cases. New Zealand Medical Journa1, 1976, 84, 309-312.

Friledman, G.D.: Primer of epidemiology. New York, McGraw-Hill Book Company, 1980.

Fries, H.: Secondary amenorrhoea, self-induced weight reduction and anorexia nervosa. Acta Psychiatr. Scand. (Suppl.), 1974, 248.

Frites, H., Nilifus, S.J., Petterson, F.: Epidemiology of secondary amenorrhea. American Journal of Obstetry and Gynaecology, 1974, $118,473-479$.

Fries, H.: Studies on secondary amenorrhea, anorectic behavior and body-image perception: Importance for the early recognition of anorexila nervosa. In: R.A. Vigersky (Ed.), Anorexia Nervosa. New York, Raven Press, 1977.

Fries, H.: Body perception in boys and girls aged 10-17 and its relationship to deviation of weight. Paper presented at the closed Conference on Anorexia Nervosa. Toronto, 9-10 September 1981.

Frisch, R.E., Revelle, R.: Height and weight at menarche and a hypothesis of critical body weights and adolescent events. Science, $169,397-398$.

Frisch, R.E.: Weight at menarche: similarity for well-nourished and undernourished girls at different ages and evidence for historical constancy. Pediatrics, 1972, 50, 445-450.

Frisch, R.E. and McArthur, J.W.: Menstrual cycles: Fatness as a determinant of minimum weight for height necessary for their maintenance or onset. Scilence, 1974, 185, 949-951.

Frisch, R.E.: Food-intake, fatness and reproductive ability. In: R.A. Vigersky (Ed.): Anorexia Nervosa. New York, Raven Press, 1977, 149-161. 
Frisch, R.E., Wyshak, G. and Vincent, L.: Delayed menarche and amenorrhea in ballet dancers. New England Journal of Medicine, 1980 , 303, 17-19.

Fromm, E.: The Dogma of Christ, "Sex and Character", London, Routledge and Kegan Paul, 1963.

Garfinke1, P.E., Brown, G.M., Stancer, H.C. and Moldofsky, H.: Hypothalamic-pituitary function in anorexia nervosa. Arch. Gen. Psychiatry, $1975,32,739-744$.

Garfinkel, P.E., Moldofsky, H. and Garner, D.M.: The outcome of anorexia nervosa: Significance of clincial features, body image and behavior modification. In: R.A. Vigersky (Ed.): Anorexia Nervosa. New York, Raven Press, 1977, 315-329.

Garfinkel, P.E., Moldofsky, H., Garner, D.M.: Prognosis in anorexia nervosa as influenced by clinical features, treatment and selfperception. CMA Journa1, 1977b, 117, 1041-1045.

Garfinke1, P.E., Moldofsky, H., Garner, D.M.: The stability of perceptual disturbances in anorexia nervosa. Psychological Medicine, $1979,9,703-708$.

Garfinke1, P.E., Moldofsky, H. and Garner, D.M.: The heterogeneitty of anorexia nervosa: bulimia as a distinct subgroup. Arch. Gen. Psychiatry, 1980, 37, 1036-1040.

Garfinkel, P.E.: Some recent observations on the pathogenesis of anorexia nervosa. Canadian Journal of Psychiatry, 1981, 26, 218223.

Garfinkel, P.E. and Garner, D.M.* Anorexia Nervosa. A multidimensional perspective. New York, Brunner/Maze1, 1982.

Garner, D.M. and Garfinke1, P.E.: The Eating Attitude Test: an Index of symptoms of anorexia nervosa. Psycho1. Med., 1979, 9, 273-280. Garner, D.M. and Garfinkel, P.E.: Socio-cultural factors in the development of anorexia nervosa. Psychol. Med., 1980, 10,647-656.

Garner, D.M., Garfinke1, P.E. Schwartz, P.E. and Thompson, M.: Cultural expectation of thinness in women. Psychological Rep., 1980, $47,483-491$.

Garner, D.M. and Bemis, K.M.: A cognitive-behavioral approach to anorexia nervosa. Cognitive Therapy and Research, 1982, 6, 123150. 
Garner, D.M., 01msted, M.P. and Garfinke1, P.E.: Does anorexia nerwosa accur on a continuum? The International Journal of Eating Disorders, 1983, 2, 11-26.

Garner, D.M., Garfinke1, P.E., Bemis, K.M.: A multidimensional psychotherapy for anorexia nervosa. International Journal of Eating Disorders, $1982,1,3-64$.

Garner, D.M. Garfinke1, P.E., 01msted, M.P.: An overview of sociocultural factors in the development of anorexila nervosa. In: Anorexila nervosa: Recent developments in research. New York, Alan R. L1s5, 1983, 65-82.

Goldberg, S.C., Eckert, E.D., Casper, R.C., Halmi, K.A., Davis, J.M., Roper, M.T.: Factors influencing hospital differneces in weight gain in anorexia nervosa. Journal of Nervous and Mental Disease, $1980,168,181-183$.

Graham, R.L., Grimes, D.L., Gambre11, R.D.: Amenorrhea secondary to voluntary weight 10ss. Southern Medical Journa1, 1979, 72, 12591261 .

Gu11, W.W.: Anorexia nervosa (apepsia hysterica, anorexia hysterica). Trans Clinincal Soc., London, 1873, 7, 22. Reprinted in: R.M. Kaufman and M. Heiman (Eds.): Evolution of Psychosomatic Concepts. Anorexia Nervosa: A paradigm. New York: International Universities Press, 1964.

Halmi, K. A., Brodland, G. and Loney, J.: Prognosís in anorexia nervosa. Annual International Medicine, 1973, 78, 907-909.

Halmi, K.A. and Rigas, C.: Urogenital malformations associated with anorexia nervosa. British Journal of Psychiatry, 1973, 122, 79-81. Halmi, K.A., Goldberg, S.C., Eckert, E., Casper, R.C. and Davis, J.M.: Pretreatment evaluation in anorexia nervosa. In: R.A. Vigersky, Anorexia Nervosa. New York, Raven Press, 1977.

Halmi, K.A;: Menstrual recovery and the relationship of psychological, physiological and nutritional factors. In: W.L. Weeda-Mannak en Fr. Smits (Red.): Eetstoornissen. Vroege diagnostiek en behandeling van anorexia nervosa en aanwerwante eetstoornissen. Maastrilcht, $1983,39-47$. 
Hamsher de, S.K., Halmi, K.A., Benton, A.L.: Prediction of outcome in anorexia mervosa from neuropsychological status. Psychiatry Research, $1981,4,79-88$.

Hermans, H.J.M.: Motivatie en prestatie. Amsterdam, Swets and Zeitlinger, 1967.

Hermans, H.J.M.: Handleiding bij de Prestatie Motivatie Test. Amsterdam, Swets and Zeitlinger, 1968.

Hermans, H.J.M.: The validity of different strategies of scale construction in predicting academic achievement. Educational and Psychological Measurement, 1969, 29, 877-883.

Hermans, H.J.M.: A questionnaime measure of achievement motivation. Journal of Applied Psychology, 1970, 54, 353-363.

Hermans, H.J.M.: Prestatiemotief en faalangst in gezin en onderwijs. Amsterdan, Swets and Zeitlinger, 1980 (First printing, 1971).

Hi11, 0.W.: Anorexia Nervosa. In: 0. Hil1 (Ed.), Modern trends in Psychosomatic Medicine. Andover, Chapel River Press, 1976.

Hirronen, E.: Etiology, clinical features and prognosis in secondary amenorrhea. International Journall of Fertility, 1977, 22, 69-76, Hodgeman, C.H.: Anorexia nervosa. Postgraduate Medicine, 1979, 65, 223-227.

Hoogendoorn, D.: Enkele summiere gegevens over $1100 \mathrm{kl}$ inisch behandelde patienten met anorexia nervosa. Nederlands Tijdschrift voor Geneeskunde, 1983, 127, 1631-1634.

Hsu, L.K.G., Crisp, A.H. and Harding, B.: Outcome of anorexila nervosa. The Lancet, 1979, 61-65.

Hsu, L.K.G., Outcome of anorexia nervosa. Arch. Gen. Psychlatry, 1980, $37,1041-1046$.

Hsu, L.K.G.: Is there a disturbance in body image in anorexila nervosa? Journal of Nervous and Mental Disease, 198C, 170, 305-307.

Hsu, L.K.G.: The aetiology of anorexia nervosa. Psychological Medicine, $1983,13,231-238$.

Kagan, J. and Moss, H.A.: Birth to maturity. New York, Wlley, 1962.

Kallucy, R.S., Crisp, A.H., Lacey, J.H., Harding, B.: Prevalence and prognosis in anorexia nervosa. Australian and New Zealand Journal of Psychiatry, 1977, 11, 251-257. 
Kardiner, A. and splegel, H.: War stress and neurotic illness. New York, Hoeber, 1947.

Kathovsky, W., Preston, A., Cranda11, V.J.: Parents achievement attitudes and their behavior with their children in achievement situations. Journal of Genetic Psychology, 1964, 104, 105-121.

Katz, J.L., Boyar, R.M., Roffwarg, H., Hellman, L. and Weiner, H.: LHRH responsiveness in anorexia nervosa: Intactness despite prepubertal clrcadian LH pattern. Psychosomatic Medicine, 1977, 39, $241-251$.

Kay, D.W.K. and Leigh, D.: The natural history, treatment and prognosis of anorexia nervosa, based on a study of 38 patients. Journal of Mental Sciences, 1954, 100, 411-431.

Keizer, H.A.: Hormonal responses in women as a function of physical exercise and training. Thesis Rijksuniverisiteit Limburg, 1983 Kende11, R.E., Hall, D.J., Hailey, A. and Babigian, H.M.: The epidemiology of anorexia nervosa. Psychological Medicine, 1973, 3, $200-203$.

Kendel1, R.E.: The role of diagnosis in psychiatry. Oxford, Blackwe11, 1975.

Keys, A., Brozek, J., Henschel, A., Mickelsen, 0. and Taylor, H.L., The biology of human starvation. 1, Minneapolis, University of Minnesota Press, 1950.

Kimba11, C.P.: The language of psychosomatic medicine. Psychotherapy and Psychosomatics, 1977, 28, 1-12.

Kimbal1, C.P.: The biopsychosocial approach to the patient. Baltimore/ London. William \&ilkins, 1981.

Knuth, U.A., Hu11, M.G.R., Jacobs, H.S.: Amenorrhea and 10ss of weight. British J. Obstetrics and Gynaecology, 1977, 84, 801-807. Kock, H.C.L.V., Smits, F. and Weeda-Mannak, W.L.: Gynaecologische diagnostiek en beleid bij gewichtsgerelateerde amenorrhoe. In: W.L. Weeda-Mannak en F. Smyts (Red.): Eetstoornissen. Vroege diagnostiek en behandeling van anorexia nervosa en aanverwante eetstoornissen. Maastricht, Uitgave Rijksuniversiteit Limburg, $1982,48-53$. 
Krans, H.M.J.: Anorexia nervosa: verstoorde endocriene regulatie. Nederlands Tijdschrift voor Geneeskunde, $1978,122,1531-1533$. Kron, L., Katz, J.L., Gorzymski, G. and Weiner, H.: Anorexia Nervsoa and gonadal dysgenesis. Arch. Gen. Psychiatry, 1977, 34, 332-335. Lafeber, C.: Anorexia Nervosa. Leiden, Stafleu, 1971. Laffeber, C.: KIinisch-psychiatrische studie over anorexia nervosa. Academisch proefschrift, 1963.

Langeveld, M.d.: Ontwikkelingspsychologie. Groningen, Wolters-Noordhof, 1969 a.

Langeveld, M.J.: Beknopte theoretische pedagogiek. Groningen, WoltersNoordhof, $1969 \mathrm{~b}$.

Lasègue, E.C.: De 1'anorexie hystërique. Arch. Gen. de Medicine, 1873. Reprinted in R.M. Kaufman and M Heiman (Eds.): Evolution of psychosomatic concepts. Anorexia nervosa: A paradigm. New York, Internation universities press, 1964.

Lipowski, Z.J.: What does the word 'psychosomatic' really means? A historical and semantic inquiry. Psychosomatic Medicine, 1984, 46, 153-171.

Liston, E.H. and Shershow, L.W.: Concurrence of anorexia nervosa and gonadal dysgenesis. (Turner's Syndrome). Arch. Gen. Psychiatry, $1973,29,834-836$.

Lucas, A.: Toward the understanding of anorexia nervosa as a disease entity. Mayo Clinic 1981, Proc. 56, 254-264.

Lucas, A.R.: Anorexia nervosa as a biopsychosocial disease: the history of several theoretical models. In: Weeda-Mannak, W.L. and Smits, F. (Red.): Eetstoornissen. Vroege diagnostlek en behandeling van anorexia nervosa en aanverwante eetstoornissen. Maastricht, Uitgave Rijksuniversiteit Limburg, 1982, 23-31.

Macleod, S.: The art of starvation. London, Virago Limited, 1981, 1983.

Macleod, S.: Hongeren. Anorexia nervosa. Een autobiografisch verslag. Haarlem, De Toorts, 1982.

Malina, R.M., Spirduso, W.W., Tate, C., Baylar, A.M.: Age at menarche and selected menstrual characteristics in athletes at different competitive levels and in different sports. Medical Sciences Sports, $1978,10,218-222$. 
Mann, A.H., Wakeling, A., Wood, K., Dobbs, R. and Schukler, G.: Screening for abnormal eating attitudes and psychiatric morbidity in an unselected population of 15-year-old schoolgirls. Psychological Medicine, 1983, 13, 573-580.

Mausner, J.S. and Bahn, A.K.: Epidemiology. Phil adelphia/London/Toronto. W.B. Saunders Company, 1974.

MCClelland, D.S., Atkinson, J.W., Clark, R.A. and Lowe1l, E.L.: The achlevement motive. New York, Appleton-Century, 1953.

McClelland, D.C.: Longitudinal trends in the relation of though to action. Journal of Consulting Psychology, 1966, 30, 479-483.

McG111, Tukey, J.W. and Larsen, W.A.: Variations of box plots. The American Statistician, 1978, 32, 12-16.

Meermann, R.: Experimental investigation of disturbances in body image estimation in anorexia nervosa patients and ballet and gymnastic pupils. The International Journal of Eating Disorders, 1983, 2, 91-100.

Meng, H.: Psyche und Hormon. Behn, Hans Huber, 1944.

Mercer, R.T.: Perspectives on the adolescent and adolescence. In: R.T.

Mercer, Perspectives on adolescent health care, Philadelphia, New York, J.B. Lippincott Company, 1979, 3-28.

Meyer, J.E.: Das Syndrom der Anorexia nervosa. Arch. Psychiatry und Nervenkrankheiten, 1961, 202, 31-49.

Minuchin, S., Rosman, B.L. and Baker, L.: Psychosomatic Families:

Anorexia Nervosa in context. Cambridge, Ma, Harvard University press, 1978.

Minuchin, S. and Rosman, B.L.: Psychosomatische ziekten in het gezin.

De behandeling van anorexia nervosa. Deventer, Van Loghum Slaterus BV., 1983.

Mogul, S.L.: Ascetism in adolescence and anorexia nervosa. Psychoanal. Study Child, 1980, 35, 155-175.

Morgan, H.G. and Russe11, G.F.M.: Value of family background and clinical features as predictors of long-term outcome in anorexia nervosa: four year follow-up study of 41 patients. Psychological Medicine 1975, 5, 355-372.

Morrison, D.G.: On the interpretation of discriminant analysis. Journal of Marketing Research, 1969, 6, 156-163. 
Morton, R.: Phtisiologia - or a Treatise of Consumptions. London, Smith and Walford, 1694.

Neale, J.M. and Liebert, R.M.: Science and Behavior. Englewood Cliffs, Prentice Hall, 1980.

Neinstein, L.S.: Menstrual disorders. Seminars in Family Medicine, $1981,2,3,184-196$.

Nemiah, J.C.: Anorexia Nervosa - a clinical psychiatric study. Medicine, 1950, 29, 225-268.

Norris, D.L.: Clinical diagnostic criteria for primary anorexia nervosa. SA Medical Journal, 1979, 56, 987-994.

Nylander, J.: The feeling of being fat and dieting in a school population. Acta Sociomed. Scand. 1971, 3, 17-26.

Ong, Y.L., Tsoi, W.F., Cheah, J.S.: A clinical and psychological study of seven cases of anorexia nervosa in Singapore. Singapore Medical J., 1982, 23, 5, 255-261.

Palmer, R.L.: The dietary chaos syndrome: A useful new term? Britisch Journal of Psychology, 1979, 52, 187-190.

Pierloot, R.A., Wellens, W. and Houben, M.E.: Elements of resistance to a combined medical and psychotherapeutic program in anorexia nervosa. Psychotherapy and Psychosomatics, 1975, 26, 101-117. Pitts, F.N. and Guze, S.B.: Anorexia Nervosa and gonadal dysgenesis (Turner's Syndrome). American Journal of Psychiatry, 1963, 119, 1100 .

Rogers, C.R.: Client-centered therapy. Boston, Houghton Mifflin, 1951. Rogers, C.R.: The necessary and sufficient conditions of therapeutic personality change. In: Southwel1, E.A. and Merbaum, M. (eds.): Personality: Readings in theory and research. Belmont, Wadsworth Publishing Company, 1971.

Rohde, J.R., Johannes, A., Labeck, L., Kelly, J.T.: Diagnosis and treatment of anorexia nervosa. The Journat of Family Practice, $1980,10,1007-1012$.

Rollins, N. and Piazza, E.: Diagnosis of anorexia nervosa. A critical reappraisal. Journal of American Academic Child Psychiatry, 1978, $17,126-137$. 
Rosentha1, R. and Fode, K.L.: The effect of experimenter bias on the performance of the albino rat. Behavioral Science, 1963a, 8, 183189.

Rosenthal, R. and Fode, K.L.: Three experiments in experimenter bias. Psychological Reports, 1963b, 12, 491-511.

Russe11, G.F.M.: Anorexia nervosa: its identity as an 111 ness and its treatment. In: Price, J.H. (Ed.): Modern Trends in Psychological Medicine, 2, London, Butterworths, 1970.

Russe11, G.F.M. and Beardwood, C.J.: Amenorrhea in the feeding disorders: anorexia nervosa and obesity. Psychotherapy and Psychosomatics, 1970, 18, 358-364.

Russe11, J.A.0.: Psychosocial aspects of weight loss and amenorrhea in adolescent girls. In: J.H. Price (Ed.), Modern Trends in psychosomatic medicine, 2, 131-164, London, Butterworth, 1972.

Russe11, G.F.M.: The dangers of slimming. Hexagon 'Roche', 1976, 4, 8, $15-21$.

Russe11, G.F.M.: General management of anorexia nervosa and difficul-

ties in assessing the efficacy of treatment. In: R.A. Vigersky (Ed.), Anorexia Nervosa. New York, Raven Press, 1977, 277-289.

Russel1, G.F.M.: The present status of anorexia nervosa. Psychological Medicine, 1977, 7, 363-367.

Russell, G.F.M.: Bulimia nervosa: An ominous variant of anorexia nervosa. Psychological Medicine, 1979, 9, 429-448.

Schwabe, A.D., Lippe, B.M., Chang, R.J., Pops, M.A. and Yager, J.: Anorexia Nervosa. Annals of Internal Medicine, 1981, 94, 371-381. Schwartz, D.M. and Thompson, M.G.: Do anorectics get we11? Current research and future needs. American Journal of Psychiatry, 1981, 3, 319-323.

Schwartz, D.M., Thompson, M.G., Johnson, C.L.: Anorexia nervosa and bulimia: the socfo-cultural context. International Journal of Eating Disorders, 1982, 1, 20-36.

Seidensticker, J.F. and Tzagournis, M.: Anorexia Nervosa - clinical features and long-term follow-up. Journal of Chronic Diseases, $1968,21,361-367$. 
Selvini Palazolli. M.: Self-starvation. From the intrapsychic to the Transpersonal Approach to Anorexia Nervosa. London, Chaucer Pub11 shing Co Ltd, 1974.

Sheehan, H.L. and Summers, V.K.: The syndrome of hypopituitarism. Quart, J. Med., 1937, 18, 319 .

Sheehan, H.L.: Nutritional state in Simmonds' disease. Proc. Roy. Soc. Med., 1948, 22, 187-195.

Simmonds, M.: Ueber embolische Prozesse in der Hypophysis. Arch. Path. Anat., $1914,217,226-239$.

Simmonds, M.: Ueber Kachexie hypophysären Ursprungs. Deutsche Medi sche Wehnschrift, 1916, 42, 190.

Skolnick, A.: Motivational imagery and behavior over twenty years. Journal of Consulting Psychology, 1966, 30, 463-478.

Slade, P.: Towards a functional analysis of anorexia nervosa and bulimia nervosa. British Journal of Clinical Psychology, 1982, 21, 167-179.

Smith, N.J.: Excessive weight loss and food aversion in athletes simulating anorexia nervosa. Pediatrics, 1980, 66, 139-143.

Speroff, L. and Redwine, D.B.: Exercise and menstrual function. The physician and sportsmedicine, 1980, 8, 41-52.

Steinhausen, H.C.: Follow-up studies of anorexia nervosa: A review of research findings. Psychological Medicine, 1983, 13, 239-249.

Strober, M.: Personality and symptomatological features in young, nonchronic anorexia nervosa patients. Journal of Psychosomatic Reserach, 1980, 24, 353-359.

Strober. M.: The significance of bulimia in Juventile anorexia nervosa: An exploration of possible etiologic factors. International Journal of Eating Disorders, 1981, 1, 28-43.

Strober, M., Salkin, B., Burroughs, J. and Morrel1, W.: Validity of the bulimia-restricter distinction in anorexia nervosa: Parental personality characteristics and family psychiatrilc morbidity. J. of Nervous and Mental Disease, $1982,170,6,345-351$.

Tabachnick, B.G. and Fidel1, L.S.: Using multivariate statistics. New York, Harper and Row, 1983. 
Theander, S.: Anorexia Nerwosa: A psychiatric investigation of 94 female cases. Acta Psychiatry Scand. (Supp1.), 1970, 214, 1-194. Tolstrup, K.: Anorexia nervosa - A typical psychosomatic disease of puberty and adolescence. Triangle, $1982,21,2 / 3,85-88$.

Tukey, J.W.: Exploratory data anlaysis. Reading, M.A., Adisson-Wesley, 1977.

Vandereycken. W. and Vanderlinden, J.: Denial of $\$ 11$ ness and the use of self-reporting measures in anorexia. International Jourmal of Eating Disorders, 1983, 2, 101-107.

Vigersky, R.A. (Ed.): Anorexla Nervosa. New York, Raven Press, 1977. (Proceedings of the International Conference on Anorexia Nerwosa in Bethesda, U.S.A.).

Vigersky, R.A., Anderson, A.E., Thompson, R.H., Loriaux, D.L.: Hypothalamic dysfunction in secundary amenorrhea associated with simple weight loss. The New England Journal of Medicine, 1977 , $297,21,1141-1145$.

Wakeling, A., De Souza, V. and Beardwood, C.J.: Effects of administered estrogen on luteinizing homone release in subjects with anorexta nervosa in acute and recovery stages. In: Vigerskey, R.A. (Ed.): Anorexia Nervosa, New York, Raven Press, 1977, 199-209. Waller, J.V., Kaufman, R.M. and Deutsch, F.: Anorexia Nervosa: A psychosomatic entity. Psychosomatïc Medicine, 1940, 2, 3-16. Weeda-Mannak, W.L.: Anorexia nervosa. Verslag van een onderzoek naar de diagnostische criteria. Mastricht, Rijksuniversiteit Limburg, 1979 .

Weeda-Mannak, W.L., Bosch van Drakesteln, J.L.L., Coelingh Bennink, H.J.T. and Mommersteeg-Flipse, E.: Different types of restricted food-intake in weight loss related amenorrhea. In: Koptagel-1lal, 0. and Tuncer, 0. (Eds.): Proceedings of the 13th European Conference on Psychosomatic Research, 1980.

Heeda-Mannak, W.L., Drop, M.J., Smits, F., Strijbosch, L.W. and Bremer, J.J.C.B.: Toward an early recognition of anorexla nervosa. In: Weeda-Mannak, W.L. and Vandereycken, W. (Eds.): Proceedings of the Satellite Conference on Anorexia Nervosa and Bulimia. International Journal of Eating Disorders, 1983, 2 . 
Weeda-Mannak, W.L.: Aspects of early detection of anorexia nervosa. In: Krakowski, A.J. and Kimbal1, C.P. (Eds.): Psychosomatic Medicine. Theoretical, Clinical and Transcultural Aspects. New York, Plenum Press, 1983, 119-124.

Weeda-Mannak, W.L., Drop, M.J., Smits, F., Strijbosch, L. and Bremer, J.J.C.B.: The discriminative value of psychological characteristics in anorexia nervosa. Paper presented at the Seventh World Conference on Psychosomatic Medicine, Hamburg, 16-22 July, 1983. Weeda-Mannak, W.L. and Vandereycken, W.: Proceedings of the Satellite Conference on Anorexia Nervosa and Bulima. International Journal of Eating Disorders, 1983, 2. (Noordwijkerhout, The Netherlands, 1982).

Weiner, H.: Psychobiology and human disease. New York, Elsevier, North-Holl and Inc., 1977.

Wentz, A.C.: Body weight and amenorrhea. Obstetry and Gynecology, $1980,56,482-487$.

Williams, P., Hand, D., Tarnopolsky, A.: The problem of screening for uncammon disorders - A comment on the eating attitudes test. Psychological Medicine, 1982, 12, 431-434.

Wolff, H.C.: Life stress and bodily disease - A formulation. In: Wolf, H.G., Wolf, S. and Hare C.E. (eds.): Life stress and bodily disease. Baltimore, Williams and Wilkins, 1950.

Wulff, M.: Ueber einen interessanten oralen Symptomenkomplex und seine

Beziehung zur Such. International Zeitschrift Psychoanalasy, 1932, $18,281-302$.

Yager, J.: Family issues in the pathogenesis of anorexia nervosa. Psychosomatic Medicine, 1982, 44, 1, 43-60.

Yates, A., Leehey, K., Shisslak, C.: Running - an analogue of anorexia? New England Journal of Medicine, 1983, 308, 251-255. 
CURRICULUM VITAE

12 meï 1950

1969

1975

1976

1976-heden

$1977-1979$

1981

1982

$1981-1984$
Geboren te Salatiga (Ind.)

Eindexamen HBS-a, gevolgd aan de RHBS te Vlissingen

Doctoraal examen $\mathrm{k} l$ inische pedagogiek "Cun laude"

Inschrijuing register 'Diagnostisch bevoegde Pedagogen' Nederlandse Vereniging voor Opvoedkundigen

Wetenschappelijk medewerker bij de Capaciteitsgroep Medische Psychologie van de Rijksuniversiteit Limburg

Onderzoeksel ement-leider 'Onderzoek naar de diagnostische criteria van anorexia nervosa'

Inschrijving register 'Klinisch sexuologen'. Vereniging voor Klinische Sexuologie.

Opleiding in Gedragstherapie, IMP-opleiding, Maastricht

Voorzitter "International Conference on Anorexia nervosa and bul imia'. Noordwijkerhout

Onderzoekselement-leider "Onderzoek naar de moge$11 j k$ heden tot vroege herkenning van anorexia nervosa (voor publicaties zie literatuuropgave) 